\title{
ESTIMATIVA DA RESISTÊNCIA AERODINÂMICA PARA O VAPOR D'ÁGUA ATRAVÉS DE MEDIDAS MICROMETEOROLÓGICAS
}

MARLENE MILHARÉZI DEL DUCCAS MENDONÇA

Orientador: Prof. Dr. JOSÉ HOLANDA CAMPELO JÚNIOR

Dissertação apresentada à Escola
Superior "Luiz de Queiroz", da
Universidade de São Paulo, para
obtenção do Título de Mestre em
Agronomia - Área de Concentração:
Agrometeorologia.

$P|R A C| C A B A$

Estado de São Paulo - Brasil

Setembro de 1995 
Dados internacionais de Catalogação na Publicação (CIP) Divisão de Biblioteca e Documentação - CAMPUS "LUIZ DE QUEIROZ"/USP

Hendonça, Marlene Milharézi Del Duccas

Est imativa da resistència aerodinâmica para o vapor d'água através de medidas micrometeorológicas. Piracicaba, 1995.

$84 p$.

Diss.(Mestre) - ESALQ

Bibliografia.

1. Evapotranspiração 2. Micrometeorologia 3. Vapor d'água - Difusão Resistência I. Escola Superior de Agricultura Luiz de Queiroz, Piracicaba 


\section{ESTIMATIVA DA RESISTÊNCIA AERODINÂMICA PARA O VAPOR D'ÁGUA ATRAVÉS DE MEDIDAS MICROMETEOROLÓGICAS}

MARLENE MILHARÉZI DEL DUCCAS MENDONÇA

Aprovada em: 9.10.1995

Comissão julgadora:

Prof. Dr. José Holanda Campelo Júnior

Prof. Dr. Antonio Roberto Pereira

Prof. Dr. Celso Luiz da Silva

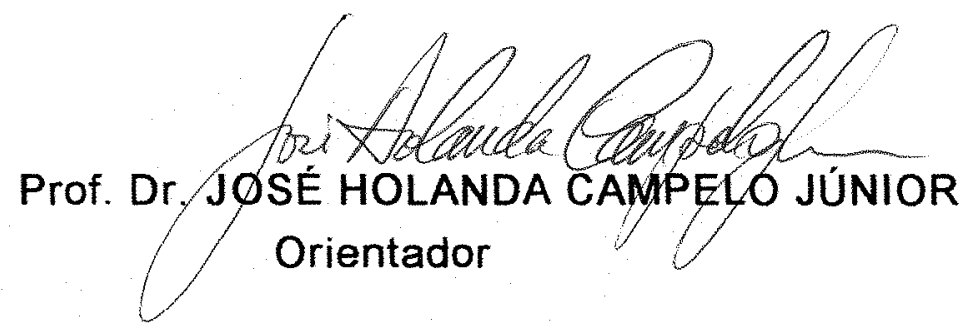




\section{AGRADECIMENTOS}

Foram muitas as dividas contraídas durante a elaboração deste trabalho. Devo um agradecimento especial ao prof.Dr. Antonio Roberto Pereira pelo desprendimento com que colocou seu material bibliográfico à minha disposição, sem o qual teria sido muito mais difícil elaborar essa dissertação.

Devo também agradecimentos à orientação do prof.Dr. José Holanda Campelo Júnior, que com constante incentivo colaborou com a finalização do trabalho e ao prof.Dr. Nicolau Priante Filho, que teve paciência para suportar e driblar a burocracia que envolveu a aquisição dos equipamentos necessários para a pesquisa.

No Departamento de Física Meteorologia, contei com a receptividade do prof.Dr. Luiz Roberto Angelocci e do prof.Dr. Nilson Augusto Villa Nova. A ambos agradeço pela confiança depositada. Também agradeço aos professores, colegas e funcionários do Curso de Agrometeorologia que colaboraram, cada um a seu modo, para a realização deste estudo.

Em Cuiabá, meus agradecimentos ao Departamento de Fisica da Universidade Federal de Mato Grosso que me oportunizou o afastamento para a realização do Curso de Mestrado. A CAPES, pela bolsa concedida.

O apoio de minha família foi fundamental; suportando e compreendendo ausências e cansaços, se envolveram sempre com a intenção de ajudar e, efetivamente, ajudaram. 


\section{SUMÁRIO}

LISTA DE ABREVIATURAS E SÍMBOLO ....................................................

RESUMO …………… vii

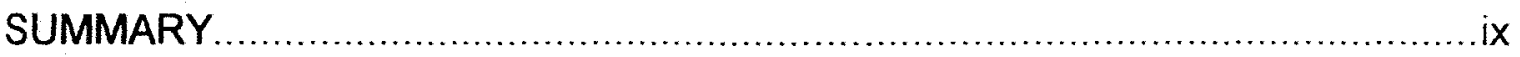

1. INTRODUÇÃO

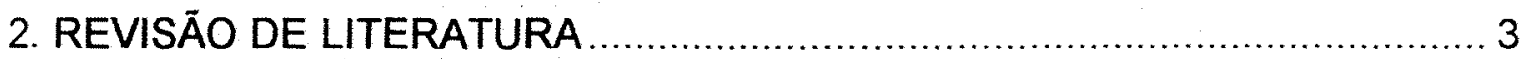

2.1. Estimativa da evapotranspiração potencial .............................................. 3

2.2. Resistência aerodinâmica em atmosfera neutra ......................................... 4

2.3. Resistência aerodinâmica - forma generalizada ......................................... 8

2.4. Perfis de vento e temperatura - relaçōes fluxo-perfil ................................ 10

2.5. Extensão e parâmetros da camada limite ................................................ 19

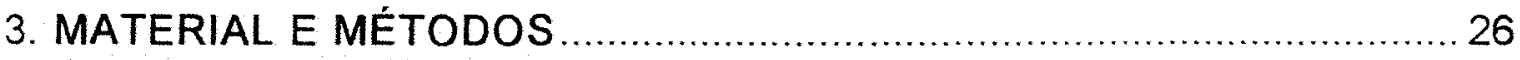

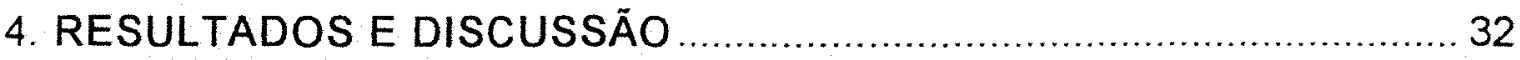

4.1. Comportamento geral dos perfis de $1 / 2$ hora ....................................... 32

4.2. Resistência Aerodinâmica por faixas de $\mathrm{Ri}$............................................ 38

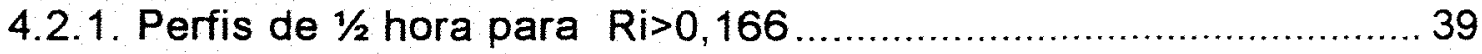

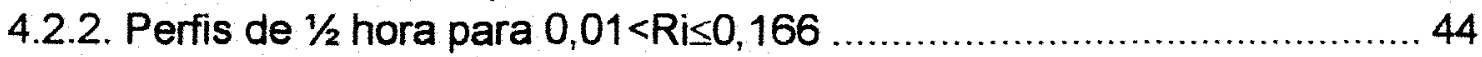

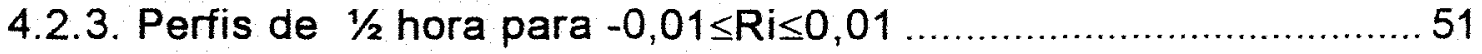

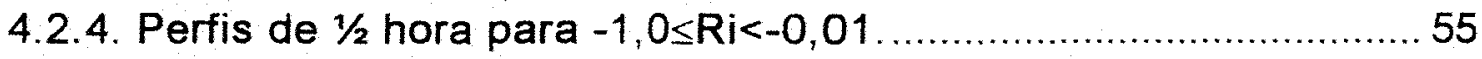

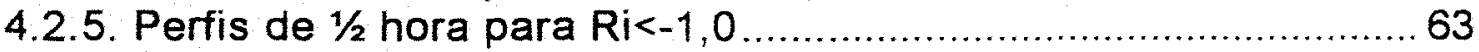

4.3. Resistência aerodinâmica efetiva diária ………………………….....64 64

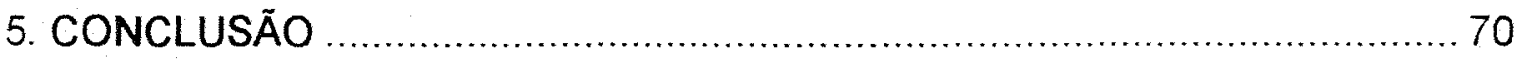

REFERÊNCIAS BIBLIOGRÁFICAS .................................................. 72

APÊNDICE 


\section{SímBOLOS}

$\beta=$ Coeficiente empirico da relação entre $\phi_{m}$ ou $\phi_{H}$ e $z / L$

$\gamma=$ Constante psicrométrica

$\Delta=\delta=$ Inclinação da curva de pressão saturante de vapor d'água

$d_{x}=$ limite superior da camada limite

$\theta=$ Temperatura potencial

$\theta_{*}=$ Temperatura potencial característica

$\lambda=$ Calor latente de evaporação

$\xi=$ Variável adimensional de Monin-Obukhov

$\xi^{\prime}=$ Variável adimensional de Monin-Obukhov corrigida

$\rho=$ Densidade

$\tau=$ Tensão de cisalhamento

$\phi=$ Gradiente adimensional

$\phi_{H}=$ Gradiente adimensional para o calor sensivel

$\phi_{m}=$ Gradiente adimensional para o momentum

$\phi_{\mathrm{V}}=$ Gradiente adimensional para o vapor de água

$\psi=$ Função de correção

$\psi_{H}=$ Função de correção para o calor sensível

$\psi_{\mathrm{m}}=$ Função de correção para o momentum

$\psi_{\mathrm{v}}=$ Função de correção para o vapor de água

$a_{\mathrm{f}}=$ Área de um lado de uma folha

$c_{p}=$ Calor específico à pressão constante 
$d=$ Deslocamento do plano zero

$e_{a}=$ Pressão de saturação do vapor de água

$e_{d}=$ Pressão atual do vapor de água

$E T_{0}=$ Evapotranspiração de referência

$\mathrm{g}=$ Aceleração da gravidade

$G=$ Densidade de fluxo de calor no solo

$h=$ Altura da vegetação

$H=$ Densidade de fluxo de calor sensivel

$\mathrm{k}=$ Constante de Von Karman

$\mathrm{K}_{\mathrm{H}}=$ Difusividade do calor

$\mathrm{K}_{\mathrm{m}}=$ Difusividade do momentum

$\mathrm{K}_{\mathrm{v}}=$ Difusividade do vapor de água

$\mathrm{L}=$ Comprimento de Monin-Obukhov

$\mathrm{L}^{\prime}=$ Comprimento de Monin Obukhov corrigido

$\mathrm{LAI}=$ Índice de área foliar

$q=$ Fluxo de calor

$r_{\mathrm{a}}=$ Resistência aerodinâmica

$r_{c}=$ Resistência do dossel

$r_{H}=$ Resistência à transferência do calor sensível

$\mathrm{Ri}=$ Número de Richardson

$r_{m}=$ Resistência à transferência do momentum

$R_{n}=$ Radiação líquida

$r_{v}=$ Resistência à transferência do vapor de água

$T=$ Temperatura

$T .=$ Temperatura característica

$u=$ Velocidade do vento

$u_{1,5}=$ Velocidade do vento a $1.5 \mathrm{~m}$ 
$u_{2}=$ Velocidade do vento a $2 \mathrm{~m}$

$u^{\star}=$ Velocidade de friç̧ão

$z=$ Altura medida a partir do solo

$\mathrm{ZOH}=$ Rugosidade do calor sensivel

zom = Rugosidade do momentum

$z_{v}=$ Rugosidade do vapor de água 


\title{
ESTIMATIVA DA RESISTÊNCIA AERODINÂMICA PARA O VAPOR D'ÁGUA ATRAVÉS DE MEDIDAS MICROMETEOROLÓGICAS.
}

\author{
Autora: MARLENE MILHAREZI DEL DUCCAS MENDONÇA \\ Orientador: PROF. DR. JOSÉ HOLANDA CAMPELO JÚNIOR
}

\section{RESUMO}

Este experimento foi conduzido na Fazenda Experimental da Universidade Federal de Mato Grosso (UFMT), ao lado da Estação Agrometeorológica Padre Ricardo Remetter, na região conhecida como Baixada Cuiabana, durante a época seca, numa área plana e coberta de grama cuja altura média foi de $14 \mathrm{~cm}$. O objetivo foi determinar a resistência aerodinâmica à difusão do vapor d'água.

Foram efetuadas medidas de velocidade de vento $e$ de temperatura de bulbo seco e de bulbo úmido, dentro da camada limite atmosférica superficial, as quais foram registradas e armazenadas a intervalos de 5 minutos em um Datalogger.

As equações referentes ao perfil de vento logarítmico e a função correção foram utilizadas para estimar o deslocamento do plano zero, o comprimento rugoso para o momentum e a resistência aerodinâmica à difusão do vapor d'água, para intervalos de meia hora. Os valores obtidos foram comparados aos valores estimados a partir da 
metodologia proposta por ALLEN (1986), verificando-se que o coeficiente de determinação variou de 0,2511, em condições estáveis, a 0,9119 em condições neutras, e diminuindo para 0,8944 em condições instáveis. Os valores obtidos pela aplicação da metodologia proposta por ALLEN (1986), subestimaram a resistência aerodinâmica à transferência de vapor d'água.

Foi estimado, pelo método aerodinâmico, o fluxo de calor latente a cada meia hora e integrado para 24 horas a fim de estimar a resistência aerodinâmica efetiva diaria. Este resultado comparado ao valor obtido, conforme proposto por ALLEN (1986), forneceu um coeficiente de determinação $r^{2}=0,1046$.

A resistência aerodinâmica à transferência de vapor d'água obtida a cada meia hora variou de 100 a $21513 \mathrm{~s} / \mathrm{m}$ e a resistência aerodinâmica efetiva diária variou de 138 a $200 \mathrm{~s} / \mathrm{m}$.

A utilização da estimativa da resistência aerodinâmica à transferência do vapor d'água, conforme proposto por ALLEN (1986) não se mostrou adequada para as condições do estudo. 


\title{
THE ESTIMATION OF AERODYNAMIC RESISTANCE TO THE WATER VAPOUR THROUGH THE MICROMETEOROLOGICAL MEASUREMENTS.
}

\author{
Author: MARLENE MILHAREZI DEL DUCCAS MENDONÇA \\ Adviser: PROF. DR. JOSÉ HOLANDA CAMPELO JÚNIOR
}

\section{SUMMARY}

This experiment was conducted in the experimental farm of Universidade Federal de Mato Grosso (UFMT), in Baixada Cuiabana, during the dry season, in a plain and grassy area. The average height of the grass was $14 \mathrm{~cm}$. The purpose of the experiment was to establish the aerodynamic resistance to the diffusion of water vapour.

Measurements of the wind speed and of temperature of dry and wet bulbs were performed, inside the atmospheric boundary layer. The data were registered and stored in intervals of 5 minutes in a Datalogger.

The equations concerning to the logarithm wind profile and the correction function were used to estimate the displacement height, the roughness length to the momentum and the aerodynamic resistance to the diffusion of water vapour were considered in intervals of half hour. The results were compared with estimate results from the methodology proposed by ALLEN (1986) and it was verified that the determination 
coefficient varied from 0.2511 in stable condition, to 0.9119 in nearneutral condition, reducing to 0.8944 in unstable condition. The values estimated by methodology proposed by ALLEN (1986) underestimated the aerodynamic resistance to transference of water vapour.

It was estimated by the aerodynamic method the latent heat flux in every half hour, and it was integrated in intervals of 24 hours in order to estimate the daily effective resitance. for comparison with Allen methodology. These results lead to the determination coefficient, $r^{2}=0.1046$.

The aerodynamic resistance to the transference of water vapour, which was taken in every half hour, varied from 100 to $21513 \mathrm{~s} / \mathrm{m}$ and the daily effective aerodynamic resistance varied from 138 to 200 $\mathrm{s} / \mathrm{m}$.

The use of the estimate of the aerodynamic resistance to the transference of the water vapour, according to what was proposed by ALLEN (1986) was not considered adequated to the conditions of this work. 


\section{INTRODUÇÃO}

A descrição e o entendimento dos fluxos de momentum, vapor de água e calor sensivel são muito importantes para a hidrologia, agricultura e meteorologia pois permitem uma descrição da camada limite convectiva, para aplicação em métodos de estimativa de evapotranspiração, problemas de poluição de ar, etc...

A evapotranspiração potencial tem uma grande importância para o cálculo das necessidades hídricas das culturas e para estimar a evapotranspiração real para efeito do cálculo do balanço hídrico, sendo de utilidade para irrigação e para zoneamento agrícola. Além disso, como a quantidade de água transpirada por uma cultura está relacionada com a produção de matéria seca, então há necessidade de conhecer a evapotranspiração da cultura a fim de estimar a produção agrícola.

A Food and Agriculture Organization of the United Nations (FAO) em 1991, realizou um encontro de especialistas, da área de agrometeorologia e afins, para revisar e propor metodologias para estimativa da evapotranspiração potencial, tendo também como objetivo uma padronização de métodos a fim de que os resultados possam ser comparados. Neste encontro foi proposto o método de Penman-Monteith como padrão, estimando-se que, em um prazo de 10 anos, a evapotranspiração máxima das culturas possa ser estimada diretamente, 
desde que sejam efetuados estudos locais envolvendo as resistências aerodinâmicas e as resistências das culturas.

A FAO (1991) propôs que a metodologia para a aplicação de Penman-Monteith seja padronizada e que sejam feitos estudos locais para validar o método sob várias condições climáticas, particularmente para climas quente-úmido e advectivos.

Dentro deste espírito, o objetivo deste trabalho foi determinar a resistência aerodinàmica para o vapor de água através de medidas micrometeorológicas e comparar os valores assim obtidos com os valores obtidos pela aplicação do método proposto pela FAO (1991), na Fazenda Experimental da Universidade Federal de Mato Grosso em Santo Antônio do Leverger, MT. 


\section{REVISÃO DE LITERATURA}

\subsection{Estimativa da evapotranspiração potencial}

PENMAN (1948), propôs um método para estimar a evaporação de um lago em que combinou o balanço de energia com um termo aerodinâmico, função da velocidade do vento e do déficit de saturação (equação de Dalton). Conforme CUENCA et alli (1982), Penman em 1952 e 1956 propôs modificações a fim de estimar a evapotranspiração potencial.

Em 1975, a FAO publicou um relatório onde uniformizou e sugeriu alguns métodos e técnicas de medidas para estimativa de evapotranspiração potencial, sendo um dos métodos recomendados, o de Penman modificado.

MONTEITH (1965 e 1981) modificou a equação de Penman para uso sobre uma superficie vegetada. Esta equação ficou conhecida como equação de Penman-Monteith e tem a seguinte forma original:

$$
\lambda E T_{0}=\frac{\delta\left(R_{n}-G\right)+\frac{\rho c_{p}\left(e_{a}-e_{d}\right)}{r_{a}}}{\delta-\gamma\left(1+\frac{r_{c}}{r_{a}}\right)}
$$

Em 1991, a FAO promoveu uma revisão das metodologias para estimativa da evapotranspiração potencial. Além de reiterar alguns métodos, recomendou que o método de Penman modificado, amplamente difundido e 
aplicado, seja substituido pelo método de Penman-Monteith, visto que existem evidências de que o primeiro superestima sob condições não advectivas enquanto o segundo tem mostrado bom desempenho sob diferentes condições climáticas.

\subsection{Resistência aerodinâmica em atmosfera neutra}

De acordo com MONTEITH (1973 e 1981), quando o transporte de qualquer entidade depende da difusão (molecular ou turbulenta), a densidade do fluxo vertical desta entidade, $F(z)$, na camada limite que caracteriza uma superfície (água, solo ou vegetação), pode ser expressa por:

$$
F(z)=-\rho(z) K(z) \frac{\partial \varphi}{\partial z}
$$

onde $\rho(z)$ é a densidade no ponto $z, K(z)$ é a difusividade ou coeficiente de difusão àquela entidade no ponto $z$ e $\partial \varphi / \partial z$ é o gradiente da entidade no ponto $z$.

Devido à dificuldade de medir diretamente o gradiente em um ponto, MONTEITH (1973 e 1981) assumiu $F(z)$ constante entre duas alturas $z_{1}$ e $z_{2}$ e $\rho(z)$ médio neste intervalo e integrou a eq. (2) obtendo:

$$
F=\rho \frac{\varphi\left(z_{1}\right)-\varphi\left(z_{2}\right)}{\int_{z_{i}} \frac{d z}{K(z)}}
$$

A eq. (3), conforme MONTEITH (1973 e 1981), é uma forma análoga à lei de Ohm, onde o numerador representa uma diferença de potencial e o denominador uma resistência ao fluxo que pode ser representada por:

$$
r=\int_{i=1}^{\infty} \frac{d z}{K(z)}
$$


Segundo MONTEITH (1973), o conceito de resistência se aplica a qualquer sistema no qual os fluxos possam ser relacionados a gradientes, de modo que a eq. (4) pode então representar as resistências ao fluxo de momentum, calor ou vapor d'água respectivamente conforme abaixo:

$$
\begin{aligned}
& r_{m}=\int_{=l}^{j} \frac{d z}{K_{m}(z)} \\
& r_{H}=\int_{=t}^{j} \frac{d z}{K_{H}(z)} \\
& r_{v}=\int_{z l}^{j} \frac{d z}{K_{v}(z)}
\end{aligned}
$$

MONTEITH (1973) afirmou que quando o processo se trata só de difusão molecular, os coeficientes de difusão para momentum, calor e vapor d'água são similares na ordem de grandeza e em sua dependência com a temperatura. No entanto, na atmosfera, onde a turbulência é o mecanismo dominante de difusão, os coeficientes de difusão são muitas ordens de grandeza maiores que o valor molecular correspondente e aumentam com a altura acima do chão.

MONTEITH (1973), por analogia com a eq. (2), apresentou a seguinte equação para o fluxo de momentum:

$$
\tau(z)=K_{m}(z) \frac{\partial(\rho u)}{\partial z}
$$

e afirmou que as equações para fluxo de calor e vapor bem como os coeficientes de difusão para calor, $K_{H}$ e para vapor d'água $K_{v}$ podem ser definidos de forma equivalente. 
6.

MONTEITH (1973) considerou que, em condições neutras, a velocidade média do vento aumenta logaritmicamente com a altura de acordo com a seguinte relação:

$$
u\left(z_{m}\right)=\frac{u *}{k} \ln \left(\frac{z_{m}-d}{z_{m m}}\right)
$$

onde:

$$
u_{*}^{2}-\frac{\tau}{\rho}
$$

MONTEITH (1973), combinando as eqs. (5), (8), (9) e (10) e considerando $z_{1}=\left(z_{0 m}+d\right), \quad z_{2}=z_{m}, u\left(z_{1}\right)=0$ e $u\left(z_{2}\right)=u\left(z_{m}\right)$ obteve, para a resistência aerodinâmica ao transporte de momentum, a seguinte equação:

$$
r_{m}=\frac{\left[\ln \left(\frac{z_{m}-d}{z_{o_{m}}}\right) l^{2}\right.}{u\left(z_{m}\right) k^{2}}
$$

Segundo MONTEITH (1973), existe muita controvérsia sobre a relação entre os coeficientes de difusão turbulenta $K_{m}, K_{H}$ e $K_{v}$. Para condições neutras, MONTEITH (1973) assumiu similaridade entre transferência de momentum, calor e vapor d'água e sugeriu que

$$
K_{m}=K_{H}=K_{v}
$$

e consequentemente:

$$
r_{m}=r_{H}=r_{r}
$$

MONTEITH (1973), sugeriu que as fontes aparentes de calor sensivel e vapor d'água devem, em geral, estar em um nível mais baixo no 
dossel do que o sumidouro de momentum e que a resistência aerodinâmica ao calor sensivel e ao vapor deve ser maior do que a resistência ao momentum.

BERKOWICZ \& PRAHM (1982) afirmaram que as resistências aerodinâmicas são governadas pela turbulência atmosférica que é mantida principalmente pela transferência de calor e momentum. As resistências aerodinâmicas dependem portanto destas grandezas. De outro lado, é a interação do vento com a superfície a maior fonte de turbulência na camada superficial.

BERKOWICZ \& PRAHM (1982) consideraram que as resistências aerodinâmicas são geralmente diferentes para diferentes fluxos e dependem das propriedades do meio no qual o fluxo é considerado, isto é, as resistências aerodinâmicas são governadas pela turbulência e consideraram que, como os transportes turbulentos do vapor de água e do calor sensivel são governados pelo mesmo mecanismo de difusão turbulenta, é razoável assumir que a resistência aerodinâmica ao transporte do vapor $\left(r_{v}\right)$ seja igual à resistência aerodinâmica do transporte turbulento para o calor $\left(r_{H}\right)$ ou seja:

$$
r_{H}=r_{\mathrm{v}}=r_{a}
$$

ALLEN (1986), definiu a resistência aerodinâmica à transferência do vapor d'água em condições de neutralidade, no interior da camada limite, como:

$$
r_{a}=r_{v}=\frac{\ln \left(\frac{z_{m}-d}{z_{O m}}\right) \ln \left(\frac{z_{H}-d}{z_{O H}}\right)}{u\left(z_{m}\right) k^{2}}
$$

A FAO (1991), sugeriu que a resistência aerodinâmica, a ser utilizada para o cálculo da evapotranspiração de referência pelo método de Penman-Monteith, seja calculada pela eq. (15). 
Assumindo $\quad z_{m}=2 m, \quad d=0.08 m, \quad z_{H}=2 m, \quad z_{0 m}=0.01476 m$, $\mathrm{Z}_{\mathrm{OH}}=0.001476 \mathrm{~m}$, correspondentes a medidas efetuadas em abrigo meteorológico situado a $2 \mathrm{~m}$ sobre um gramado de $12 \mathrm{~cm}$ de altura e velocidade do vento medida a $2 \mathrm{~m}$ de altura a FAO (1991) recomendou que:

$$
r_{a}=\frac{208}{U_{z}}
$$

\subsection{Resistência aerodinâmica - forma generalizada}

Para BERKOWICZ \& PRAHM (1982), a estimativa empírica da resistência aerodinâmica para o vapor d'água conforme foi formulada por PENMAN (1948) é uma função inversa da velocidade do vento a $2 \mathrm{~m}$ de altura. Esta relação linear foi baseada em medidas diárias para superfícies de água livre e, com pequenas modificações é utilizada ainda hoje nos estudos de evaporação de longo prazo.

BERKOWICZ \& PRAHM (1982) afirmaram que esta simplificação pode ser adequada quando se considera médias sobre períodos de um dia ou mais. Para valores horários, consideraram que 0 efeito da condição de estabilidade atmosférica no interior da camada limite é muito importante.

BERKOWICZ \& PRAHM (1982) utilizaram as relações fluxo-perfil baseadas na teoria de similaridade de Monim-Obukhov; os trabalhos de BUSINGER et alli (1971), de PAULSEN (1970) e de BARKER \& BAXTER (1975) e obtiveram a seguinte expressão geral para a resistência aerodinâmica ao vapor d'água: 
$r_{a}=\frac{R}{k^{2} u\left(z_{m}\right)}\left[\ln \left(\frac{z_{m}-d}{z_{O_{m}}}\right)-\psi_{m}\left(\frac{z_{m}-d}{L}\right)+\psi_{m}\left(\frac{z_{O m}}{L}\right)\right]\left(\ln \left(\frac{z_{H}-d}{z_{O m}}\right)-\psi_{H}\left(\frac{z_{H}-d}{L}\right)-\psi_{H}\left(\frac{z_{O m}}{L}\right)\right]$

onde $R=0,74, k=0,35$, e, fazendo $\xi=\left(z_{x}-d\right) / L$ ou $\xi=z_{x} / L$ com $x=m, H$ ou $v$, tem-se: Para $\xi<0$

$$
\begin{aligned}
& \psi_{m}(\xi)=\ln \left(\frac{1+x}{2} f\left(\frac{1-x^{2}}{2}\right)-2 \arctan x+\pi / 2\right. \\
& \psi_{H}(\xi)=2 \ln \left(\frac{1-y}{2}\right) \\
& x=(1-15 \xi)^{\frac{1}{4}} \\
& y=(1-9 \xi)^{1 / 2}
\end{aligned}
$$

Para $\xi>0$

$$
\begin{aligned}
& \psi_{m}(\xi)=+.7 \xi \\
& \psi_{H}(\xi)=-\left(\frac{4,7}{R}\right) \xi
\end{aligned}
$$

onde $\mathrm{L}$, o comprimento de Monin-Obukhov, é dado por:

$$
L=-\rho c_{p} \frac{T u_{*}^{3}}{k g H}
$$

BERKOWICZ \& PRAHM (1982) referiram-se ao trabalho de DYER \& HICKS (1970) e destacaram como principais diferenças em relação ao de BUSINGER et alli (1971) os valores assumidos, $R=1$ e $k=0,41$, afirmando 
que os valores da resistência aerodinâmica não são sensiveis às diferentes formulações.

THOM \& OLIVER (1977) expressaram a resistência aerodinâmica para o vapor d'água, em condições não neutras como:

$$
r_{a}=\frac{\left[\ln \left(\frac{z-d}{z_{0 m}}\right)-\psi_{m}(\xi)\right]\left[\ln \left(\frac{z-d}{z_{O H}}\right)-\psi_{H}(\xi)\right]}{k^{2} u}
$$

onde $z=z_{m}=z_{H}$ porque a velocidade e a temperatura foram medidas no mesmo nível $z$.

THOM \& OLIVER (1977) baseados em Thom et alli admitiram que a diferença entre $\mathrm{Z}_{\mathrm{Om}}$ e $\mathrm{Z}_{\mathrm{OH}}$ possa ser parcialmente compensada pelo aumento efetivo de $\mathrm{Z}_{\mathrm{OH}}$ e em vista desta incerteza e de muitas outras fontes de erro na estimativa regional de evaporação propuseram a seguinte expressão simplificada para o cálculo da resistência aerodinâmica:

$$
r_{a}=\frac{\left[\ln \left(\frac{z-d}{z_{o m}}\right)-\psi_{m}(\xi) /\left[\ln \left(\frac{z-d}{z_{o_{m}}}\right)-\psi_{H}(\xi)\right]\right.}{k^{2} u}
$$

\subsection{Perfis de vento e temperatura - relações fluxo-perfil}

DYER (1974), afirmou que Monin e Obukhov baseados em argumentos adimensionais, estabeleceram a seguinte generalização fluxoperfil:

$$
\frac{\partial \theta}{\hat{c} z}=-\frac{H}{\rho c_{F} k u * z} \phi_{H}(\xi)
$$




$$
\frac{\partial q}{\partial z}=-\frac{E}{\rho L_{v} k u * z} \phi_{v}(\xi)
$$

$$
\frac{\partial u}{\partial z}=\frac{u *}{k z} \phi_{m}(\xi)
$$

Segundo DYER (1974), uma vez conhecidas as funções $\phi_{V}, \phi_{H} e$ $\phi_{m}$ como funções de $z / L$, as relações fluxo-perfil ficam especificadas e tem-se que:

$$
\begin{aligned}
& K_{H}=\frac{k u * z}{\phi_{H}} \\
& K_{v}=\frac{k u * z}{\phi_{v}} \\
& K_{m}=\frac{k u * z}{\phi_{m}}
\end{aligned}
$$

e

$$
R i=\frac{z}{L} \frac{\phi_{H}}{\phi_{m}{ }^{2}}
$$

O número de Richardson, Ri, conforme PEREIRA (1992), é um indicador da condição atmosférica, compara os efeitos das forças térmicas com os efeitos das forças mecânicas, é computado a partir de medidas de perfis e é dado por:

$$
R i=\frac{g \frac{d \theta}{d z}}{\theta\left(\frac{d u}{d z}\right)^{2}}
$$

onde, para:

$$
\begin{array}{cc}
R i=0 & \text { atmosfera est vel } \\
R i=0 & \text { atmosfera neutra } \\
R i=0 & \text { atmosfera inst vel }
\end{array}
$$


Segundo TANNER (1967), o perfil de vento sobre uma superfície vegetada, quando a condição atmosférica é neutra, pode ser expresso pela eq. (9).

TANNER (1967) afirmou que superfícies em processo de resfriamento ou aquecimento alteram a curvatura do perfil logaritmico, mudando sua inclinação sendo necessária uma correção.

A eq. 9, segundo TANNER (1967), foi modificada para representar perfis não neutros, para superfícies aquecidas ou resfriadas quando o processo de transferência térmica convectiva (convecção livre) tornase importante comparada ao processo mecânico de transferência (convecção forçada), da sequinte maneira:

$$
u=\frac{u *}{k}\left[\ln \left(\frac{z-d}{z_{\theta}}\right)+\psi_{m}(R i)\right]
$$

onde $\psi_{\mathrm{m}}(\mathrm{Ri})$ é a função de correção.

SAUGIER \& RIPLEY (1978), mediram a velocidade do vento, temperatura e umidade sobre a área de uma pradaria natural durante muitos meses e para representar o perfil de vento e de temperatura usaram as seguintes equações:

$$
\begin{aligned}
& u=\frac{u *}{k}\left[\ln \left(\frac{z-d}{z_{\theta}}\right)-\psi(\xi)\right] \\
& T=-\frac{T *}{k}\left[\ln (z-d)-\psi_{H}(\xi)\right]-\text { constante }
\end{aligned}
$$

Foi adotada também para perfil de vapor de água uma função de correção $\psi_{v}(\xi)=\psi_{H}(\xi)$.

Segundo PAULSON (1970), a função $\psi_{m}(\xi)$ pode ser obtida por: 
$\psi_{m}=\int_{0}^{\xi} \frac{1-\phi_{m}(\xi)}{\xi} d \xi$

Analogamente:

$$
\psi_{v}=\psi_{H}=\int_{0}^{5} \frac{1-\phi_{v}(\xi)}{\xi} d \xi
$$

SAUGIER \& RIPLEY (1978) afirmaram que em condições instáveis, o perfil de temperatura afasta-se mais do perfil logarítmico do que o perfil de vento e em condiçōes estáveis tem aproximadamente a mesma forma, afastando-se do perfil logarítmico para estabilidade moderada e retornando a ele para forte estabilidade.

STEARNS (1970), expressou a variação da temperatura potencial com a altura como:

$$
\theta(z)-\theta_{0}=-T_{*}\left[\ln \left(\frac{z-d}{z_{0}}\right)+\psi_{H}(z)\right]
$$

De acordo com SAUGIER \& RIPLEY (1978), as funções de correção $\psi$ têm sido determinadas somente empiricamente. Como L é uma função do fluxo de superfície ( $\rho u_{*}^{2}$ e H), não pode ser computado diretamente da observação dos perfis, mas pode ser obtido a partir de um outro parâmetro de estabilidade, o número de Richardson ( $R i)$, e baseados em Dyer \& Hicks e Webb, utilizaram:

$$
\begin{aligned}
& \text { inst vel }(R i \leq 0) \quad L=\frac{z_{I}}{R i} \\
& \text { est vel }(0<R i \leq 0.16) \quad L=z_{1}\left(\frac{l}{R i}-4.7\right)
\end{aligned}
$$


BERKOWICZ \& PRAHM (1982) consideraram as relações fluxoperfil importantes para o cálculo da resistência aerodinâmica pois estas expressam as condições atmosféricas das quais a resistência depende.

Segundo DYER (1974), os parâmetros u*, d e $z_{0}$, necessários para estimar os fluxos turbulentos de superfície (de calor, vapor d'água e momentum), fundamentais para o entendimento da atmosfera, são estimados a partir das relações fluxo-perfil.

DYER (1974) afirmou não existir uma teoria capaz de predizer as relações existentes entre fluxos e perfis, entretanto os dados experimentais tem sido bem explicados e interpretados através da teoria baseada em grupos adimensionais de Monin-Obukhov.

Segundo HOGSTROM (1990), a teoria de Monin-Obukhov prevê que variáveis dependentes que caracterizam os fluxos turbulentos podem ser normalizadas com os parâmetros característicos da camada superficial e com a altura acima do solo, $z$, as quais são funções universais de $z / L$ onde $L$ é comprimento de Monin-Obukhov.

DYER (1974) sugeriu as seguintes relações para os gradientes adimensionais:

para condições instáveis:

$$
\begin{aligned}
& \phi_{H}=\phi_{v}=\left(1-16\left(\frac{z}{L}\right)\right)^{-\frac{1}{2}} \\
& \phi_{m}=\left(1-16\left(\frac{z}{L}\right)\right)^{-\frac{1}{4}}
\end{aligned}
$$

e para condições estáveis:

$$
\phi_{H}=\phi_{v}=\phi_{m}=1-5\left(\frac{z}{L}\right)
$$


15.

PAULSON (1970) propôs, baseado nas relações empíricas de KEYPS, citado por PANOFSKY et alli (1960) e nas de Businger e de Dyer, alguns procedimentos para, a partir de medidas de perfis, calcular $\psi_{\mathrm{m}}(\xi)$ e $\psi_{\mathrm{H}}(\xi)$ para condições instáveis.

PAULSON (1970) baseado na hipótese da similaridade de MoninObukhov, apresentou o gradiente adimensional de velocidade do vento e temperatura, $\phi_{\mathrm{m}}$ e $\phi_{\mathrm{H}}$ como:

$$
\begin{aligned}
& \phi_{m}=\frac{k z}{u *} \frac{\partial u}{\partial z} \\
& \phi_{Y I}=\frac{z}{\theta * \frac{\partial \theta}{\partial z}}
\end{aligned}
$$

Para o perfil logaritmico do vento e da temperatura, utilizou as seguintes equações:

$$
\begin{aligned}
& u=\frac{u *}{k}\left[\ln \left(\frac{z-d}{z_{0}}\right)-\psi_{m}\left(\xi^{\prime}\right)\right] \\
& \left.\theta-\theta_{0}=\theta * / \ln \left(\frac{z-d}{z_{0}}\right)-\psi_{H}\left(\xi^{\prime}\right)\right]
\end{aligned}
$$

onde $\xi^{\prime}$ é uma variável adimensional que define as características do escoamento numa altura $z$ e é dado por:

$$
\xi^{\prime}=\frac{z-d}{L^{\prime}}
$$

onde:

$$
L^{\prime}=\frac{K_{H}}{K_{m}} L
$$

e de acordo com MONIN \& YAGLON (1971): 
16.

$$
L^{\prime}=\frac{u * \frac{\partial u}{\partial z}}{k \frac{g}{T_{0}} \frac{\partial T}{\partial z}}
$$

PAULSON (1970) utilizando as eqs. (35) e (37) e considerando que:

$$
\phi^{4}-\beta \frac{Z}{L^{\prime}} \phi^{3}=1
$$

conforme sugerido por PANOFSKY et alii (1960), onde $\beta$ é uma constante, obteve, para condições neutra e instável, o seguinte resultado para a função $\psi$ $m\left(\xi^{\prime}\right):$

$\psi_{m}\left(\xi^{\prime}\right)=1-\phi_{m}-3 \ln \phi_{m}-2 \ln \left(\frac{1+\phi_{m}}{2}\right)+2 \arctan \phi_{m}-\pi / 2+\ln \left(\frac{1+\phi_{m}^{2}}{2}\right)$

PAULSON (1970), estabeleceu que a relação entre o comprimento de Monin-Obukhov ( $\left(/ L^{\prime}\right)$ e Ri é dado por:

$$
\frac{z}{L^{!}}=\frac{R i_{z}}{\left(1-\beta R i_{z}\right)^{1 / 4}}
$$

onde $\mathrm{Ri}_{z}$ é característico da altura $z=\left(z_{1} z_{2}\right)^{1 / 2}$ utilizando as seguintes aproximações dos gradientes sugeridas por Panofsky:

$$
\left.\frac{\partial X}{\partial z}\right|_{z_{1} z_{2}^{1 / 2}} \approx \frac{X_{2}-X_{1}}{z_{1} z_{2}^{l / 2}} \ln \left(z_{2}, z_{l}\right)
$$

PAULSON (1970) afirmou que, a partir de medidas de perfil, Ri e o comprimento de Monim-Obukhov podem ser determinados pelo procedimento acima. A eq. (38) pode ser resolvida pelo uso de tabela ou através de programas computacionais e a função $v_{\mathrm{m}}\left(\xi^{\prime}\right)$ pode finalmente ser obtida. PAULSON (1970) se referiu a este procedimento como modelo KEYPS. 
17.

O outro procedimento que PAULSON (1970), sugeriu para encontrar $\psi_{m}(\xi)$ e $\psi_{H}(\xi)$, é baseado nas relações de Businger-Dyer (B-D), resumidas por ele nas seguintes equações:

$$
\begin{aligned}
& R i=\frac{z}{L} \\
& \phi_{m}=\left(1-\beta \frac{z}{L}\right)^{-1 / 4} \\
& \phi_{H}=\left[1-\beta\left(\frac{z}{L}\right)\right]^{1 / 2}
\end{aligned}
$$

obtendo para $\psi_{\mathrm{m}}(\xi)$ e $\psi_{H}(\xi)$ respectivamente:

$$
\psi_{n}(\xi)=2 \ln \left(\frac{1+x}{2}\right)-\ln \left(\frac{1+x^{2}}{2}\right)-2 \arctan x-\frac{\pi}{2}
$$

e:

$$
\psi_{H}-2 \ln \left[\frac{1+x^{2}}{2}\right]
$$

onde:

$$
x=\left(1-\beta \frac{z}{L}\right)^{1 / 4}
$$

De acordo com PAULSON (1970), a representação B-D implica em $u \mu z^{-1 / 4}$ e a de KEYPS em $u \mu z^{-1 / 3}$ para comprimentos de Monim-Obukhov grandes (ou seja não se comportam da mesma maneira, isto é, não são universais).

PAULSON (1970) concluiu que tanto o modelo de KEYPS como o de B-D sāo igualmente bons para descreverem o perfil de vento e sugere que 
18.

deve ser melhor estudada a constante $\beta$ visto os diferentes valores sugeridos tais como: $\beta=18$ (PANOFSKY (1960)), $\beta=15$ (DYER (1967)), e o valor obtido por ele igual a 16 .

PARLANGE \& KATUL (1992a) citaram as seguintes equações para as funções $\psi$ de correção Businger-Dyer para a transferência do momentum:

$$
\begin{gathered}
\psi_{m}(\xi)=\ln / \frac{(1+x)^{2}\left(1-x^{2}\right)}{\left(1+x_{0}\right)^{2}\left(1-x_{0}^{2}\right)} /-2 \arctan (x)+2 \arctan \left(x_{0}\right) \quad \xi \cdots 0 \\
\psi_{m}(\xi)-5\left(\frac{z_{0}}{L}-\xi\right) \quad 0<\xi \leq 1 \\
\psi_{m}(\xi)=-5 \ln \left(\frac{z-d}{z_{0}}\right) \quad I<\xi
\end{gathered}
$$

e para a transferência do vapor d'água:

$$
\begin{aligned}
& \psi_{H}(\xi)=2 \ln \left(\frac{1+x^{2}}{2}\right) \quad \quad \xi<0 \\
& \psi_{H}(\xi)=5\left(\frac{z_{0}}{L}-\xi\right) \quad 0<\xi \leq 1 \\
& \psi_{H}(\xi)=-5 \ln \left(\frac{z-d}{z_{\theta}}\right) \quad 1<\xi
\end{aligned}
$$

onde:

$$
x=(1-16 \xi)^{i . t}
$$

e

$$
x_{0}=\left(1-16 \frac{z_{0}}{L}\right)^{\frac{1}{x}}
$$

Conforme VISWANADHAM et alli (1990), as funçōes universais $\psi$ não podem ser previstas somente pela teoria da similaridade, mas devem ser 
suplementadas com trabalhos experimentais onde os fluxos de momentum, calor e vapor d'água devem ser medidos independentemente.

\subsection{Extensão e parâmetros da camada limite}

Segundo Munro e Oke, citado por KIZER \& ELLIOTT (1991) o contorno superior $\left(\delta_{\mathbf{X}}\right)$ da camada limite deve ser estimado através da seguinte equação:

$$
\delta_{x}=0.1 x^{0.8} z_{0 m}^{0.2}
$$

onde $x$ é a distância da borda de ataque.

Kanemasu et alii e Rosenberg et alii citados por KIZER \& ELLIOTT (1991) sugeriram 100:1 como razão entre o comprimento e a altura mais apropriada que a relação 50:1 derivada da eq. 74 .

LO (1977) afirmou que a interação entre a camada limite atmosférica e a superficie afeta o desenvolvimento do perfil de vento e altera as características aerodinâmicas da superfície e que o elemento rugoso de superfície tem sido caracterizado em termos de um comprimento rugoso $z_{0}$ e um deslocamento de altura, $d$.

SAXTON (1975) verificou que a evapotranspiração potencial não foi muito sensível aos parâmetros de perfil do vento, mas como podem ocorrer erros muito grandes nas estimativas destes parâmetros (200 a 300\% conforme Saxton; Munro \& Oke,) então seu efeito sobre evapotranspiração potencial, em muitos casos, pode ser significante.

SZEICZ et alii (1969) desenvolveram a seguinte equação empirica para comprimento rugoso para o momentum:

$$
\log \left(z_{1 / m}\right)=0.997 \log (h)-0.883
$$


De acordo com BRUTSAERT (1975a), $z_{0 m}$ é uma função bastante complicada da geometria, espaçamento e natureza do elemento rugoso sendo que as variáveis que influenciam $z_{0 m}$ mais diretamente são: altura, área frontal, densidade, concentração, espaçamento, fatores de forma, etc...dos elementos rugosos.

Como é difícil obter uma boa relação entre todas estas variáveis, BRUTSAERT (1975a) recomendou que o melhor recurso é estabelecer uma relação entre $z_{o m}$ e $h$, por ser $h$ o parâmetro mais óbvio, sem ambiguidades e o mais disponivel. Paeschke (1937), segundo BRUTSAERT (1975a), foi provavelmente o primeiro a propor uma relação entre $z_{0 m}$ e $h$, para várias espécies de gramas, dada por:

$$
\frac{h}{z_{\text {om }}}=7.35
$$

De acordo com BRUTSAERT (1975a), Kondo em 1971, utilizando-se do perfil de vento seno-hiperbólico de COWAN (1968), no interior de um dossel com elementos rugosos pequenos colocados espaçadamente, obteve, considerando deslocamento do plano zero nulo, a seguinte relação:

$$
\frac{h}{z_{\partial m}}=e^{2}
$$

BRUTSAERT (1975a) derivou teoricamente a relação de Paeschke a partir do perfil de vento seno-hiperbólico de COWAN (1968) no interior de um dossel, considerando elementos rugosos pequenos densamente colocados e o deslocamento do plano zero. Considerou que o perfil logarítmico e de seno-hiperbólico devem apresentar continuidade para a função vento e sua primeira derivada e assumindo uma aproximação devida a Kondo (1972), determinou que: 


$$
\left(\frac{h-d}{z_{\theta_{m}}}\right)=e=2.72
$$

Considerando que a razão $\mathrm{d} / \mathrm{h}$ é relativamente insensível a natureza da superfície e outros fatores, ao contrário da razão $\mathrm{z}_{\mathrm{Om}} / \mathrm{h}$, BRUTSAERT (1975a) adotou para uma superfície natural coberta de cultura a seguinte aproximação:

$$
d=\frac{2 h}{3}
$$

obtendo finalmente:

$$
\frac{h}{z_{\theta m}}=3 e
$$

Devido a similaridade dos resultados obtidos por diversos métodos, BRUTSAERT (1975a) sugeriu que $\mathrm{h} / \mathrm{z}_{\mathrm{om}}$ é relativamente insensivel ao método adotado para seu cálculo.

BRUTSAERT (1975a), afirmou que qualquer resultado obtido a partir das relaçōes discutidas acima, não implica que sejam bons substitutos para d e $z_{0 m}$ obtidos experimentalmente para uma dada superfície. Considera que a equação acima deve ser utilizada como uma primeira aproximação ou como uma estimativa de magnitude a ser utilizada quando não existem valores experimentais disponiveis.

\section{BRUTSAERT (1975b) afirmou que apesar da analogia} frequentemente assumida entre a transferência turbulenta de momentum e a transferência turbulenta de calor e de vapor d'água, esta analogia não pode ser transferida para os respectivos comprimentos rugosos pois, enquanto a transferência de massa e calor é controlada principalmente pela difusão 
molecular, a transferência de momentum é controlada também por forças de pressão.

BRUTSAERT (1975b) afirmou que o comprimento rugoso é afetado pela natureza da superfície, pela natureza do fluido e do fluxo. Ele afirmou também que a suposição de que o comprimento rugoso para o momentum seja igual ao comprimento rugoso para o vapor d'água leva a erros marcantes nas análises de perfis. Para dados típicos, a relação sugerida por BRUTSAERT (1975b) é que o comprimento rugoso para o vapor d'água é aproximadamente 0,096 do comprimento rugoso para o momentum.

ALLEN et alii (1989) consideraram que o comprimento rugoso para transferência de momentum e do vapor eram diferentes e baseando-se no trabalho de Brutsaert, sugeriram:

$$
\begin{aligned}
& z_{O m}=0.123 \mathrm{~h} \\
& z_{O H}=0.1 z_{O m}
\end{aligned}
$$

Baseando-se em Plate, Monteith e em Brutsaert, ALLEN et alii (1989) recomendaram que

$$
d=\frac{2}{3} h
$$

Estas mesmas equaçōes e consideraçōes foram adotadas pela FAO (1991) para a estimativa de evapotranspiraçăo para períodos iguais ou maiores do que um dia.

DUYNKERKE (1992) considerou os comprimentos rugosos como constantes de integração dos perfis logarítmicos da temperatura e do vento; que existe diferença entre os comprimentos rugosos para calor e momentum, que está relacionada à resistência adicional para troca de calor devido à 
difusão molecular. O momentum é transferido para a superfície por meio de gradientes de pressão sobre os elementos rugosos, enquanto o calor e a umidade são transferidos desde as folhas e o solo por difusão molecular. Ele assumiu que $d=d_{h}=d_{m}$, onde $d_{h}$ é o deslocamento do plano zero em relação ao fluxo de calor e $d_{m}$ é o deslocamento do plano zero em relação ao fluxo de momentum.

Baseado na análise teórica de Brutsaert e com algumas considerações adicionais, DUYNKERKE (1992) obteve a seguinte relação:

$$
\begin{aligned}
& \ln \left(\frac{z_{\text {OII }}}{z_{\text {om }}}\right)=-\frac{13 u *}{L A I}+0.85 \\
& L A I=h \frac{A_{f}}{2}
\end{aligned}
$$

Para a expressão $\ln \left(\mathrm{Z}_{\mathrm{OH}} / \mathrm{z}_{\mathrm{O} m}\right)$, DUYNKERKE (1992) encontrou 0 valor de 0.85 e considerou isto como uma estimativa grosseira que leva a aumento de erro para pequenos valores de u*. DUYNKERKE (1992) observou que principalmente durante a noite com estratificação amplamente estável, envolvendo baixas velocidades do vento, a determinação de u* não é muito exata para valores menores do que $0.1 \mathrm{~m} / \mathrm{s}$.

DUYNKERKE (1992), afirmou que a relação entre o comprimento rugoso do calor e do momentum depende fortemente do indice de área foliar, LAI, e da velocidade de fricção u* e, baseado em observações, verificou que $\mathrm{z}_{\mathrm{on}} / \mathrm{z}_{\mathrm{Om}}$ varia desde 10 (para pequenos valores de $\mathrm{U}_{*}$ ) até cerca de $10^{-6}$ (para grandes valores de $u_{*}$ ).

STEARNS (1970) propôs que os parâmetros de rugosidade para o momento e o deslocamento do plano zero sejam estimados pelo Método do Mínimo Quadrado, o qual requer que o erro entre o valor medido e o valor 
estimado do perfil de velocidade do vento seja minimizado em relação aos parâmetros citados.

LO (1977) propôs que os parâmetros de rugosidade do momentum e o deslocamento do plano zero sejam estimados através do Método dos Residuos Ponderados, com funções pesos: $f 1=1$ e $f 2=z$. De acordo com LO (1977), este método além de minimizar os erros envolvidos durante o processo também suaviza e redistribue os erros já minimizados de modo mais favorável.

Os resultados de LO (1977) indicam que quando a velocidade do vento aumenta, o comprimento rugoso aumenta, enquanto que o deslocamento do plano zero diminui.

LO (1977) fez uma análise dos elementos rugosos classificandoos em rígidos e flexiveis. Os elementos rugosos rígidos respondem ao aumento da velocidade do vento aumentando o comprimento rugoso e diminuindo o deslocamento do plano zero. De outro lado, o aumento da velocidade do vento tende a reduzir o comprimento rugoso e o deslocamento do plano zero com o aumento de movimento dos elementos rugosos flexiveis.

A razão apresentada por LO (1977) é que os elementos rugosos rígidos, se há um aumento da velocidade do vento, tendem a transformar os redemoinhos grandes em redemoinhos pequenos no topo dos elementos rugosos. O aumento do número de redemoinhos induz um influxo de energia adicional a qual é a maior fonte de intensificação de flutuações de velocidade turbulenta, consequentemente o efeito líquido é um aumento do coeficiente de arrastro e do comprimento rugoso. Ao mesmo tempo, ventos de velocidades superiores penetram mais profundamente dentro da vegetação diminuindo assim a altura do deslocamento do plano zero. No caso de elementos rugosos flexiveis, para altas velocidades do vento deve ocorrer o selamento da vegetação levando assim a uma diminuição de ambos os parâmetros. 
PARLANGE \& KATUL (1992a) propuseram para o comprimento rugoso para a transferência de calor:

$$
\frac{z_{O H}}{z_{0}}=7,4 \exp \left[-2,46 z_{0_{*}}^{\frac{1}{4}}\right]
$$

onde o número de Reynolds rugoso é dado por:

$$
z_{0+}=\frac{u * z_{0}}{v}
$$

De acordo com PARLANGE \& KATUL (1992b), o comprimento rugoso para o vapor de água para superfícies rugosas flexíveis pode ser determinado por:

$$
\frac{z_{0_{v}}}{z_{0}}=7.4 \exp \left[-2.25\left(z_{0+}\right)^{\frac{1}{4}}\right]
$$


26.

\section{MATERIAL E MÉTODOS}

O experimento foi conduzido na Fazenda Experimental da Universidade Federal de Mato Grosso (UFMT), situada no município de Santo Antonio do Leverger - MT, na regiāo conhecida como Baixada Cuiabana. Esta região caracteriza-se por apresentar estação seca e estação úmida bem definidas e velocidades de vento muito baixas, praticamente durante o ano todo.

Os equipamentos foram montados ao lado da Estação Agrometeorológica Padre Ricardo Remetter (latitude: 1547'11"S, longitude: $56^{\circ} 04^{\prime} 17^{\prime \prime} \mathrm{W}$ e altitude: $140 \mathrm{~m}$ ) numa área plana e coberta de grama, cuja altura média foi de $14 \mathrm{~cm}$.

As medidas foram efetuadas dentro da camada limite superficial em três niveis diferentes: nível 1,2 e 3 situados respectivamente a $0,40,0,80$ e $1,5 \mathrm{~m}$ de altura em relação ao solo. A velocidade do vento foi medida nos níveis 1,2 e 3 . No nível 1 foi medida a temperatura de bulbo seco e a temperatura de bulbo úmido e entre os níveis 1 e 3 foi medida a diferença de temperatura de bulbo seco e de bulbo úmido. Todas as medidas foram feitas simultaneamente.

Para determinar a velocidade do vento foram utilizados anemómetros, modelo $\mathrm{A} 100 \mathrm{R}$, com contatos de ressalto livre, tipo três conchas. 
As temperaturas foram medidas com o termopar cobreconstantam. Como a diferença de temperatura entre os niveis 1 e 3 , necessária para o problema, poderia ser menor do que o erro inerente às medidas efetuadas com termopar, optou-se por medir diretamente a diferença de temperatura. Para a medida da temperatura de cada nivel, a temperatura de referência foi o gelo fundente (mistura de água e gelo em uma garrafa térmica de 1 I), monitorado através de um termômetro de mercúrio. Para a medida da diferença de temperatura entre os níveis 1 e 3 , o nivel 1 foi usado como referência.

No local de medida, foi instalado um cano de ferro galvanizado, com $10 \mathrm{~cm}$ de diâmetro, na posiçâo vertical, com hastes perpendiculares que foram ajustadas na posição da altura dos niveis de medida. Nas extremidades destas hastes foram fixados os anemômetros a $30 \mathrm{~cm}$ destes foram instalados os termopares. (Os instrumentos foram fixados nas extremidades destes braços). As medidas foram registradas e armazenadas através de um Datalogger, modelo MM900, ELE.

Foram efetuadas cinco séries de medidas entre os dia 30 de agosto a 03 de setembro de 1994 .

A velocidade do vento foi registrada a intervalos de 5 minutos. Ou seja, a cada 5 minutos tinha-se um valor de velocidade do vento que representava a velocidade média neste intervalo.

As medidas de temperatura e de diferença de temperatura foram feitas a cada 60 segundos e a média registrada a cada 5 minutos.

A partir destes registros de cinco minutos, foram feitas médias de 30 minutos que deram, então origem aos perfis de 30 minutos. 
28.

A partir das diferenças de temperatura e velocidade entre os níveis 1 e 3 , foi calculado o número de Richardson, $\mathrm{Ri}$, através da eq. 89, de acordo com a aproximação proposta por PANOFSKY (1960) para os gradientes.

$$
R i=\frac{g \Delta T\left(z_{1} z_{3}\right)^{0,5} \Delta \ln z}{\bar{T}(\Delta u)^{2}}
$$

A partir dos valores obtidos para o número de Richardson, a atmosfera foi classificada em:

a) neutra, quando $-0,01 \leq R i \leq 0,01$

b)instável, quando $\mathrm{Ri}<-0,01$

c)estável, quando Ri>0,01

Quando a atmosfera foi neutra, o perfil de velocidade foi representado pela eq. (9), que pode ser colocada na seguinte forma:

$$
u=U_{*}[\ln (z-d)]-U_{*} \ln z_{o m}
$$

onde

$$
U_{*}=\frac{u_{*}}{k}
$$

Quando a atmosfera foi instável, a eq. (39) juntamente com a eq. (66), deu origem ä equação 92 para representar o perfil:

$$
u=U \cdot\left[\ln (z-d)-\ln (1+x)^{2}\left(1+x^{2}\right)+2 \operatorname{arctg} x\right]-\left[\ln z_{0 m}-\ln \left(1+x_{0}\right)^{2}\left(1+x_{n}{ }^{2}\right)+2 \operatorname{arctg} x_{0}\right]
$$

onde $x_{e} x_{0}$ foram dados pelas eqs. (72) e (73) respectivamente e $\xi=(z-d) / L$. 
29.

Para se determinar o comprimento adimensional de MoninObukhov, $L$, necessário para a determinação de $\xi$ e posteriormente de $x$ e $x_{0}$, como não se dispunha de medidas de fluxo de calor sensível, utilizou-se, para atmosfera instável, a seguinte expressão empírica que expressa a relação entre $L$ e o número de Richardson considerado médio no intervalo:

$$
L=\frac{\left(z_{1} z_{3}\right)^{0,5}}{R i_{\xi}}
$$

Para condição atmosférica estável, considerou-se que o perfil de velocidade poderia assumir duas formas. Quando $0<\xi \leq 1$, o que equivale a $0<R i \leq 0,166$, a eq. (39) juntamente com a eq. (67) fornece a seguinte equação para o perfil:

$$
u=U_{*}[\ln (z-d)+5 \xi]-U_{+}\left[\ln z_{0_{m}}+5 \frac{z_{0 m}}{L}\right]
$$

onde $\xi=(z-d) / L$ e $L$ foi determinado através de uma relação empírica com $\mathrm{Ri}$, conforme abaixo:

$$
L=\left(z_{1} z_{3}\right)^{0,5}\left(\frac{1}{R i_{\bar{z}}}-5\right)
$$

Para condição atmosférica estável, quando $\xi>1, \quad$ o que equivale a $\mathrm{Ri}>0,166$, a eq. (39) juntamente com a eq. (68) forneceram a seguinte equação para o perfil:

$$
u=U_{*}[6 \ln (z-d)]-U_{*}\left(6 \ln z_{0 m}\right)
$$

Assumindo então que as eqs. (90), (92), (94) e (96) são equações do tipo $y=a x+b$, onde $a=U * x$ é o conteúdo do colchete e b é 
30.

é o segundo termo de cada uma das equações, foi aplicado o Método do Mínimo Desvio Quadrado para estimativa de $d, z_{0 m}$ e u*. O comprimento rugoso $\mathrm{z}_{\mathrm{OH}}$ foi estimado pela eq. (86).

As funções correções para o perfis de velocidade e de temperatura, $\psi_{m}(\xi)$ e $\psi_{H}(\xi)$, para atmosfera estável ou instável foram então determinadas com os valores de $d, z_{0 m}, z_{O H} e u$.

A resistência aerodinâmica, para intervalos de 30 minutos, foi determinada através da eq. (25).

A resistência foi também estimada a partir de valores médios de $d, z_{0 m}$ e $z_{0 H}$ conforme eq. (16) proposta por ALLEN (1986).

Com a resistência aerodinâmica, as medidas da temperatura de bulbo seco no nível 1 e da diferença de temperatura de bulbo seco e de bulbo úmido entre os níveis 1 e 3 e a pressão atmosférica obtida dos dados da estação agrometeorológica, foi possivel através da eq. 97 estimar o fluxo de calor latente a cada meia hora.

$$
\lambda \mathrm{E}=\frac{0,622 \cdot \lambda \cdot \rho \cdot \Delta e_{d}}{P \cdot r a}
$$

onde:

$$
\begin{aligned}
& \lambda=2,501-\left(2,361.10^{-3}\right) \cdot T \\
& \rho=3,486 \cdot \frac{P}{275+T} \\
& \Delta e_{. t}=\Delta T U \cdot(\delta+\gamma)-\gamma \cdot \Delta T S
\end{aligned}
$$

onde: 
31.

$$
\begin{aligned}
& \gamma=0,0016286 \cdot \frac{P}{\lambda} \\
& \delta=\frac{4098 \cdot e_{a}}{(T+237,3)^{2}}
\end{aligned}
$$

onde:

$$
e_{a}=0,6108 \cdot e^{\left(\frac{17.27 \cdot T}{T+237.3}\right)}
$$

Foi feita o somatório do fluxo de calor latente para períodos de 24 horas que juntamente com os valores médios das grandezas envolvidas na eq. 97 permitiram obter a resistencia aerodinâmica efetiva diária conforme eq. 104. abaixo:

$$
r a_{\text {tha } n a}=\frac{0,622 \cdot \bar{\lambda} \cdot \bar{\rho} \cdot \Delta \bar{e}_{d}}{\bar{P} \cdot \sum \lambda \mathrm{E}}
$$


32.

\section{RESULTADOS E DISCUSSÃO}

\subsection{Comportamento geral dos perfis de $1 / 2$ hora}

Foram obtidos 230 conjuntos de dados médios de meia hora, com amostragem de 5 em 5 minutos de temperatura e de velocidade de vento. Os valores medidos de velocidade do vento variaram de $0 \mathrm{~m} / \mathrm{s}$ a $3,215 \mathrm{~m} / \mathrm{s}$ para o nivel 1 ; de $0 \mathrm{~m} / \mathrm{s}$ a $3,702 \mathrm{~m} / \mathrm{s}$ para o nivel 2 e de $0,040 \mathrm{~m} / \mathrm{s}$ a $4,163 \mathrm{~m} / \mathrm{s}$ para o nivel 3 . A temperatura variou para o nível 1 , de $14,05^{\circ} \mathrm{C}$ a $39,65^{\circ} \mathrm{C}$ e para o nível 3 , de $14,24^{\circ} \mathrm{C}$ a $39,17^{\circ} \mathrm{C}$.

A partir destes dados foram calculados os números de Richardson, $R i$, a partir dos quais os perfis foram classificados de acordo com a condição de estabilidade atmosférica. O número de Richardson variou de $-1,103$ a 12,987 com uma média de 0,227 e um desvio padrão de 1,089 . Quando $-0,01 \leq R i \leq 0,01$, a atmosfera foi considerada neutra conforme MONTEITH (1975) que considerou este intervalo como sendo aquele em que o fator de estabilidade variava por menos de $10 \%$ da unidade. Desta maneira, dos 230 perfis obtidos, 86 perfis referem-se à condição de atmosfera instável, 131 referem-se atmosfera estável e 13 perfis atmosfera neutra.

No ciclo de um dia, verificou-se que entre 7:00 e 8:00 horas ocorreu uma transição de condição atmosférica estável para instável e 
entre 15:00 e 17:00 horas de condição atmosférica instável para estável. Os períodos de atmosfera neutra ou próximos de neutra ocorreram principalmente nestes períodos de transição.

Observou-se, portanto, que atmosfera instável ocorreu principalmente no período diurno e atmosfera estável no período noturno. SANTOS \& ANDRÉ (1993), para medidas feitas entre 7:00 e 18:30 horas durante dois dias também observaram atmosfera instável no período diurno com atmosfera neutra por volta das 17:00/18:00 horas. Este mesmo padrão, no comportamento da estabilidade atmosférica, foi observado para a maioria dos dias estudados por PARLANGE \& KATUL (1992b). Tal fato se justifica, visto que durante o dia, com o aquecimento da superfície pelo sol, o processo convectivo é favorecido enquanto à noite a superfície fica mais fria, a convecção é inibida e o fluxo se dá do ar para a superfície. Este comportamento da atmosfera foi bem descrito e explicado por SMITH (1990) e por PEREIRA (1992).

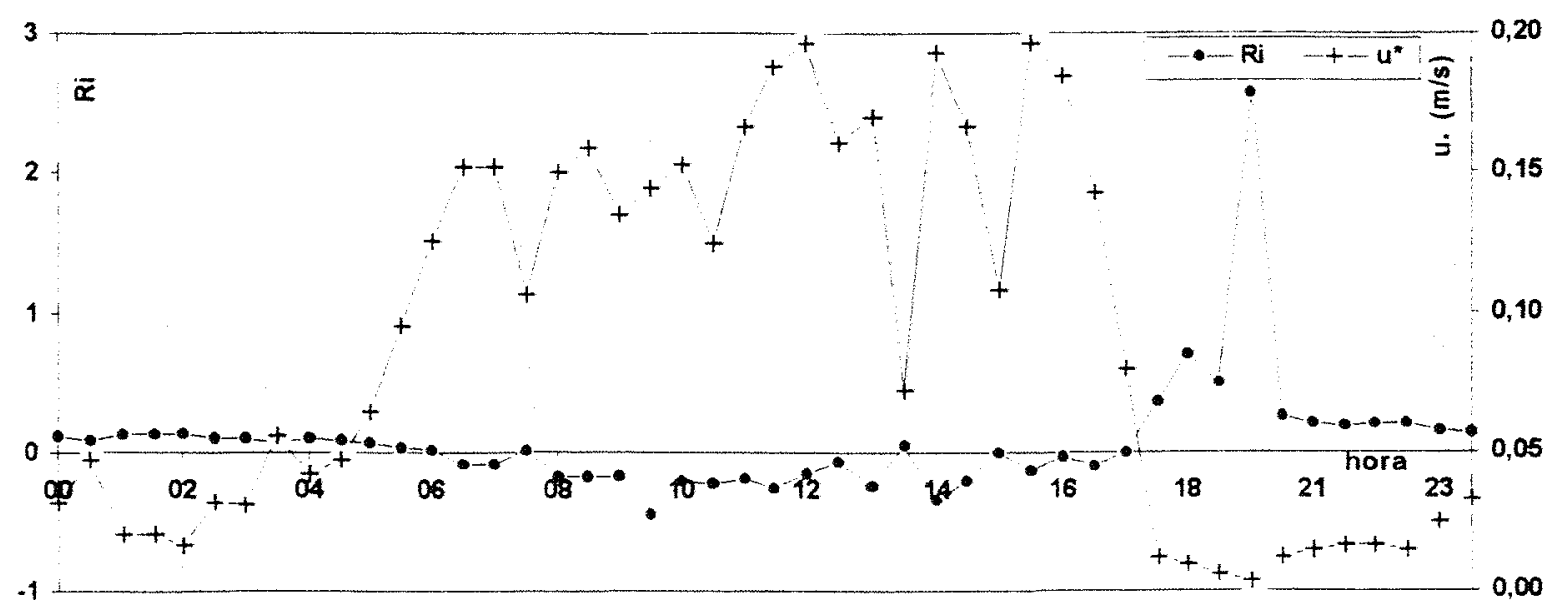

Figura 1 - Número de Richardson e velocidade caracteristica em função do tempo para o dia 03 de setembro. 
A Figura 1 exemplifica e representa o comportamento de $\mathrm{Ri}$ em função do tempo para o período de um dia.

A relação entre o campo de tensões tangenciais e o campo de velocidades médias existe e é simples para o escoamento laminar mas não para o escoamento turbulento. As flutuações aleatórias de velocidade nos escoamentos turbulentos transferem quantidades de movimento através das linhas de corrente do movimento médio que devem ser somadas as tensões causadas pelos gradientes das velocidades médias. A velocidade de fricção resulta da combinação do gradiente da velocidade média com a média da flutuação da velocidade.

A velocidade de fricção é portanto uma função do escoamento que por sua vez depende das características da geometria dos elementos rugosos (altura, espaçamento, arranjo, distribuição foliar), do tipo de fluido, da velocidade e gradiente de velocidade do escoamento, assim como das condições de estabilidade. Quanto maior o módulo do número de Richardson, normalmente, menores são os gradientes de velocidade e menos turbulento é o escoamento, conseqüentemente a velocidade característica é menor pois esta é uma característica da dinâmica do escoamento. Inclusive, de acordo com MONIN \& YAGLOM (1977) $u_{*}$ tende a zero se o regime tende a convecção livre.

Ao longo de um dia, verificou-se que a velocidade característica, assumiu os menores valores à noite, quando a estabilidade aumentou. Este comportamento se repetiu para quase todos os dias e está representado na Figura 1 através da variação temporal da velocidade característica para o dia 03/09. 
Os valores da velocidade característica, para os 230 perfis obtidos, variaram entre o mínimo de $0,0020 \mathrm{~m} / \mathrm{s}$ e o máximo de 0,2663 $\mathrm{m} / \mathrm{s}$ sendo o valor médio de $0,0814 \mathrm{~m} / \mathrm{s}$ com um desvio padrão de 0,0712 $\mathrm{m} / \mathrm{s}$.

Dos 230 perfis, 137 tiveram $u_{*}<0,1 \mathrm{~m} / \mathrm{s}$ e a maioria (109) ocorreu à noite justamente no período em que a atmosfera se encontrava fortemente estável e para 110 perfis as velocidades de vento envolvidas foram menores que $1,0 \mathrm{~m} / \mathrm{s}$ (nível 3). Nestas circunstâncias, a determinação da velocidade característica não possui boa exatidão, devido às baixas velocidades de vento envolvidas, conforme foi observado por DUYNKERKE (1992).

Neste experimento, verificou-se que para uma variação de $u_{*}$ de $0,0020 \mathrm{~m} / \mathrm{s}$ a $0,2663 \mathrm{~m} / \mathrm{s}$, houve uma variação para a razão entre 0 comprimento rugoso para o vapor de água e o comprimento rugoso para o momentum, de 0,000136 a 6,20459. DUYNKERKE (1992) observou uma variação que foi de 10 , para valores pequenos de $u_{*}$, a $1.10^{-6}$ para grandes valores de $u_{*}$. GARRATT et alii (1993) verificou que para esta faixa de variação da razão entre os comprimentos rugosos acima citados há um aumento de 0,05 a $0,2 \mathrm{~m} / \mathrm{s}$ para $u_{*}$. A FAO (1991) sugeriu que esta razão seja da ordem de 0,01 .

Como a estimativa de $\mathrm{z}_{\mathrm{OH}}$ foi realizada através de uma relação empírica de $z_{0 m}$, que por sua vez depende fortemente de $u_{*}$, então a incerteza de $u_{*}$ se transferiu à $z_{0 m}$ e conseqüentemente a $z_{0 H} e$ também ao deslocamento do plano zero, conforme constatou DUYNKERKE (1992). Foi justamente no periodo em que $u_{*}<0,1 \mathrm{~m} / \mathrm{s}$ (137 perfis) que se observou os maiores valores de $z_{0 m}$ e d com 48 perfis se 
linearizando para valores de $d+z_{0 m}>h_{c}$. Dos 93 perfis em que $u_{*}>0,1$ $\mathrm{m} / \mathrm{s}$, todos os perfis se linearizaram para $d+z_{0 m}<h_{c}$.

O comprimento rugoso, $z_{0 m}$, variou de $0 \mathrm{~m}$ a $0,5001 \mathrm{~m}$, com média de $0,0408 \mathrm{~m}$ (e desvio padrão de $0,0726 \mathrm{~m}$ ), portanto bem superior ao valor utilizado por ALLEN (1989) que foi de 0,01476 para uma altura de planta, $h_{C}$, de $12 \mathrm{~cm}$. Utilizando a proposta de Allen para o cálculo de $\mathrm{z} 0 \mathrm{~m}$ e a altura da grama, sobre a qual foram efetuadas as medidas, que foi em média de 0,14 m obteve-se para $z_{0 m}$ o valor de $0,0172 \mathrm{~m}$, ainda assim bem inferior a média obtida através da correlação dos perfis. No período diurno, entre 6:00 e 17:00 horas, não houve valores elevados de $z_{0 m}$. Quanto ao deslocamento do plano zero, d, não foi possivel verificar nenhum padrão na sua variação com o tempo, aparentemente aleatória, entre um mínimo de $0 \mathrm{~m}$ e um máximo de $0,119 \mathrm{~m}$.

SENTELHAS et alii (1992) concluiram que a "influência" de $u_{*}$ é "marcante" no comportamento de de $z_{0 m}$ e através das figuras por eles apresentadas foi possivel observar que $u_{*}$ esteve sempre acima de $0,1 \mathrm{~m} / \mathrm{s}$. Nestas circunstâncias concluiram que existe uma grande interdependência entre d e zom e observaram que para uma variação em $u_{*}$ de 0,10 a $0,42 \mathrm{~m} / \mathrm{s}$ houve uma variação de 1,60 a $1,10 \mathrm{~m}$ no deslocamento do plano zero. O comprimento rugoso $\mathrm{z} 0 \mathrm{~m}$ aumentou com a velocidade característica sendo que para uma variação de 0,10 a 0,54 $\mathrm{m} / \mathrm{s}$ em $u_{*}$, houve uma variação de 0 a $0,40 \mathrm{~m}$ em $\mathrm{z}_{0 \mathrm{~m}}$ aproximadamente.

PEREIRA (1992) apresentou uma relação de interdependência entre $d$ e $z_{0 m}$, onde $z_{0 m}=\lambda(h-d)$ e $0,3<\lambda<0,4$, afirmando que no caso de aumento da velocidade do fluido, o deslocamento do plano zero diminui enquanto $z_{0 m}$ aumenta, ocorrendo assim um 
selamento da vegetação e apresentou um gráfico para o arroz em que $z_{0 m}$ aumentou enquanto d diminuiu com o aumento de $u_{*}$.

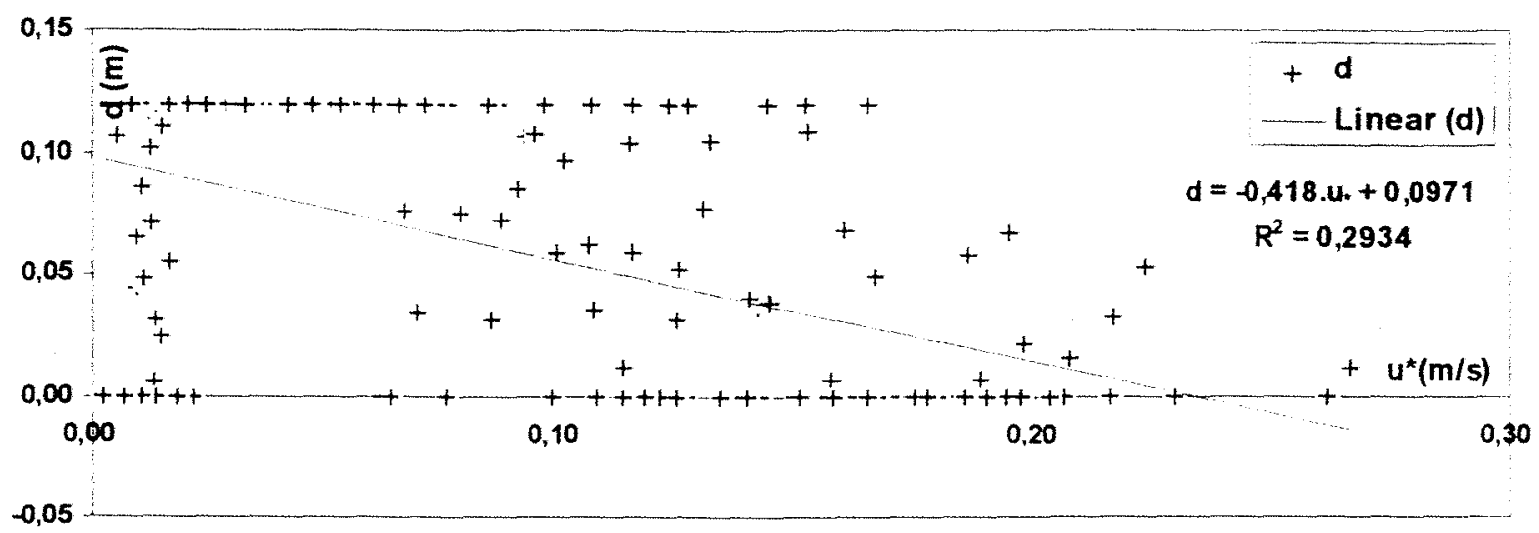

Figura 2 - Deslocamento do plano zero, d, em funcão da velocidade característica, $u^{*}$, para todos os perfis

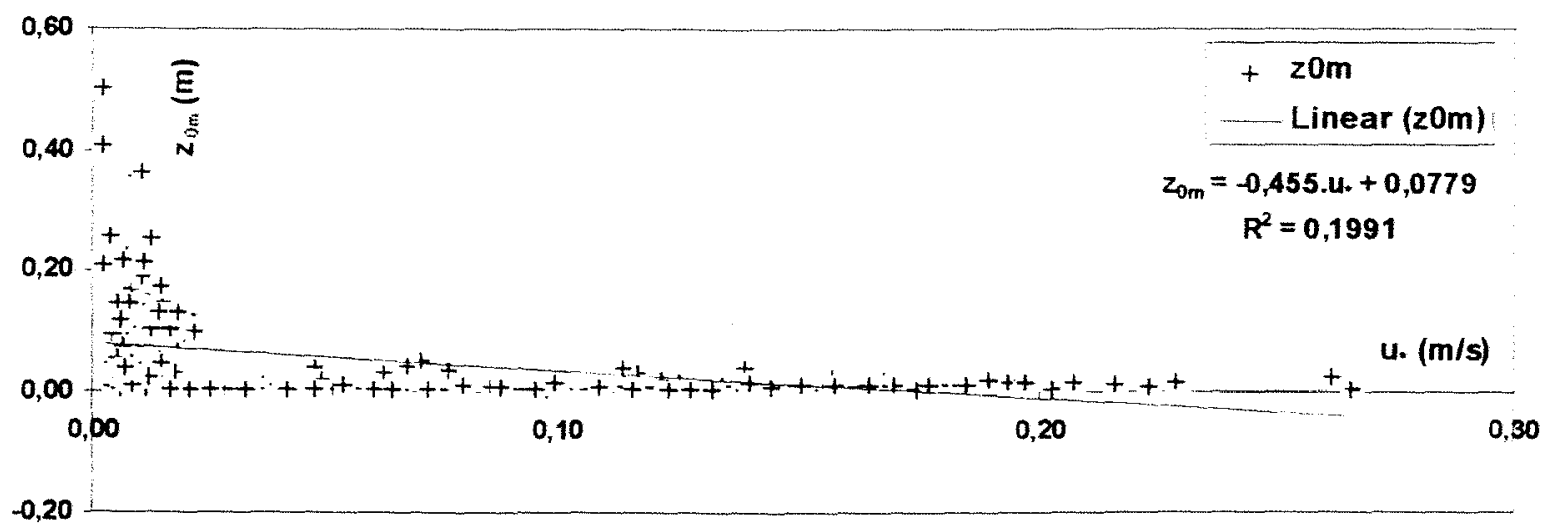

Figura 3 - Comprimento rugoso, $\mathrm{Z}_{0 \mathrm{~m}}$, em função da velocidade característica, $u^{*}$, para todos os perfis.

Ao se fazer a correlação entre $z_{0 m} e(h-d)$, com a reta de regressão passando pela origem, obteve-se $\lambda=0,3766$, com um 
coeficiente de determinação de 0,0768 . Ao se plotar $z_{0 m}$ e d em função da velocidade característica $u^{*}$, verificou-se, que ambos tendem a diminuir com o aumento de $u^{\star}$ (Figuras 2 e 3 ). Provavelmente, um dos fatores que influenciaram no comportamento de $d$ e $z_{0 m}$ foi o valor da velocidade característica.

\subsection{Resistência Aerodinâmica por faixas de Ri}

Tabela 1 - Valores mínimo e máximo, média e desvio padrão da temperatura nos niveis $1\left(\mathrm{TS}_{1}\right)$ e $3\left(\mathrm{TS}_{3}\right)$ e da velocidade nos niveis $1\left(u_{1}\right), 2\left(u_{2}\right)$ e $3\left(u_{3}\right)$ respectivamente para os diferentes intervalos de Ri.

\begin{tabular}{|c|c|c|c|c|c|c|}
\hline & & $\begin{array}{l}\mathrm{TS}_{4} \\
\left({ }^{\circ} \mathrm{C}\right)\end{array}$ & $\begin{array}{l}\mathrm{TS}_{3} \\
\left({ }^{\circ} \mathrm{C}\right)\end{array}$ & $\begin{array}{c}u_{1} \\
(m / s)\end{array}$ & $\begin{array}{c}u_{2} \\
(\mathrm{~m} / \mathrm{s})\end{array}$ & $\begin{array}{c}u_{3} \\
(\mathrm{~m} / \mathrm{s})\end{array}$ \\
\hline \multirow{4}{*}{$\begin{array}{l}\text { Ri }>0,166 \\
79 \text { perfis }\end{array}$} & Mínimo & 14,56 & 14,83 & 0 & 0 & 0,040 \\
\hline & Máximo & 36,49 & 36,74 & 0,754 & 0,919 & 1,078 \\
\hline & Média & 22,11 & 22,66 & 0,249 & 0,374 & 0,470 \\
\hline & Desvio & 4,97 & 5,03 & 0,186 & 0,209 & 0,244 \\
\hline \multirow{4}{*}{$\begin{array}{l}0,01<\mathrm{Ri} \leq 0,166 \\
52 \text { perfis }\end{array}$} & Minimo & 14,05 & 14,24 & 0,265 & 0,391 & 0,465 \\
\hline & Máximo & 37,90 & 38,04 & 3,215 & 3,702 & 4,163 \\
\hline & Média & 20,85 & 21,13 & 0,970 & 1,164 & 1,346 \\
\hline & Desvio & 6,03 & 6,05 & 0,649 & 0,720 & 0,794 \\
\hline \multirow{4}{*}{$\begin{array}{l}-0,01 \leq \mathrm{Ri} \leq 0,01 \\
13 \text { perfis }\end{array}$} & Mínimo & 14,58 & 14,61 & 0,348 & 0,478 & 0,595 \\
\hline & Máximo & 38,48 & 38,48 & 2,624 & 3,003 & 3,330 \\
\hline & Média & 23,14 & 23,15 & 1,260 & 1,476 & 1,665 \\
\hline & Desvio & 7,09 & 7,08 & 0,607 & 0,679 & 0,742 \\
\hline \multirow{4}{*}{$\begin{array}{l}-1 \leq \mathrm{Ri}<-0,01 \\
85 \text { perfis }\end{array}$} & Mínimo & 15,03 & 14,62 & 0,217 & 0,322 & 0,365 \\
\hline & Máximo & 39,65 & 39,17 & 2,098 & 2,492 & 2,817 \\
\hline & Média & 27,69 & 27,07 & 1,310 & 1,520 & 1,696 \\
\hline & Desvio & 6,96 & 6,90 & 0,385 & 0.436 & 0,489 \\
\hline $\begin{array}{l}R \mathrm{R}<-1 \\
1 \text { perfil }\end{array}$ & & 31,31 & 30,82 & 0,551 & 0,638 & 0,672 \\
\hline
\end{tabular}

Qualquer processo de transferência vertical é mais ou menos eficiente dependendo do regime de convecção em vigor. MONTEITH (1975) estabeleceu uma classificação (arbitrária) entre os regimes 
39.

convectivos e faixas de intervalos de número de Richardson. A Tabela 1 mostra os perfis agrupados em faixas de números de Richardson, conforme MONTEITH (1975), com os respectivos valores mínimo e máximo, média e os desvio padrão das temperaturas $T_{1}$ e $T_{3}$ e das velocidades $u_{1}, u_{2}$ e $u_{3}$. Os 230 perfis ficaram assim distribuídos: $79 \mathrm{com}$ $R i>0,166,52 \mathrm{com} 0,01<R i \leq 0,166,13 \mathrm{com}-0,01 \leq \mathrm{Ri} \leq 0,01,85 \mathrm{com}-1 \leq \mathrm{Ri}<-$ 0,01 e 1 com $R i<-1$.

\subsubsection{Perfis de $1 / 2$ hora para $R i>0,166$}

Conforme Tabela 1, pode ser observado que $34 \%$ dos perfis ficaram na faixa de $\mathrm{Ri}>0,166$, situação em que a condição atmosférica é de alta estabilidade. Estes dados ocorreram principalmente entre 16:00 e 6:00 horas (período noturno) sendo que as mais fortes inversões (números de Richardson maiores) ocorreram principalmente durante a madrugada.

Nestes períodos, o escoamento caracterizou-se pela inibição do movimento convectivo. Com condições de estratificação muito estáveis, o movimento do meio toma um caráter muito especial, inibindo a turbulência.

Se a convecção livre ou forçada é impedida, a altura da camada onde as forças dinâmicas são importantes deve tender a zero e conseqüentemente 0 comprimento de Monin-Obukhov também. Provavelmente por isso a literatura consultada näo estabelece nenhuma relação entre $\mathrm{Ri}$ e $\mathrm{L}$ para esta faixa de escoamento o que tornou impossivel avaliar o comprimento de Monin-Obukhov, L. 
40.

A Tabela 2 contém os valores mínimo e máximo, média e

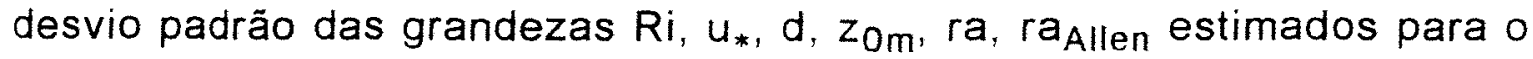
intervalo de $\mathrm{Ri}>0,166$.

Tabela 2 - Valores mínimo e máximo, média e desvio padrão das grandezas $\mathrm{Ri}, u_{*}, d, z_{0 m}$, ra, ra $A$ llen estimados para o intervalo de $\mathrm{Ri}>0,166$.

\begin{tabular}{|l|r|r|r|r|}
\cline { 2 - 5 } \multicolumn{1}{c|}{} & \multicolumn{4}{c|}{ Ri>0,166 (79 perfis) } \\
\cline { 2 - 5 } \multicolumn{1}{c|}{} & Minimo & Máximo & \multicolumn{1}{c|}{ Média } & \multicolumn{1}{c|}{ Desvio } \\
\hline $\mathrm{Ri}$ & 0,1669 & 12,9076 & 0,7957 & 1,6939 \\
\hline $\mathrm{u}_{*}(\mathrm{~m} / \mathrm{s})$ & 0,0020 & 0,0219 & 0,0103 & 0,0043 \\
\hline $\mathrm{d}(\mathrm{m})$ & 0 & 0,119 & 0,075 & 0,054 \\
\hline $\mathrm{z}_{\mathrm{m}}(\mathrm{m})$ & 0,002 & 0,500 & 0,104 & 0,096 \\
\hline $\mathrm{ra}(\mathrm{s} / \mathrm{m})$ & 2503 & 21513 & 6638 & 3595 \\
\hline ra & 173 & 4665 & 650 & 788 \\
\hline
\end{tabular}

Verificou-se neste experimento que os valores estimados de $u_{*}$ foram menores do que $0,1 \mathrm{~m} / \mathrm{s}$ em $100 \%$ dos perfis em que $\mathrm{Ri}>0,166$ conforme pode ser visto na Tabela 2, justamente quando as velocidades de vento envolvidas foram baixas (ver médias das velocidades nos três niveis na Tabela 1).

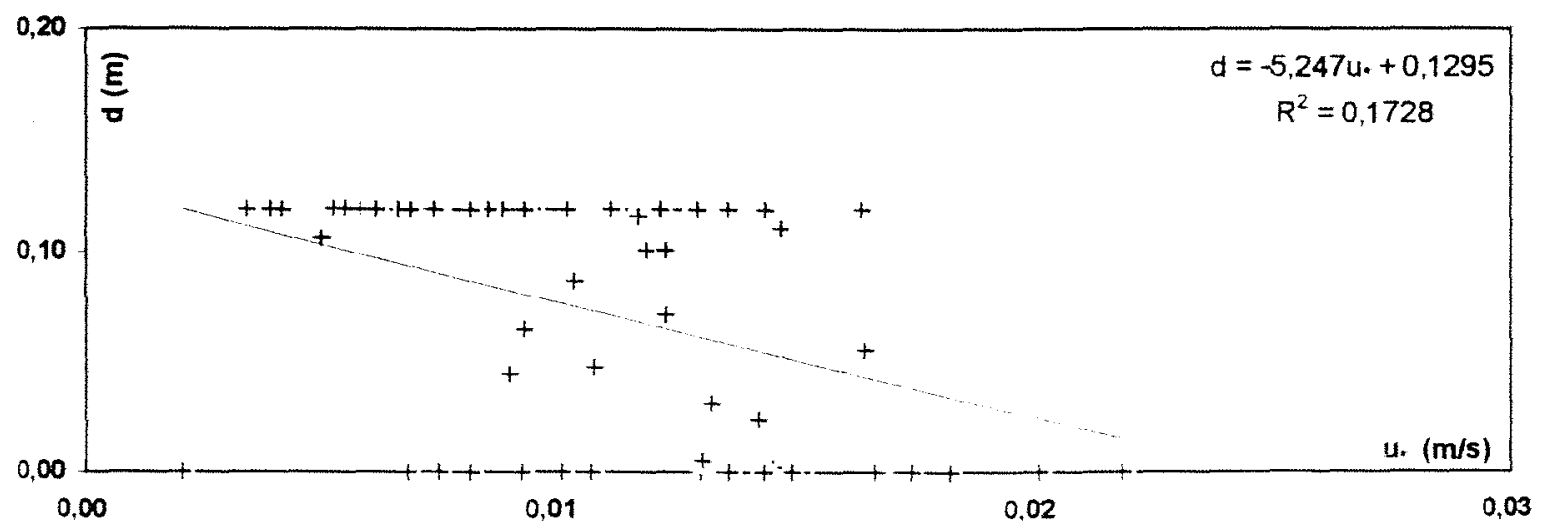

Figura 4 - Deslocamento do plano zero, d, em função da velocidade caracteristica, $u_{*}$, para $\mathrm{Ri}>0,166$. 
Os valores de $d$ e $z_{0 m}$, apresentaram um comportamento aleatório com grande dispersão dos dados. Pode ser visto nas Figuras 4 e 5, que apesar da dispersão, o deslocamento do plano zero, d, e, o comprimento rugoso, $z_{0 m}$, tendem a diminuir com a velocidade característica, $u_{*}$. A reprodução dos perfis de velocidade através dos dados obtidos foi boa, com um coeficiente de determinação médio $\left(r^{2}\right)$ de 0,9922 e com um desvio padrão de 0,0307 .

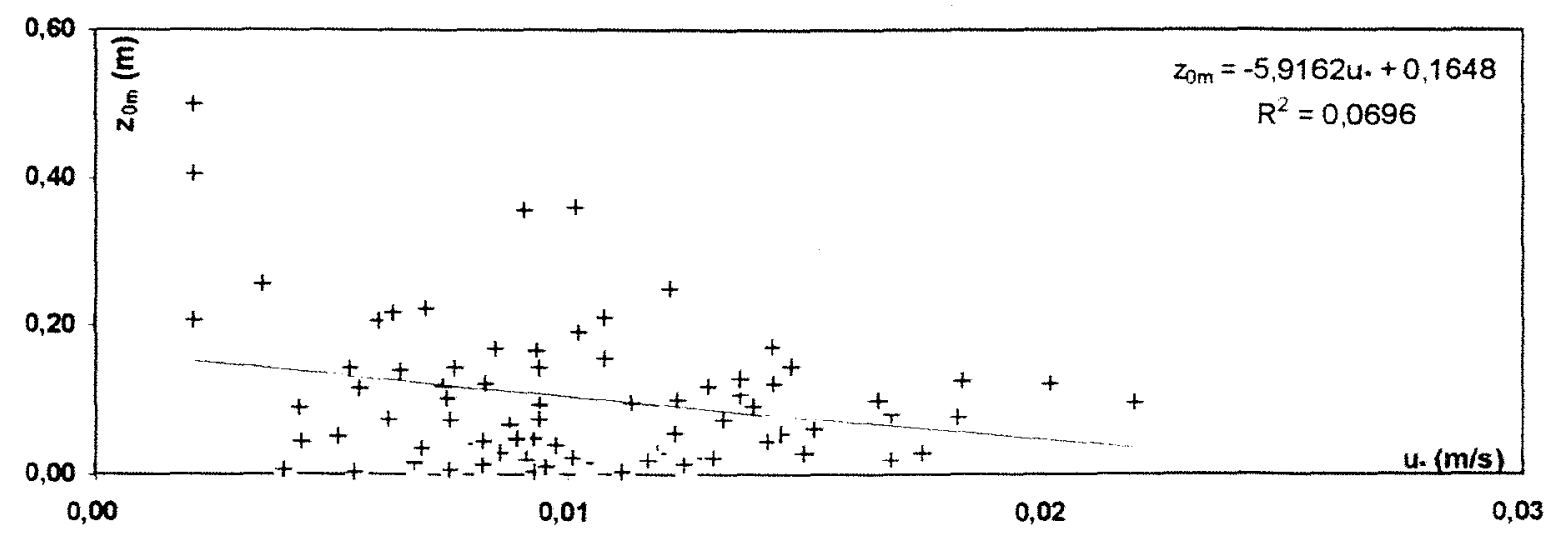

Figura 5 - Comprimento rugoso, $z_{0 m}$, em função da velocidade característica, $u_{*}$, para $\mathrm{Ri}>0,166$.

Apesar da evolução de ra e raAllen no tempo serem semelhantes (Figura 6), quando se plotou ra contra raAllen, verificou-se que o coeficiente de determinação foi muito baixo conforme pode ser visto na Figura 7. 


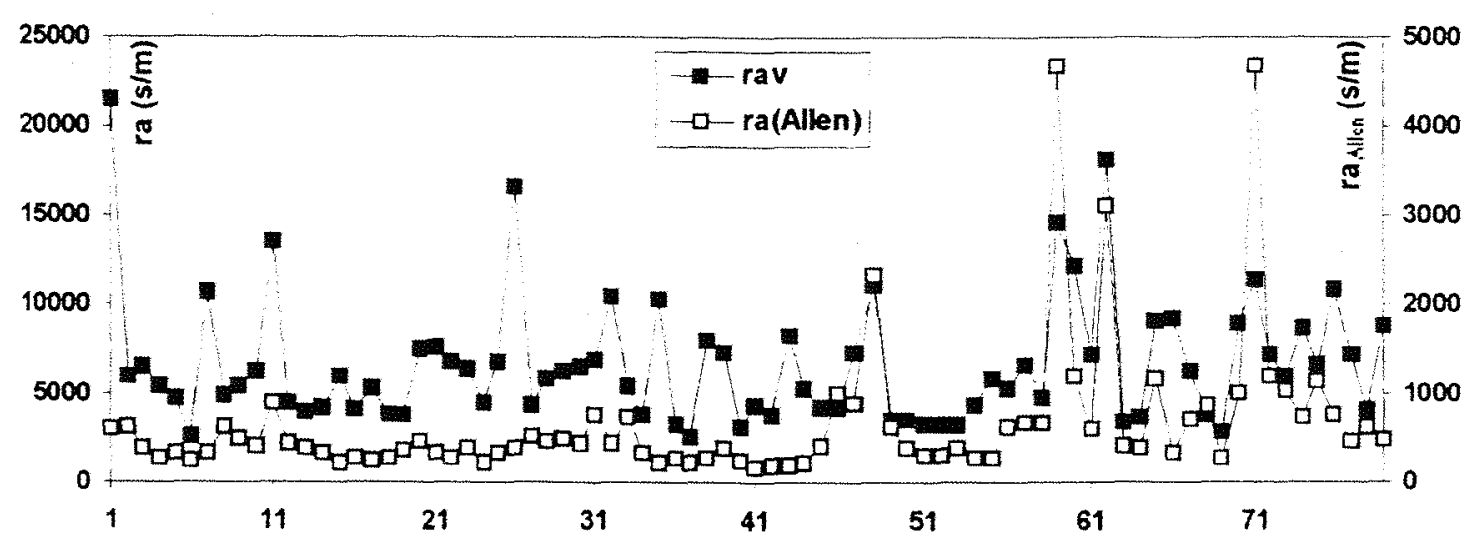

Figura 6 - Variação da resistência aerodinâmica (ra e raAllen), ao longo do período de medidas, para $\mathrm{Ri}>0,166$.

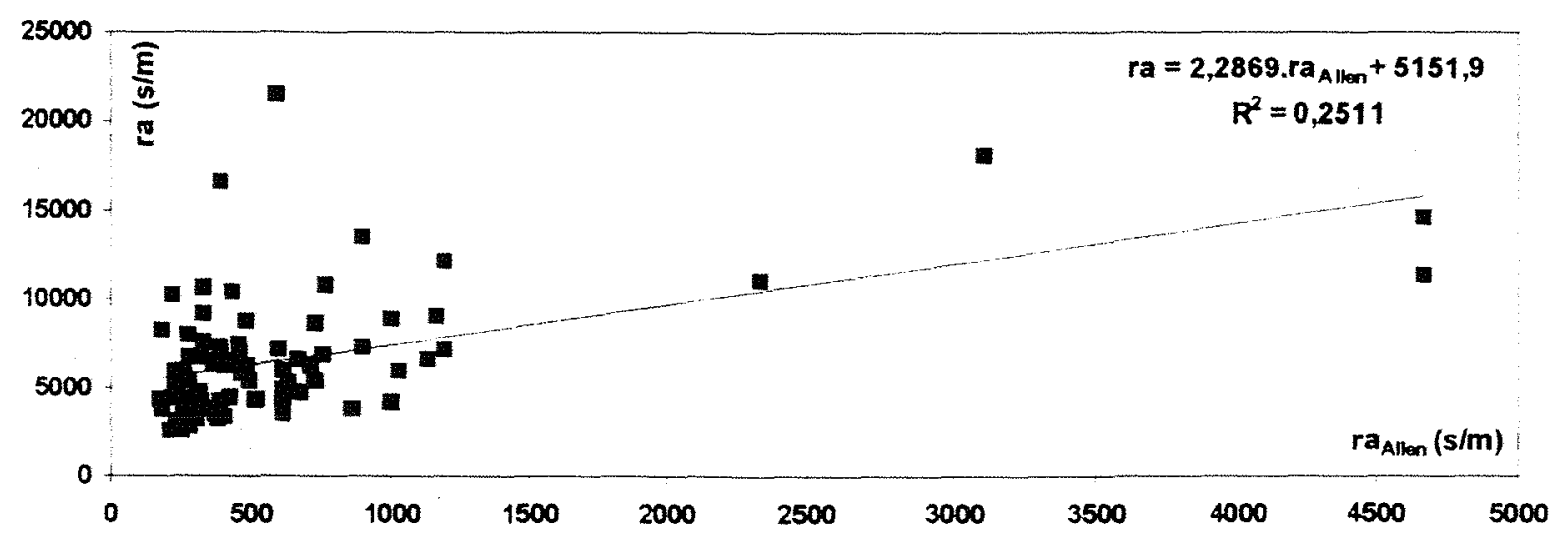

Figura 7 - Resistência aerodinâmica obtida a partir dos parâmetros estimados, em função da resistência aerodinâmica obtida conforme proposto por ALLEN (1986), para Ri>0,166.

A resistência a qualquer fluxo, neste intervalo de $\mathrm{Ri}$ deve ser alta pois conforme MONTEITH (1975), a convecção é totalmente inibida. Os valores obtidos para a resistência aerodinâmica ao vapor de água, ra, calculada respectivamente a partir dos parâmetros estimados e 
43.

raAllen pela equação proposta por ALLEN (1986) foram os mais altos e apresentaram uma grande dispersão em torno da média $(6637 \pm 3595$ e $650 \pm 788 \mathrm{~s} / \mathrm{m}$ respectivamente). Comparativamente, no entanto, os

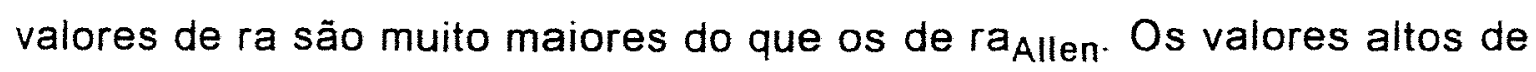
resistência dificultaram a transferência vertical de vapor de água. Desse modo, quando o gradiente de vapor foi negativo, a evapotranspiração se deu a uma taxa mais reduzida, enquanto quando o gradiente foi positivo, houve deposição de orvalho, que na maioria dos casos sequer foi observado ao amanhecer.

No intervalo em que $\mathrm{Ri}>0,166$, o perfil de vento deve sofrer uma correção e a resistência aerodinâmica também. Como a proposta de ALLEN (1989) não leva em consideração a correção, então é natural que nesta faixa a discrepância entre os valores da resistência aerodinâmica obtida a partir dos parâmetros estimados e a resistência obtida a partir de valores médios seja grande e com coeficiente de determinação entre elas muito baixo conforme pode ser visto nas Figuras 6 e 7 . Vale a pena salientar que estes valores, apesar de serem muitos (34\% do total), concentraram-se no periodo noturno, quando a evapotranspiração é extremamente reduzida. As transferências verticais de vapor d'água podem se dar do campo cultivado para a atmosfera ou vice-versa em função do gradiente de umidade. Nos dois casos os fluxos resultantes correspondem à evaporação e à condensação, respectivamente. As duas mudanças de estado dependem da disponibilidade de energia proveniente sobretudo do balanço de radiação cujo resultado efetivo acaba provocando uma retirada ou deposição de água relativamente pequena quando comparado com a evapotranspiração diurna. Além disso o fechamento dos estômatos no período noturno praticamente impede a 
transpiração. Desse modo mesmo que haja baixa correlação, ela tem pouca importância, já que o total envolvido neste período, é muito pequeno comparado ao resto do dia.

\subsubsection{Perfis de $1 / 2$ hora para $0,01<R i \leq 0,166$}

Quando $0,01<\mathrm{Ri} \leq 0,166$, o escoamento caracteriza-se como uma transição entre o regime turbulento com convecção exclusivamente forçada $(-0,01 \leq \mathrm{Ri} \leq 0,01)$ para o regime não turbulento (Ri>0,166). Nesta faixa foram obtidos 52 perfis, $23 \%$ do total, com maior concentração entre 16:00 e 6:00 horas portanto também período noturno.

Verificou-se que o comprimento de Monin-Obukhov variou de 1,22 a $61 \mathrm{~m}$, com um desvio padrão de $15,67 \mathrm{~m}$ em torno de uma média de 12,14 m (Tabela 3). O aumento de $\mathrm{L}$ indicou o aumento da espessura da camada onde a influência das forças dinâmicas é mais importante quando comparada à influência térmica.

Para este intervalo a velocidade de friç̧ão $u_{*}$ estimada, também assumiu valores muito pequenos sendo menores que $0,1 \mathrm{~m} / \mathrm{s}$ para $50 \%$ dos perfis desta faixa.

Em relação ao intervalo anterior (Tabela 2), verificou-se (Tabela 3) que a dispersão tanto para $z_{0 m}$ como para o deslocamento do plano zero, $d$, foi menor. A média do deslocamento do plano zero, 0,093, e do comprimento rugoso, 0,004 , foram respectivamente superior e inferior à média do intervalo anterior. 
45.

Tabela 3 - Valores mínimo e máximo, média e desvio padrão das grandezas $R i, L, u_{*}, d, z_{0 m}$, ra, raAllen estimados para o intervalo em que $0,01<\mathrm{Ri} \leq 0,166$.

\begin{tabular}{|c|c|c|c|c|}
\hline & \multicolumn{4}{|c|}{$0,01<R i \leq 0,166 \quad(52$ perfis $)$} \\
\hline & Mínimo & Máximo & Média & Desvio \\
\hline $\mathrm{Ri}$ & 0,0120 & 0,1520 & 0,0829 & 0,0438 \\
\hline$L$ & 1,22 & 61,05 & 12.14 & 15,67 \\
\hline$u_{*}(\mathrm{~m} / \mathrm{s})$ & 0,0153 & 0,2663 & 0,0695 & 0,0583 \\
\hline $\mathrm{d}(\mathrm{m})$ & 0 & 0,119 & 0,093 & 0,047 \\
\hline$z_{a m}(m)$ & 0 & 0,036 & 0,004 & 0,007 \\
\hline $\mathrm{ra}(\mathrm{s} / \mathrm{m})$ & 100 & 3380 & 707 & 601 \\
\hline$r a_{\text {Allen }}(\mathrm{s} / \mathrm{m})$ & 45 & 401 & 182 & 89 \\
\hline
\end{tabular}

Os valores da resistência aerodinâmica obtidos a partir dos parâmetros estimados apresentaram também uma grande dispersão em torno do valor médio $(707 \mathrm{~s} / \mathrm{m} \pm 601 \mathrm{~s} / \mathrm{m})$ enquanto a resistência aerodinâmica obtida pelo método proposto por ALLEN (1986) apresentou uma dispersão menor, mas ainda assim alta (182 s/m $\pm 89 \mathrm{~s} / \mathrm{m})$, conforme Tabela 3 .

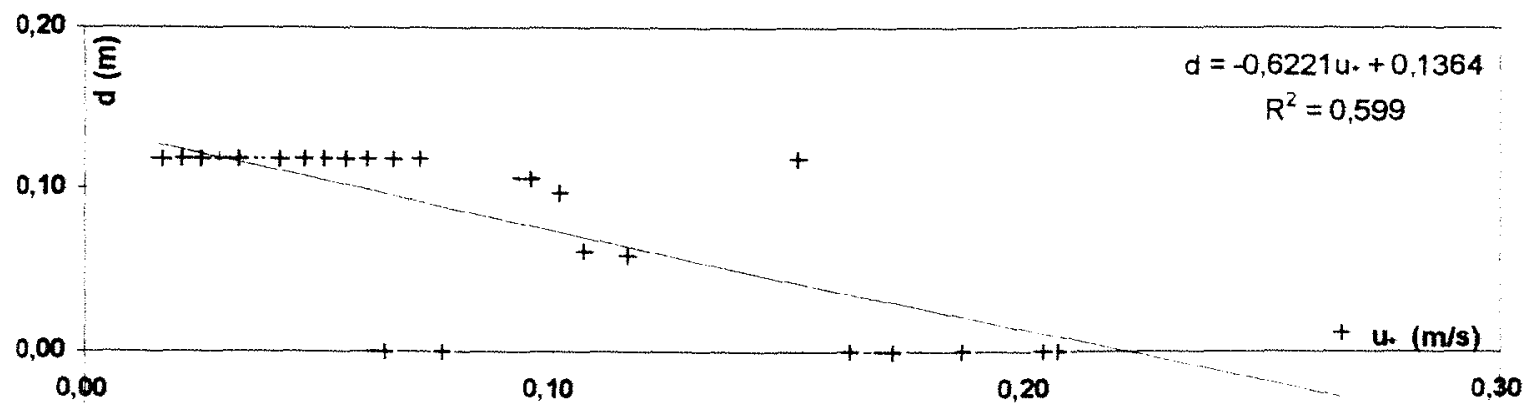

$-0,10$

Figura 8 - Deslocamento do plano zero, d, em função da velocidade característica. $u_{*}$, para $0,01<R i \leq 0,166$ 
46.

O deslocamento do plano zero, d, diminuiu com $u_{*}$, enquanto $z_{0 m}$ aumentou muito lentamente (Figuras 8 e 9 ).

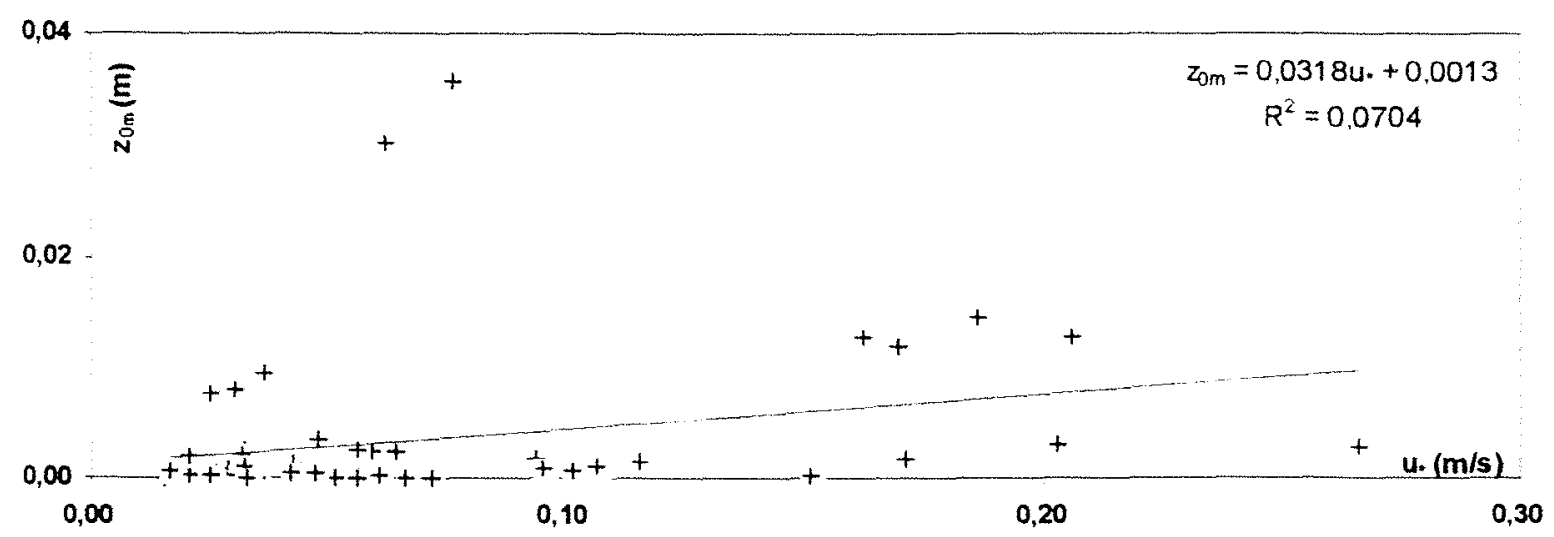

Figura 9 - Comprimento rugoso, $z_{0 m}$, em função da velocidade característica, $u_{*}$, para $0,01<\mathrm{Ri} \leq 0,166$.

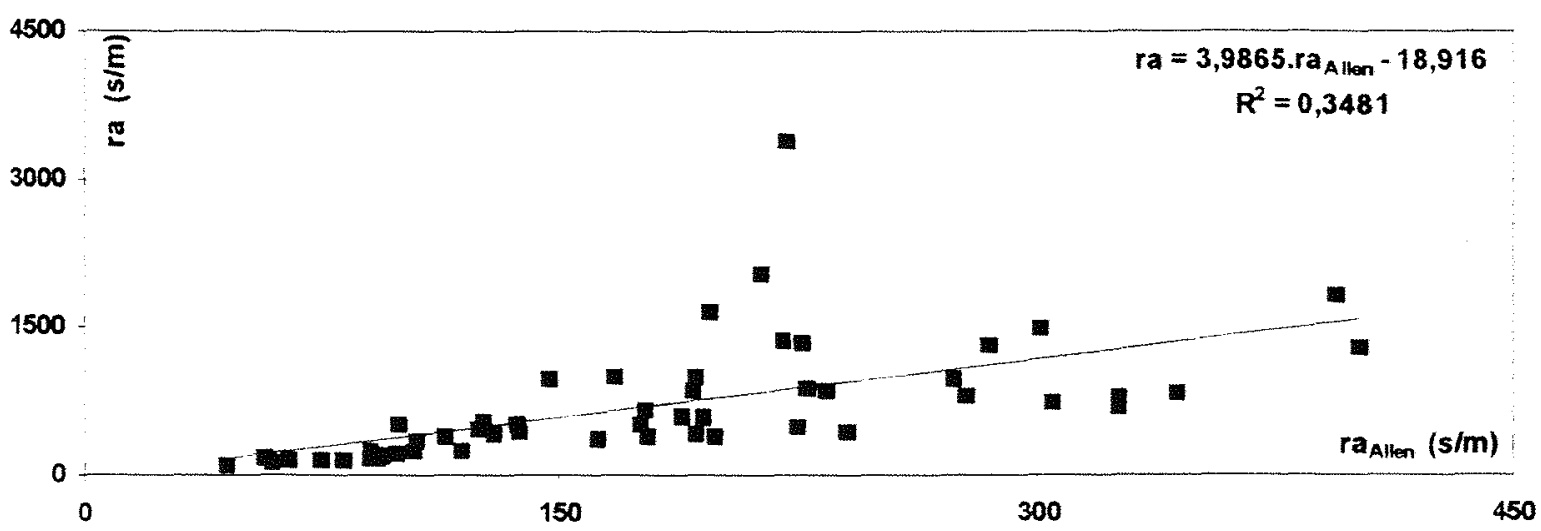

Figura 10 - Resistência aerodinâmica obtida a partir dos parâmetros estimados, em função da resistência obtida conforme proposto por ALLEN (1986), para $0,01<\mathrm{Ri} \leq 0,166$ 
Quando se plotou ra contra raAllen verificou-se que o coeficiente de determinação foi de 0,3481 (Figura 10), portanto melhor que no intervalo anterior que foi de 0,2511 (Figura7).

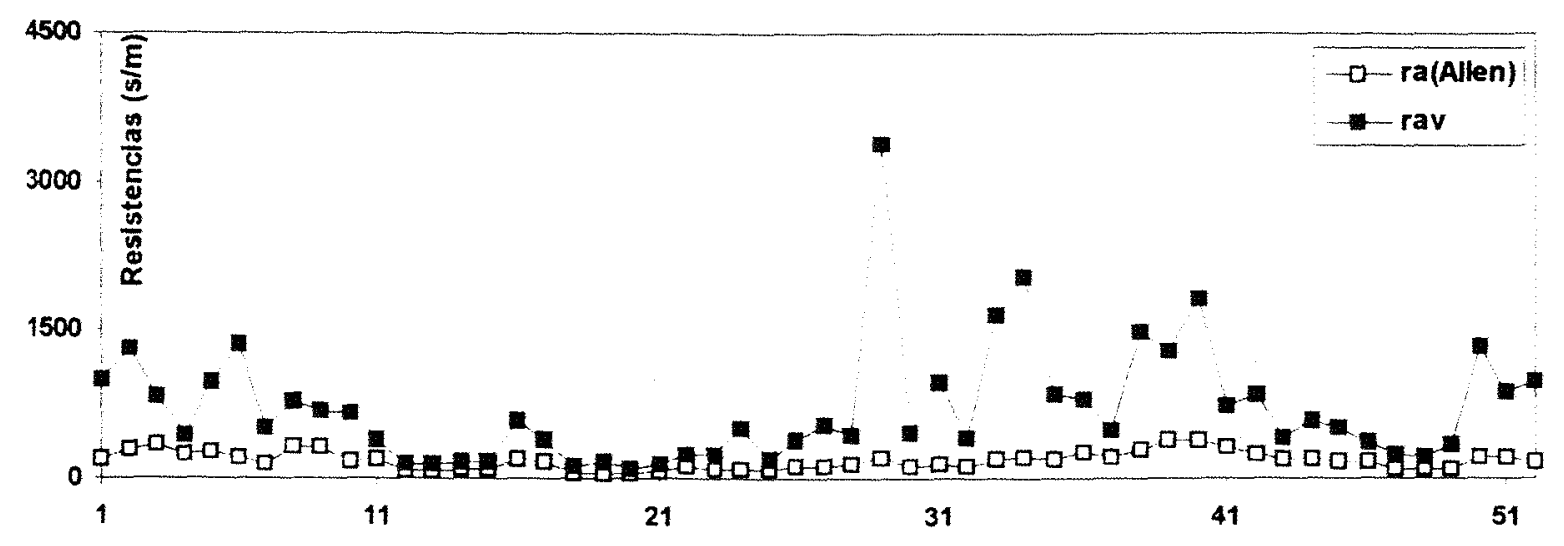

Figura 11 - Variaçăo da resistência aerodinâmica (ra e raAllen), ao longo do período de medidas, para $0,01<\mathrm{R} i \leq 0,166$.

Pela observação da Figura 11, em alguns trechos parece existir alguma relação entre as resistências e em outros não. Isto aconteceu próximo ao limite inferior de Ri neste intervalo. Conforme pode ser visto na Figura 12, as resistências se afastam à medida que Ri aumenta. 
48.

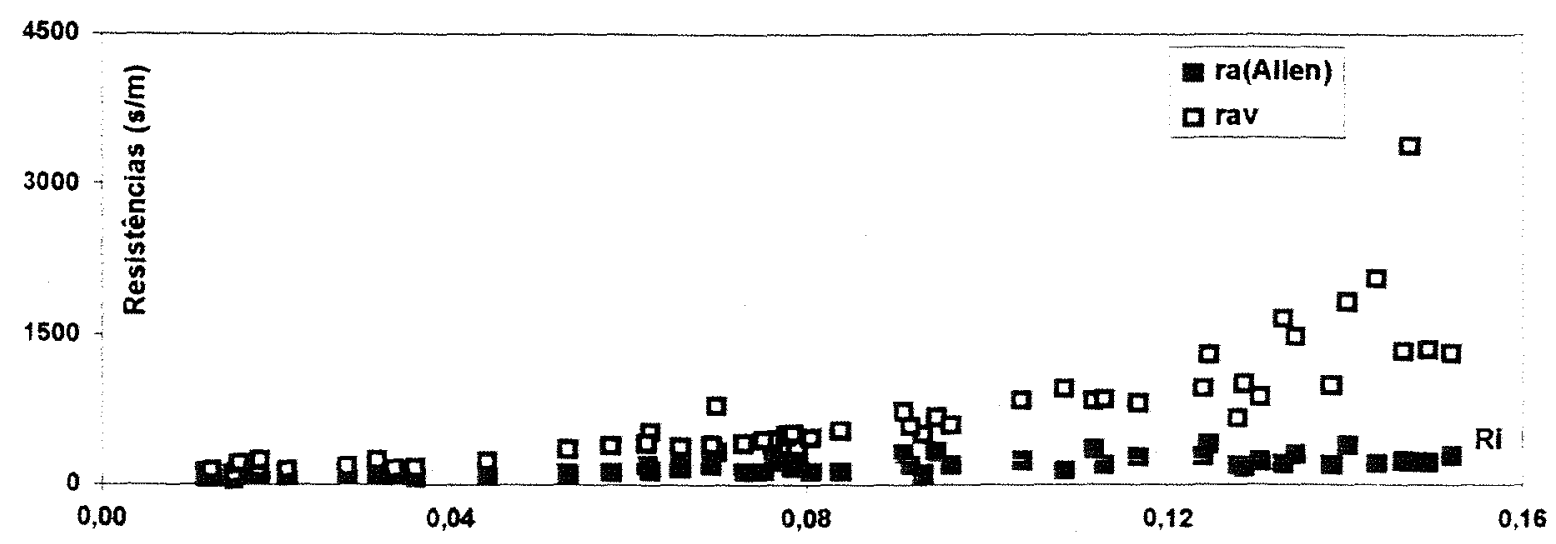

Figura 12 - Variação da resistência aerodinâmica (ra e ra Allen $_{\text {) em função }}$ do número de Richardson, para $0,01<\mathrm{Ri} \leq 0,166$

Quando se dividem os perfis em intervalos, é preciso observar que os valores podem estar concentrados em uma extremidade do intervalo podendo não representar o intervalo mas se identificar mais com o intervalo do qual são limites. Assim sendo, de acordo com Fichtl (1968), citado por MONIN \& YAGLOM (1977), os perfis classificados dentro da faixa de $0,01<R i \leq 0,166$ foram divididos em dois outros subintervalos: $0,01<R i \leq 0,1$ e $0,1<R i \leq 0,166$, conforme Tabela 4 .

Quanto menor, em módulo, o número de Richardson do intervalo, maiores as médias de velocidade característica, do comprimento adimensional de Monin Obukhov, $L$, e do comprimento rugoso, $z_{0 m}$, e menores as médias do deslocamento do plano zero.

Verificou-se que para ambos subintervalos o deslocamento do plano zero diminuiu com $u_{*}$ e o comprimento rugoso $z_{0 m}$ cresceu com $u_{*}$ e que $d$ e $z_{0 m}$ foram interdependentes ou seja enquanto um cresceu, o outro diminuiu mantendo o mesmo comportamento do intervalo todo. 
Tabela 4 -Valores mínimos e máximos, média e desvio padrão das grandezas $R i, L, u_{*}, d, z_{0 m}$, ra e raAllen estimados para os subintervalos intervalos $0,01<R i \leq 0,1$ e $0,1<R i \leq 0,166$.

\begin{tabular}{|c|c|c|c|c|c|}
\hline \multirow{8}{*}{$\begin{array}{l}0,01<\mathrm{Ri} \leq 0,1 \\
34 \text { perfis }\end{array}$} & & Mínimo & Máximo & Média & Desvio \\
\hline & $\mathrm{Ri}$ & 0,0119 & 0,1038 & 0,0570 & 0,0296 \\
\hline & $\mathrm{L}$ & 3,59 & 61,05 & 17,47 & 17,17 \\
\hline & $u_{*}(\mathrm{~m} / \mathrm{s})$ & 0,0287 & 0,2663 & 0,0919 & 0,0611 \\
\hline & $d(m)$ & 0 & 0,119 & 0,080 & 0,053 \\
\hline & $z_{n m}(m)$ & 0 & 0,036 & 0,005 & 0,008 \\
\hline & $\mathrm{ra}(\mathrm{s} / \mathrm{m})$ & 100 & 843 & 386 & 202 \\
\hline & $\mathrm{ra}_{\text {Allen }}(\mathrm{s} / \mathrm{m})$ & 45 & 326 & 147 & 76 \\
\hline \multirow{7}{*}{$\begin{array}{l}0,1<\mathrm{Ri} \leq 0,166 \\
18 \text { perfis }\end{array}$} & $\mathrm{Ri}$ & 0,109 & 0,152 & 0,132 & 0,013 \\
\hline & L & 1,22 & 3,27 & 2,07 & 0,63 \\
\hline & $u_{*}(\mathrm{~m} / \mathrm{s})$ & 0,015 & 0,042 & 0,027 & 0,007 \\
\hline & $d(m)$ & 0,119 & 0,119 & 0,119 & 0 \\
\hline & $\mathrm{z}_{\mathrm{Om}}(\mathrm{m})$ & 0 & 0,008 & 0,001 & 0,002 \\
\hline & $\mathrm{ra}(\mathrm{s} / \mathrm{m})$ & 665 & 3380 & 1313 & 640 \\
\hline & $r a_{\text {Allan }}(\mathrm{s} / \mathrm{m})$ & 147 & 401 & 248 & 74 \\
\hline
\end{tabular}

Quando se compararam as resistências verificou-se que a diferença entre as médias foi grande (386 e 147 para $0,01<R i \leq 0,1$ e 1313 e 248 respectivamente para $0,1<\mathrm{Ri} \leq 0,166)$ e o desvio em torno delas também foi grande (Tabela 4).

Pode ser observado nas Figuras 13 e 14 que a correlação entre as resistências foi acentuadamente melhor para $0,01<R i \leq 0,1$. 0 resultado é lógico visto que quanto mais estável é a atmosfera mais o perfil se distancia do tipo log-linear com conseqüentes discrepâncias nos resultados, justificando assim a divisão do intervalo. 
50.

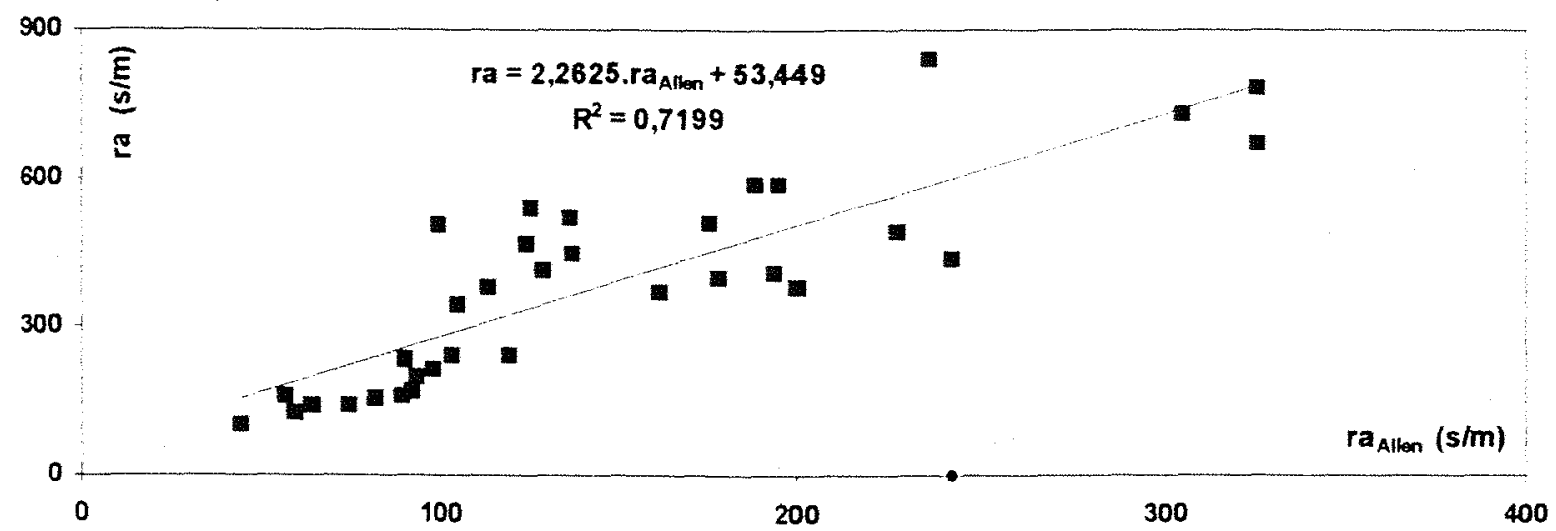

Figura 13 - Resistência aerodinâmica obtida a partir dos parâmetros estimados, em função da resistência aerodinâmica obtida

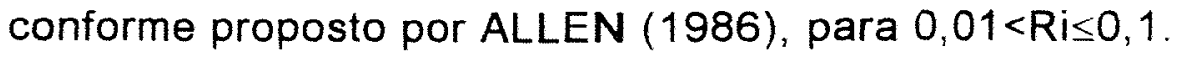

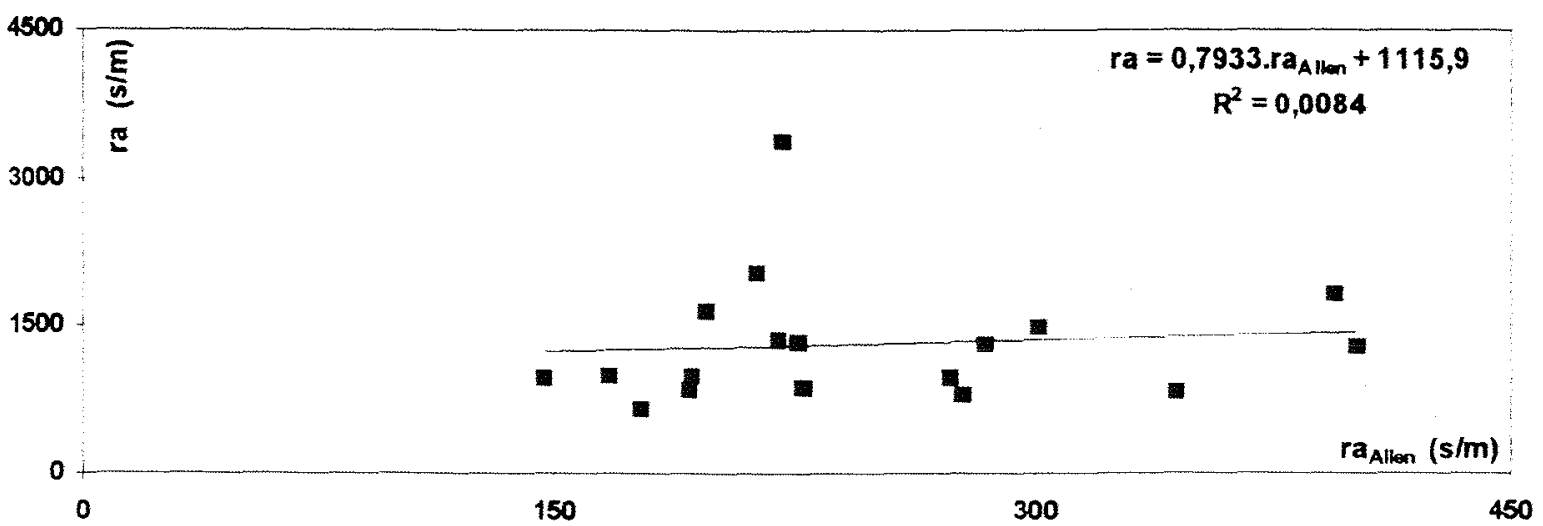

Figura 14 - Resistência aerodinâmica obtida a partir dos parâmetros estimados, em função da resistência aerodinâmica obtida conforme proposto por ALLEN (1986), para 0,1<Ri $\leq 0,166$. 
51.

\subsubsection{Perfis de $1 / 2$ hora para $-0,01 \leq R i \leq 0,01$}

Quando o número de Richardson esteve compreendido entre 0,01 e -0,01, a atmosfera foi considerada neutra. Dos 230 perfis, somente $13,5,6 \%$ do total puderam ser classificados como próximos de neutro. Portanto, a condição de atmosfera neutra foi rara e ocorreu normalmente próximo do nascer e do por do sol, quando a atmosfera encontrava-se na transição da condição estável para instável e viceversa, conforme também observado por PARLANGE \& KATUL (1992b).

Muitos autores, entre eles DEHEER-AMISSAH et alii (1981), sugerem que o comprimento rugoso, $z_{0 m}$, e o deslocamento do plano zero, d, sejam estimados em condições neutra ou próxima de neutra, pois nesta situação, o comprimento de Monin-Obukhov, L, se aproxima do infinito e então os fatores térmicos podem ser ignorados na camada mais próxima da superfície. Isto porque o parâmetro $\mathrm{z}_{0 \mathrm{~m}}$ depende tanto das irregularidades da superfície como da interação entre a superfície e o escoamento turbulento, sendo inclusive por este motivo denominado rugosidade dinâmica da superfície. Uma outra vantagem em determinar o comprimento rugoso $\mathrm{z}_{0 \mathrm{~m}}$, e o deslocamento do plano zero, d, em condições atmosféricas próxima de neutra, é que sendo esses fatores função somente do tipo das características da superfície e do escoamento turbulento, se estimados em outras condições, além da influência dos fatores térmicos como tal, poderiam ser influenciados pelo empirismo dos termos de correção para os perfis logarítmicos. 
Tabela 5 - Valores mínimo e máximo, média e desvio padrão das grandezas $\mathrm{Ri}, \mathrm{L}, \mathrm{u}_{*}, \mathrm{~d}, \mathrm{z}_{0 \mathrm{~m}}$, ra ra rllen estimados para 0 intervalo em que $-0,01 \leq R i \leq 0,01$.

\begin{tabular}{|l|r|r|r|r|}
\cline { 2 - 5 } \multicolumn{1}{c|}{} & \multicolumn{4}{c|}{$-0,01 \leq$ Ri $\leq 0,01$ (13 perfis) } \\
\cline { 2 - 5 } \multicolumn{1}{c|}{} & Mínimo & \multicolumn{1}{c|}{ Máximo } & \multicolumn{1}{c|}{ Média } & \multicolumn{1}{c|}{ Desvio } \\
\hline $\mathrm{Ri}_{\mathrm{u}}(\mathrm{m} / \mathrm{s})$ & $-0,0096$ & 0,0090 & $-0,0018$ & 0,0059 \\
\hline $\mathrm{d}(\mathrm{m})$ & 0,0534 & 0,1941 & 0,1147 & 0,0417 \\
\hline $\mathrm{Zam}_{\mathrm{m}}(\mathrm{m})$ & 0 & 0,119 & 0,055 & 0,042 \\
\hline $\mathrm{ra}(\mathrm{s} / \mathrm{m})$ & 0,001 & 0,049 & 0,009 & 0,013 \\
\hline $\mathrm{ra}$ & 125 & 407 & 234 & 86 \\
\hline
\end{tabular}

O valor médio obtido de d foi de $0,055 \mathrm{~m}$ e o de $z_{0 \mathrm{~m}}$ foi de $0,009 \mathrm{~m}$ conforme pode ser visto na Tabela 5. Conforme ALLEN (1986) para uma altura de planta $h_{C}$ igual a $0,014 \mathrm{~m}$, o deslocamento do plano zero é de $0,0933 \mathrm{~m}$ (aproximadamente $50 \%$ maior que o valor aqui apresentado) e o comprimento rugoso para o momentum é de $0,0172 \mathrm{~m}$ (cerca de aproximadamente $100 \%$ maior que o valor aqui apresentado).

Neste intervalo, as correções, $\psi_{\mathrm{m}}$ e $\psi_{\mathrm{h}}$, em valor absoluto, são muito pequenas visto que os números de Ri estão muito próximos de zero (próximo neutro), além do que se alternam no sentido de aumentar ou diminuir a resistência dependendo de Ri ser positivo ou negativo. Isto deveria conduzir a valores de resistência, pelo menos na média, iguais ou muito mais próximas dos valores obtidos conforme proposto por ALLEN (1986). Isto sugere que os parâmetros estimados, $d$ e $z_{0 m}$, muito menores que os propostos por ALLEN (1986), sejam os maiores responsáveis pela diferença entre as resistências.

As Figuras 15 e 16 mostram o comportamento de d e $\mathrm{z}_{\mathrm{Om}}$ com $u_{*}$. A velocidade caracteristica, $u_{*}$, foi maior do que $0,1 \mathrm{~m} / \mathrm{s}$ em todos os perfis com um valor médio de $0,1147 \mathrm{~m} / \mathrm{s}$. 
53.

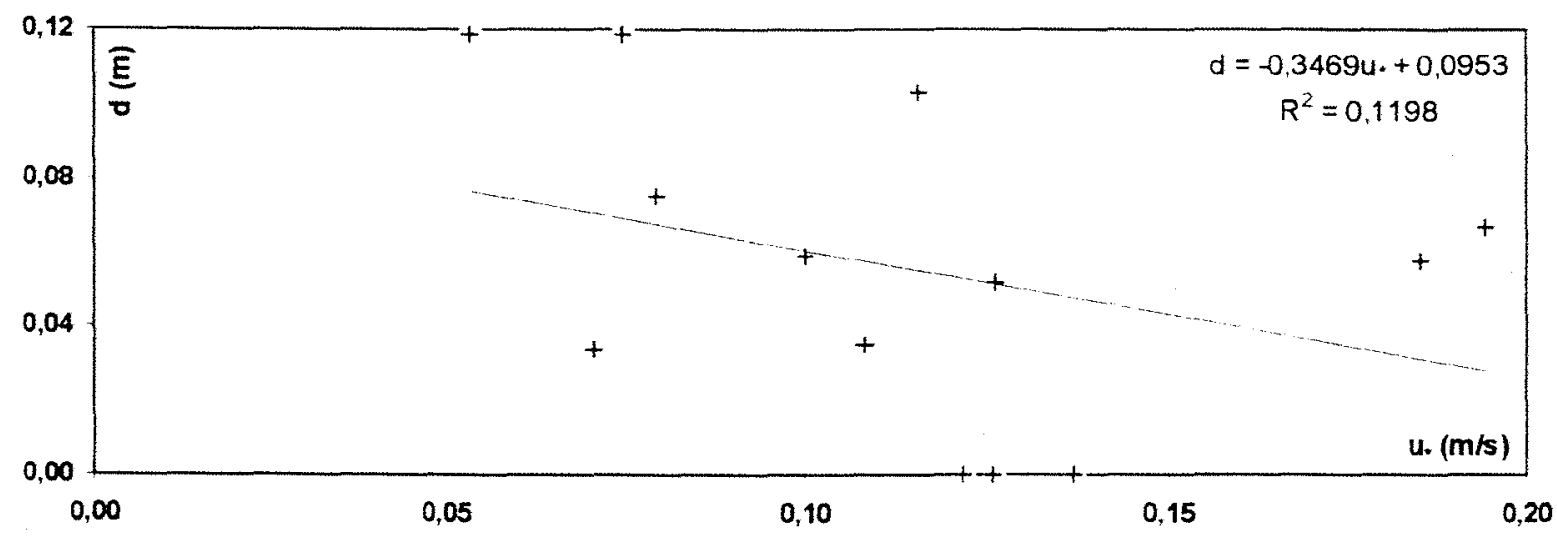

Figura 15 - Deslocamento do plano zero, d, em função da velocidade característica, $u_{*}$, para $-0,01 \leq \mathrm{Ri} \leq 0,01$

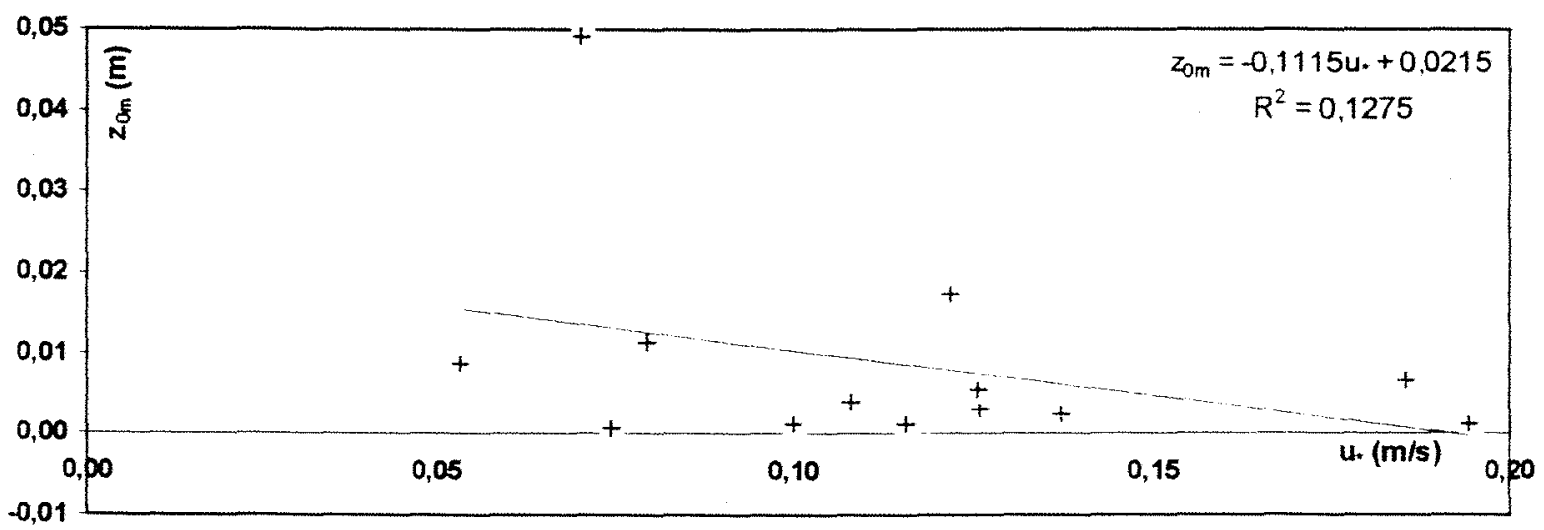

Figura 16 - Comprimento rugoso, $z_{0 m}$, em função da velocidade característica, $u_{*}$, para $-0,01 \leq \mathrm{Ri} \leq 0,01$.

Neste intervalo, os valores para a resistência aerodinâmica apresentaram a melhor correlação com os valores da resistência obtida através de parâmetros médios conforme proposto por ALLEN (1986) com um coeficiente de determinação de 0,9119 como pode ser visto na Figura 17 . Este resultado era esperado 
54.

pois os valores sugeridos por ALLEN (1986) foram obtidos em condições de atmosfera neutra.

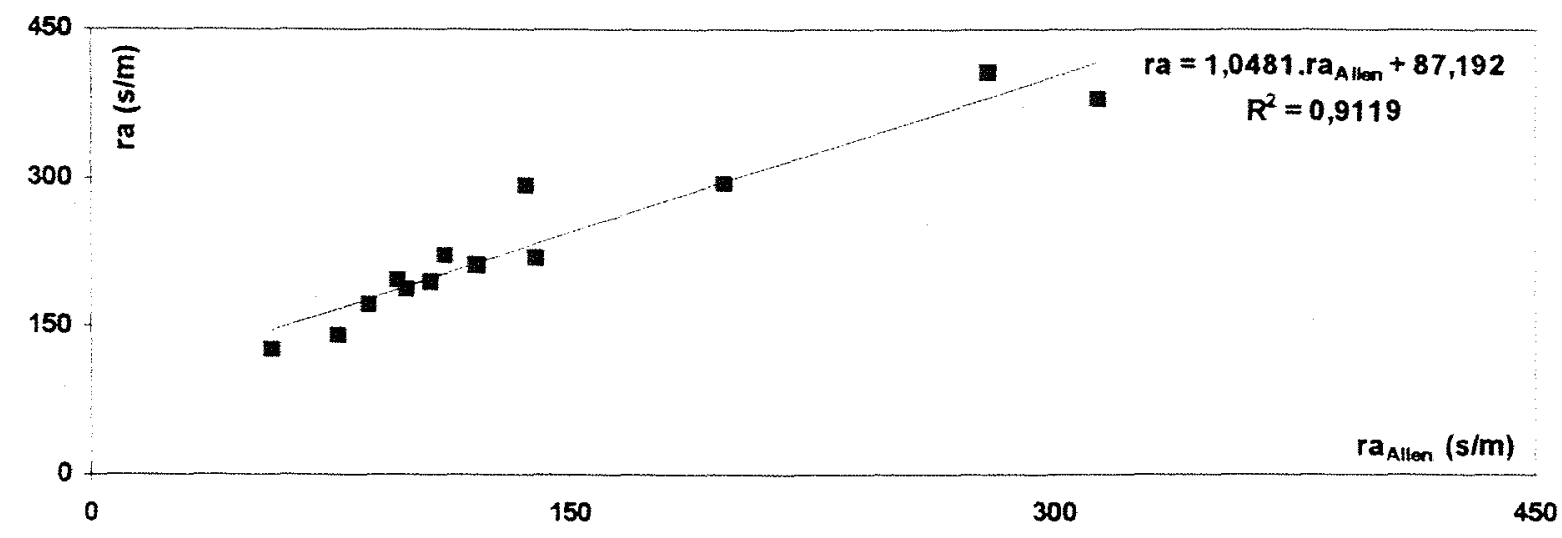

Figura 17 - Resistência aerodinâmica obtida a partir dos parâmetros estimados, em função da resistência aerodinâmica obtida conforme proposto por ALLEN(1986), para $-0,01 \leq R i \leq 0,01$.

$\mathrm{Na}$ Figura 18, pode ser observado como as resistências tiveram o mesmo comportamento, apesar dos valores aqui obtidos superestimarem os valores de ALLEN (1986), ou seja, a resistência aerodinâmica obtida pelos parâmetros estimados foi sempre maior que a resistência aerodinâmica obtida conforme proposto por ALLEN (1986) (a qual leva em consideração somente a influência da altura do dossel para a estimativa dos parâmetros $\mathrm{z}_{\mathrm{Om}}$ e d). 
55.

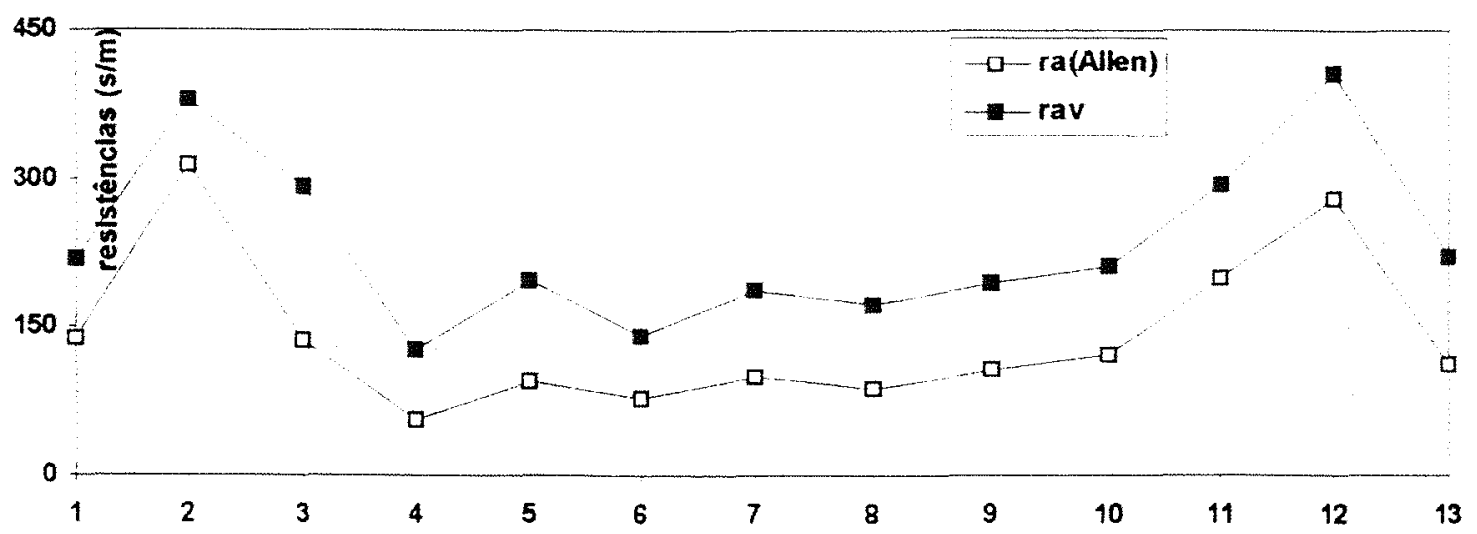

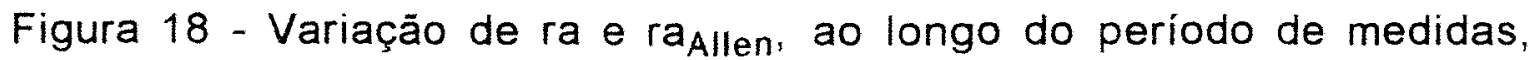
para o perfis próximos de atmosfera neutra.

\subsubsection{Perfis de $1 / 2$ hora para $-1,0 \leq R i<-0,01$.}

Quando os perfis possuem $-1,0 \leq R i<-0,01$, a atmosfera é instável e o escoamento é turbulento com convecção mista. Esta classificação considera que nesta faixa os processos turbulentos são causados tanto pela turbulência dinâmica (mecânica) como pela convecção livre. Esta condição ocorreu no período diurno, entre 6:00 e 17:00 horas e correspondeu a 85 perfis $(37 \%)$.

Os valores do deslocamento do plano zero, $d, e$ do comprimento rugoso, $\mathrm{z}_{\mathrm{om}}$, neste intervalo, também se mantiveram bem abaixo dos valores, 0,0933 e $0,0172 \mathrm{~m}$ respectivamente, conforme proposto por ALLEN (1986) como pode ser visto na Tabela 6.

O comprimento rugoso, $z_{0 m}$, se manteve praticamente igual ao do intervalo anterior, com uma pequena variação no desvio, para menor. A média do deslocamento do plano zero, d, no entanto, diminuiu, 
56.

enquanto o desvio permaneceu o mesmo. Os valores de $u_{*}$ neste intervalo foram maiores que $0.1 \mathrm{~m} / \mathrm{s}$ em todos os perfis.

Tabela 6 - Valores mínimo e máximo, média e desvio padrão das grandezas $\mathrm{Ri}, \mathrm{L}, \mathrm{u}_{*}, \mathrm{~d}, \mathrm{z}_{0 \mathrm{~m}}$, ra e ra ${ }_{\text {Allen }}$ estimados para o intervalo de $-1,0 \leq \mathrm{Ri}<-0,01$.

\begin{tabular}{|l|r|r|r|r|}
\cline { 2 - 5 } \multicolumn{1}{c|}{} & \multicolumn{4}{c|}{$-1,0 \leq$ Ri<-0,01 (85 perfis) } \\
\cline { 2 - 5 } \multicolumn{1}{c|}{} & Mínimo & \multicolumn{1}{c|}{ Máximo } & \multicolumn{1}{c|}{ Média } & \multicolumn{1}{c|}{ Desvio } \\
\hline $\mathrm{Ri}$ & -0.8310 & $-0,0104$ & $-0,1684$ & 0,1495 \\
\hline $\mathrm{L}$ & $-74,20$ & $-0,93$ & $-10,05$ & 11,48 \\
\hline $\mathrm{u}_{*}(\mathrm{~m} / \mathrm{s})$ & 0,0473 & 0,2620 & 0,1498 & 0,0417 \\
\hline $\mathrm{d}(\mathrm{m})$ & 0 & 0,119 & 0,034 & 0,048 \\
\hline $\mathrm{Z}_{\text {am }}(\mathrm{m})$ & 0,001 & 0,043 & 0,010 & 0,008 \\
\hline $\mathrm{ra}(\mathrm{s} / \mathrm{m})$ & 115 & 466 & 169 & 60 \\
\hline $\mathrm{ra}$ & 66 & 511 & 127 & 70 \\
\hline
\end{tabular}

O comportamento de $d, z_{0 m}$, ra e ra ${ }_{\text {Allen }}$ pode ser observado nas Figuras $19,20,21$ e 22 .

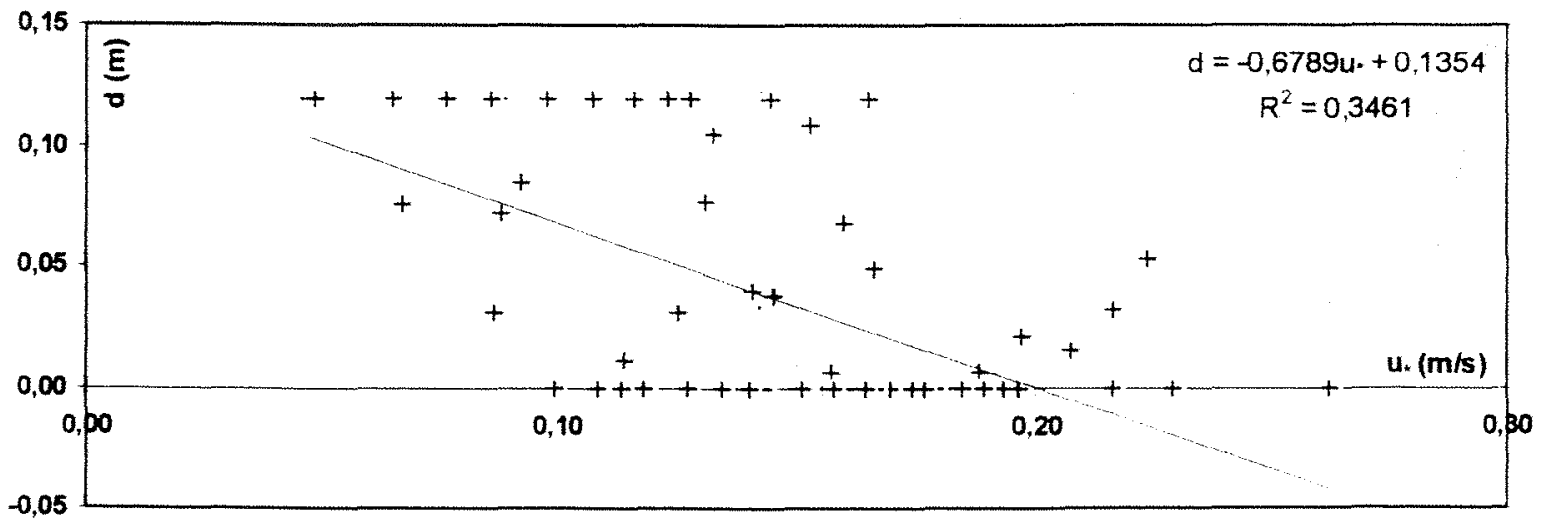

Figura 19 - Deslocamento do plano zero, d, em função da velocidade característica, $u_{*}$, para $-1,0 \leq \mathrm{Ri}<-0,01$. 


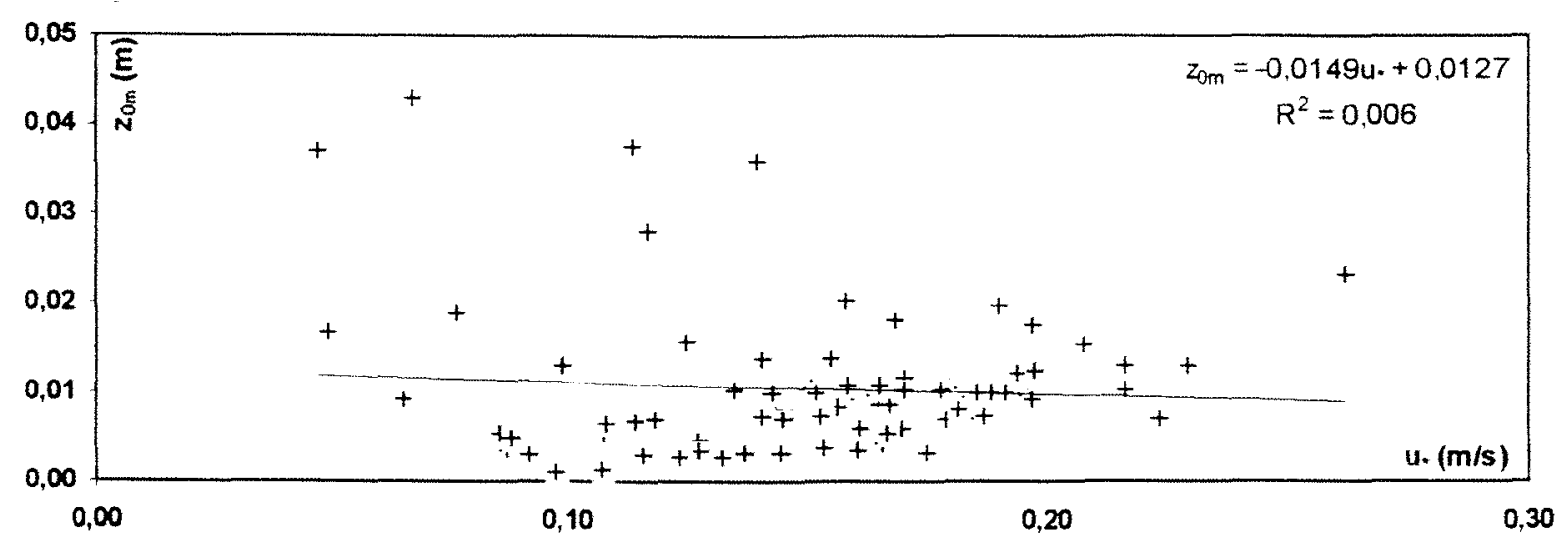

Figura 20 - Comprimento rugoso, $z_{0 m}$, em função da velocidade característica, $u_{*}$, para $-1,0 \leq \mathrm{Ri}<-0,01$.

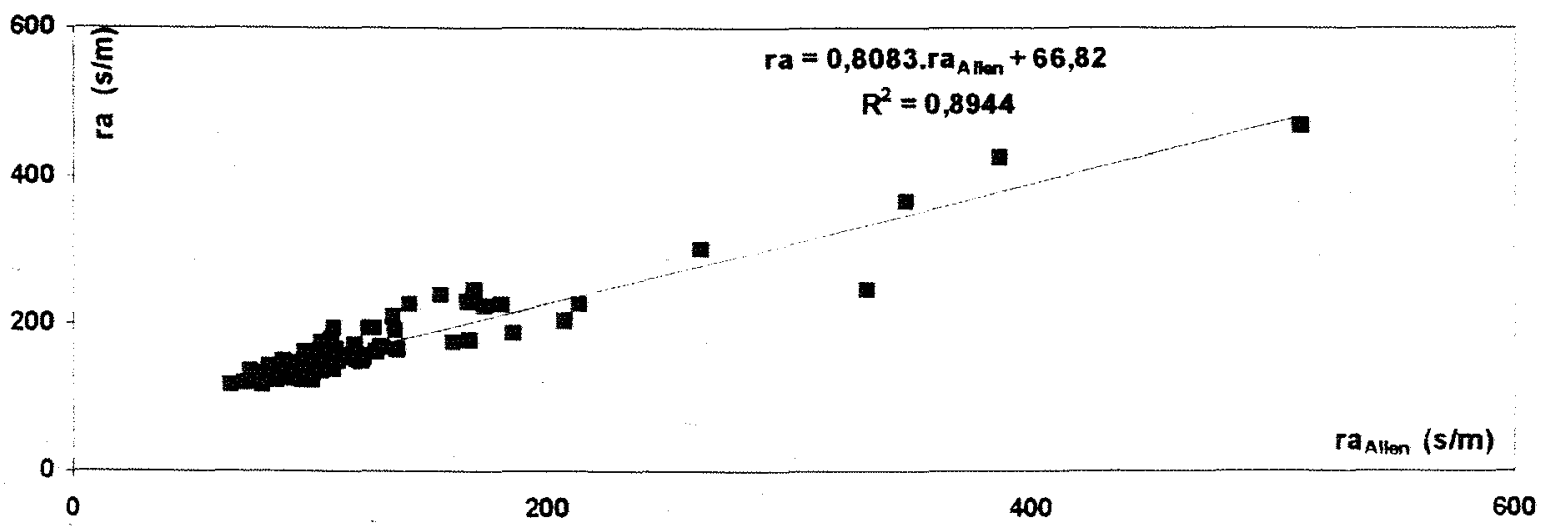

Figura 21 - Resistência aerodinâmica, obtida a partir dos parâmetros estimados, em função da resistência aerodinâmica obtida conforme proposto por ALLEN (1986), para -1,0 $\leq \mathrm{Ri}<-0,01$. 
58.

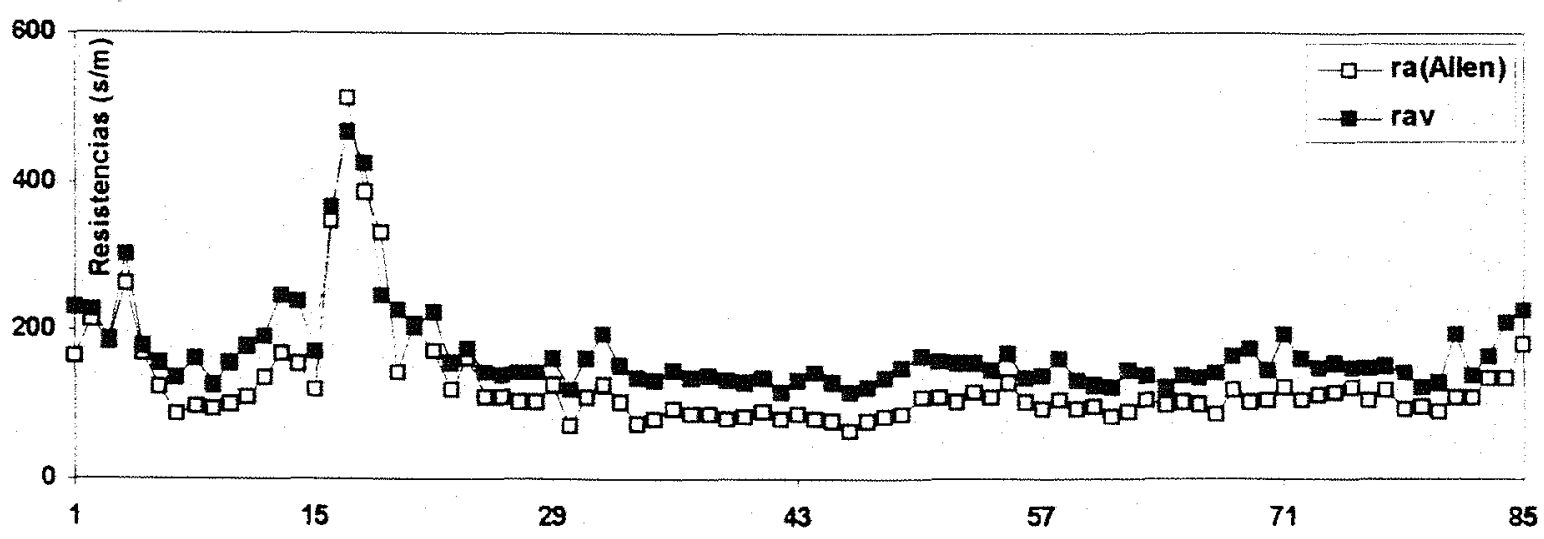

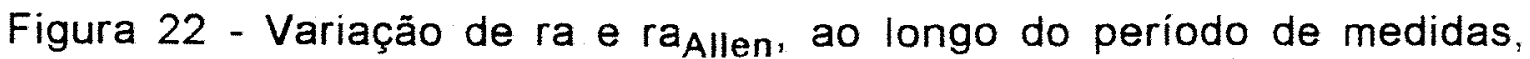
para o intervalo $-1,0 \leq R i<-0,01$.

A resistência aerodinâmica obtida através dos parâmetros estimados e a resistência aerodinâmica calculada conforme proposto por ALLEN (1986) tiveram o mesmo comportamento com uma defasagem entre elas aparentemente menor do que no intervalo em que $0,01 \geq \mathrm{Ri} \geq-$ 0,01 conforme Figura 22. Aqui, apesar dos valores de d e z0m terem se mantido próximos dos valores do intervalo anterior, contribuindo para aumentar ra em relação a ra $a_{\text {Allen, }}$ as correções, $\psi_{m}$ e $\psi_{h}$, são maiores e contribuem, em todo intervalo, para diminuir a resistência, o que fez com que a diferença entre elas ficasse menor. Verificou-se que o coeficiente de determinação, 0,894 (Figura 21), foi levemente inferior ao intervalo anterior que foi de 0,9119 (Figura 17).

De acordo com MONIN \& YAGLOM (1977), existe uma discrepância teórica entre a eq. 60,61 e 62 para representar os perfis de velocidade aqui utilizada e a chamada lei da potência de $1 / 3$, colocando em dúvida a validade destas equações. Entretanto, o mesmo autor afirma 
que existe justificativa empírica satisfatória para esta equação a qual tem sido usada em algumas situações.

Quando há tendência à convecção livre, o que teoricamente deveria acontecer em torno de $\mathrm{Ri}=-1$, a equação que descreve o perfil de velocidade é a lei de potência de $1 / 3$, válida para quando só existe agitação térmica. A agitação térmica é caracterizada pelo comprimento de Monin-Obukhov nulo e a espessura da camada dinâmica conseqüentemente será igual a zero. No entanto, verifica-se experimentalmente que para $\mathrm{Ri}=-0,1$, já começa a valer a lei de potência de 1/3. Nesta situação tem-se agitação térmica e turbulência mecânica de tal modo que a agitação térmica já está mais efetiva que a mecânica. No entanto, nesta situação contrariamente ao que se espera, $L$ ainda é grande, mas, por outro lado, a camada dinâmica é, de fato, pequena. Existe então uma contradição ao se representar a camada dinâmica pelo comprimento de Monin-Obukhov. O que ocorre é que a espessura da sub camada dinâmica, na realidade, compreende somente uma pequena parte de L. Tal fato poderia ser explicado pela existência da constante de Von Karman no denominador da eq. 24 (que de acordo com MONIN-YAGLOM (1977) não tem motivo para ai estar a não ser historicamente) que define o comprimento de Monin-Obukhov, fazendo com que ele seja 2,5 maior do que deveria.

Vale a pena salientar que de acordo com Taylor, citado por MONIN \& YAGLOM (1977), a transição ocorre na atmosfera para o regime de convecção livre com $\mathrm{Ri}=-0,03$. 
Tabela 7 - Valores mínimo e máximo, média e desvio padrão das grandezas $R i, L, u_{*}, d, z_{0 m}$, ra e raAllen estimados para o subintervalos $-0,1 \leq \mathrm{Ri}<-0,01$ e $-1,0 \leq \mathrm{Ri}<-0,1$.

\begin{tabular}{|c|c|c|c|c|c|}
\hline & & Minimo & Máximo & Média & Desvio \\
\hline \multirow{7}{*}{$\begin{array}{l}-1,0 \leq \mathrm{Ri}<-0,1 \\
49 \text { perfis }\end{array}$} & $R i$ & $-0,8310$ & $-0,1071$ & $-0,2496$ & 0,1508 \\
\hline & $\mathrm{L}$ & $-7,24$ & $-0,93$ & $-3,89$ & 1,62 \\
\hline & $u_{*}(\mathrm{~m} / \mathrm{s})$ & 0,0654 & 0,2292 & 0,1484 & 0,0355 \\
\hline & $d(m)$ & 0 & 0,119 & 0,041 & 0,052 \\
\hline & $z_{0 m}(m)$ & 0,001 & 0,038 & 0,010 & 0,007 \\
\hline & $\mathrm{ra}(\mathrm{s} / \mathrm{m})$ & 115 & 301 & 160 & 36 \\
\hline & $\mathrm{ra}_{\text {Allen }}(\mathrm{s} / \mathrm{m})$ & 80 & 331 & 126 & 48 \\
\hline \multirow{7}{*}{$\begin{array}{l}-0,1 \leq \mathrm{Ri}<-0,01 \\
36 \text { perfis }\end{array}$} & $\mathrm{Ri}$ & $-0,0997$ & $-0,0104$ & $-0,0580$ & 0,0265 \\
\hline & $\mathrm{L}$ & $-74,20$ & $-7,78$ & $-18,42$ & 13,70 \\
\hline & $u_{*}(\mathrm{~m} / \mathrm{s})$ & 0,0473 & 0,2620 & 0,1518 & 0,0495 \\
\hline & $d(m)$ & 0 & 0,119 & 0,023 & 0,041 \\
\hline & $z_{0 m}(m)$ & 0,001 & 0,043 & 0,011 & 0,009 \\
\hline & $\mathrm{ra}(\mathrm{s} / \mathrm{m})$ & 118 & 466 & 183 & 81 \\
\hline & ra $a_{\text {Allen }}(\mathrm{s} / \mathrm{m})$ & 66 & 511 & 129 & 94 \\
\hline
\end{tabular}

Diante do exposto, o intervalo $-1,0 \leq \mathrm{Ri}<-0,01$ foi dividido em dois intervalos ou seja $-0,1 \leq \mathrm{Ri}<-0,01$ e -1,0 $\mathrm{Ri}<-0,1$ conforme Tabela 7.

O comportamento de de $z_{0 m}$ em função de $u_{*}$, para os sub intervalos, foi o mesmo que para o intervalo todo ou seja permaneceu a tendência de crescimento de $z_{0 m} \operatorname{com} u_{*}$ e de diminuição de $d$ com $u_{*}$.

Foi possivel verificar (Tabela 7) que as médias das resistências não foram muito diferentes de um subintervalo para outro. $O$ comportamento das resistências ao longo do período de medidas também não sofreu variação do intervalo para os subintervalos (ver Figuras 22, 24 e 26$)$. 
61.

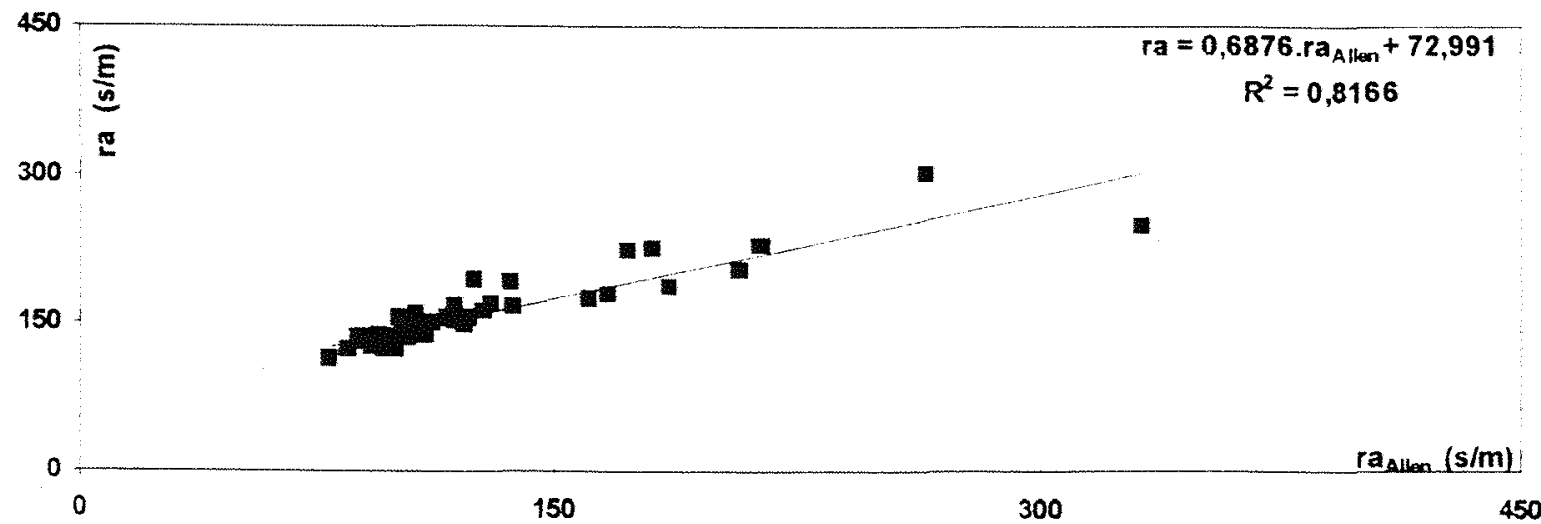

Figura 23 - Resistência aerodinâmica, obtida a partir dos parâmetros estimados, em função da resistência aerodinâmica obtida conforme proposto por ALLEN (1986), para -1,0 $\mathrm{Ri}<-0,1$.

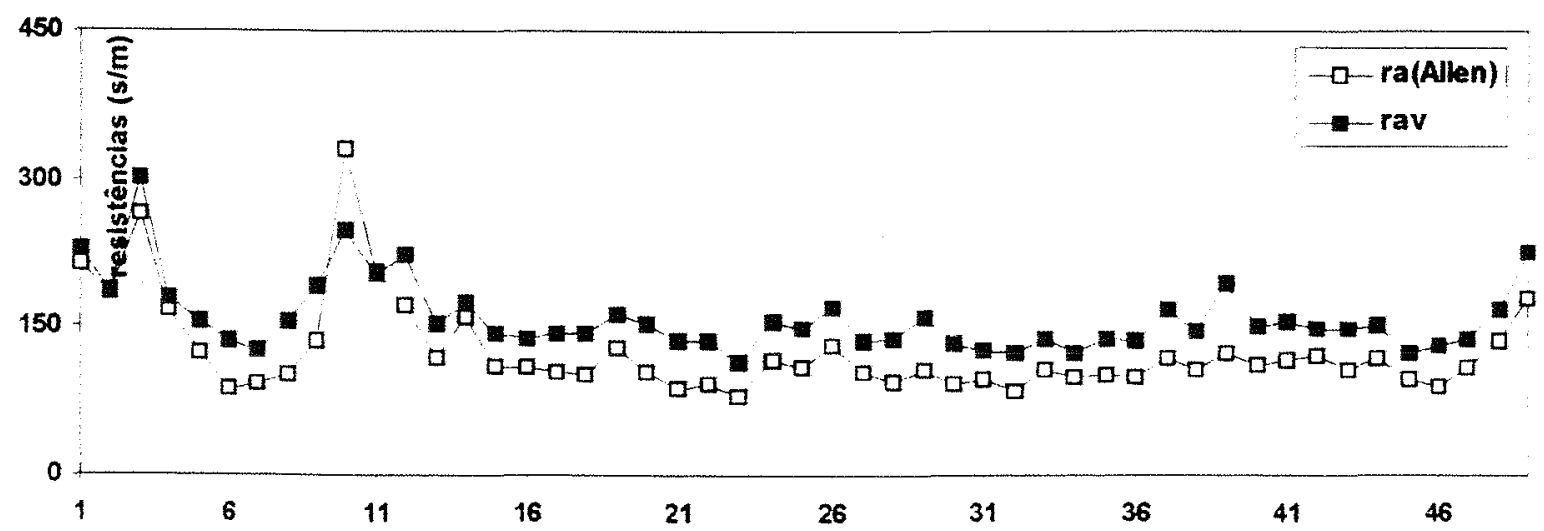

Figura 24 - Variação de ra e raAllen, ao longo do período de medidas, para o intervalo $-1,0 \leq \mathrm{Ri}<-0,1$. 
62.

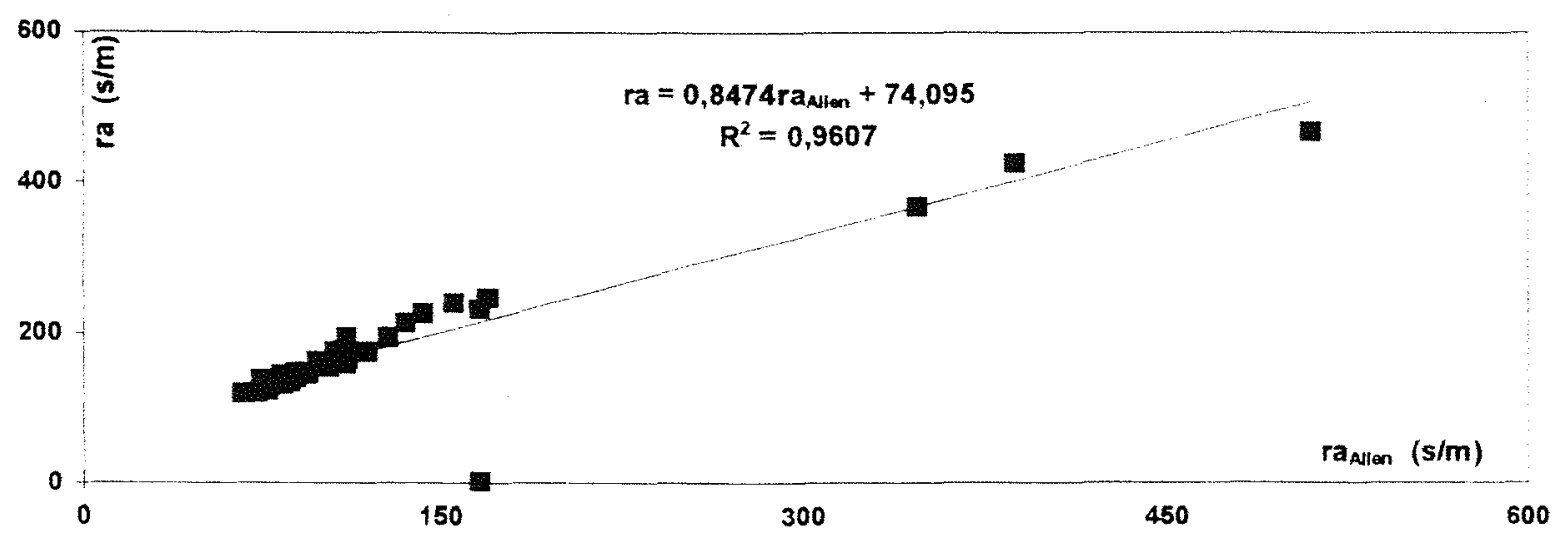

Figura 25 - Resistência aerodinâmica, obtida a partir dos parâmetros estimados, em função da resistência aerodinâmica conforme proposto por ALLEN (1986) para $-0,1 \leq \mathrm{Ri}<-0,01$.

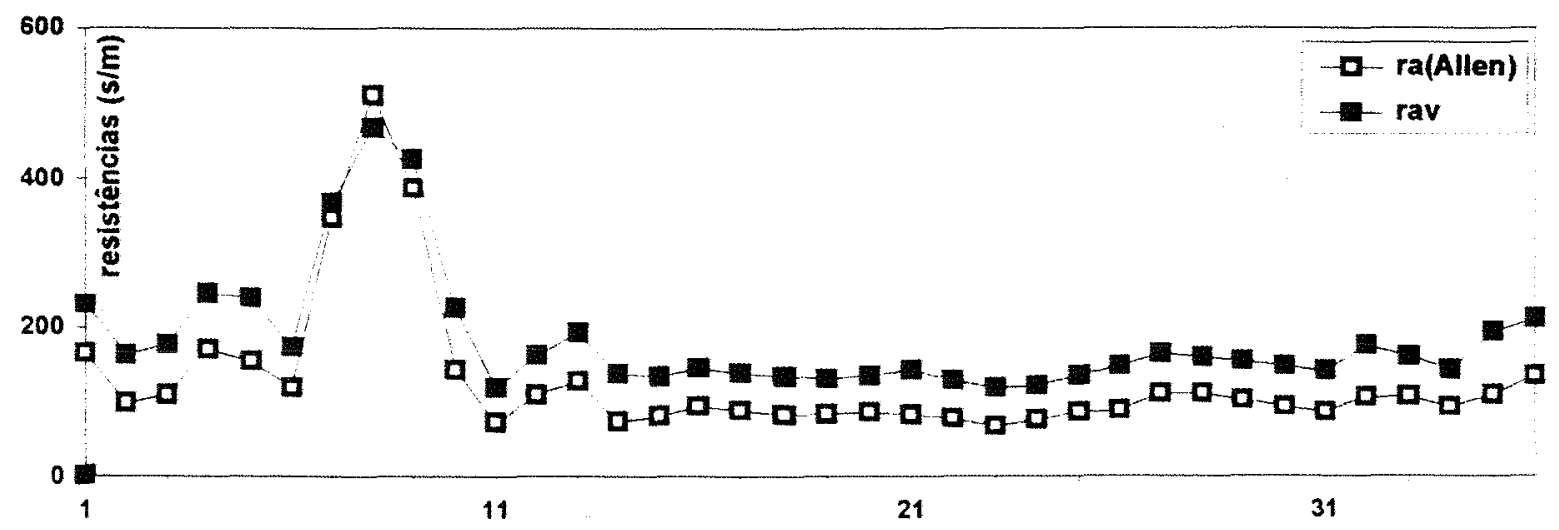

Figura 26 - Variação de ra e ra Allen, ao longo do período de medidas, para o intervalo $-0,1 \leq \mathrm{Ri}<-0,01$.

Quanto ao coeficiente de determinação, de 0,8944 no intervalo $-1,0 \leq \mathrm{Ri}<-0,01$ (Figura 21), passou para 0,8166 e 0,9607 nos 
subintervalos $-1,0 \leq \mathrm{Ri}<-0,1$ e $-0,1 \leq \mathrm{Ri}<-0,01$, respectivamente (Figuras 23 e 25). Este comportamento e estes coeficientes de determinação não foram diferentes, nem grandes o suficiente para justificar a divisão do intervalo.

\subsubsection{Perfis de $1 / 2$ hora para $\mathrm{Ri}<-1,0$}

Somente 1 perfil teve $\mathrm{Ri}<-1,0$. Nesta situação o escoamento é quase laminar e a convecção é livre. Aqui voltam a se repetir baixas velocidades de vento e o número de Richardson obtido foi de $-1,10$. Este perfil ocorreu no período diurno, mais especificamente às 9:00 horas aproximadamente.

Neste perfil, o deslocamento do plano zero, $d$, foi $0,119 \mathrm{~m} \mathrm{e}$ o comprimento rugoso, $\mathrm{zOm}, 0,0036 \mathrm{~m}$

A resistência aerodinâmica conforme proposto por ALLEN (1986) foi de $278 \mathrm{~s} / \mathrm{m}$, superior portanto a resistência aerodinâmica calculada a partir dos parâmetros estimados que foi de $250 \mathrm{~s} / \mathrm{m}$.

Convém ressaltar que em todos os intervalos considerados os valores da resistência aerodinâmica superestimaram os valores de ALLEN (1986). No entanto verificou-se que a média da diferença entre as duas decresceu significativamente (Tabela 8 ) à medida que o número de Richardson diminuiu indicando portanto a possibilidade de que para perfis em que $\mathrm{Ri}<-1,0$, pudesse haver uma inversão ou seja os valores da resistência aerodinâmica obtida a partir dos parâmetros estimados subestimassem os valores da resistência aerodinâmica conforme proposto por ALLEN (1986). No entanto, não foi possivel confirmar esta tendência por falta de maior número de perfis neste intervalo. 
Tabela 8 - Valores mínimo e máximo, média e desvio padrão das diferenças entre a resistências obtidas respectivamente a partir dos parâmetros estimados e dos parâmetros médios, para os diferentes intervalos de Ri.

\begin{tabular}{|l|r|r|r|r|}
\cline { 2 - 5 } \multicolumn{1}{c|}{} & Mínimo & Máximo & \multicolumn{1}{c|}{ Média } & Desvio \\
\hline $\begin{array}{l}\text { Ri }>0,16 \\
79 \text { perfis }\end{array}$ & 2292 & 20924 & 5988 & 3272 \\
\hline $\begin{array}{l}0,01<\text { Ri } \leq 0,166 \\
52 \text { perfis }\end{array}$ & 55 & 3156 & 524 & 553 \\
\hline $\begin{array}{l}-0,01 \leq R i \leq 0,01 \\
13 \text { perfis }\end{array}$ & 65 & 156 & 94 & 26 \\
\hline $\begin{array}{l}-1,0 \leq R i<-0,01 \\
85 \text { perfis }\end{array}$ & -83 & 83 & 42 & 23 \\
\hline $\begin{array}{l}\text { Ri<-1,0 } \\
1 \text { perfil }\end{array}$ & -27 & & & \\
\hline
\end{tabular}

\subsection{Resistência aerodinâmica efetiva diária}

A partir dos resultados obtidos a cada meia hora para a resistência aerodinâmica e de posse dos gradientes verticais de pressão de vapor, foi possivel estimar o fluxo de vapor d'água nesses mesmos intervalos de tempo. Em cada dia, o somatório dos fluxos de cada meiahora resultou no fluxo total do vapor d'água.

O valor obtido para o fluxo médio diário foi baixo, o que foi coerente com o pequeno valor do gradiente de pressão do vapor d'água (Tabela 9), característico da região para a época em que as medidas foram efetuadas.

Os resultados obtidos para a resistência aerodinâmica efetiva diária a partir da média dos parâmetros estimados e para a resistência aerodinâmica efetiva diária obtida conforme proposto por 
ALLEN (1986) estão na Tabela 9, juntamente com os valores médios da velocidade no nível 3 .

Tabela 9: Valores médios das grandezas envolvidas na determinação da resistência aerodinâmica efetiva diária e respectivas resistências.

\begin{tabular}{|l|r|r|r|r|r|}
\cline { 2 - 6 } \multicolumn{1}{c|}{} & \multicolumn{1}{c|}{$31 / 08$} & \multicolumn{1}{c|}{$01 / 09$} & $02 / 09$ & $03 / 09$ & \multicolumn{1}{c|}{$04 / 09$} \\
\hline $\mathrm{TS}_{1}\left({ }^{\circ} \mathrm{C}\right)$ & 28,18 & 29,11 & 20,36 & 19,93 & 22,52 \\
\hline $\mathrm{TS}_{2}\left({ }^{\circ} \mathrm{C}\right)$ & 28,38 & 29,27 & 20,23 & 19,81 & 22,50 \\
\hline $\mathrm{TU}_{1}\left({ }^{\circ} \mathrm{C}\right)$ & 23,05 & 23,89 & 18,40 & 17,67 & 20,19 \\
\hline $\mathrm{TU}_{2}\left({ }^{\circ} \mathrm{C}\right)$ & 22,80 & 23,43 & 18,02 & 17,00 & 19,34 \\
\hline $\mathrm{u}_{1}(\mathrm{~m} / \mathrm{s})$ & 0,591 & 0,679 & 1,522 & 0,893 & 0,608 \\
\hline $\mathrm{u}_{2}(\mathrm{~m} / \mathrm{s})$ & 0,740 & 0,842 & 1,769 & 1,073 & 0,751 \\
\hline $\mathrm{u}_{3}(\mathrm{~m} / \mathrm{s})$ & 0,868 & 0,981 & 1,988 & 1,225 & 0,860 \\
\hline$\Delta \mathrm{e}_{\mathrm{d}}(\mathrm{kPa})$ & $-0,09$ & $-0,15$ & $-0,08$ & $-0,13$ & $-0,20$ \\
\hline$\lambda \mathrm{E}(\mathrm{mm} /$ dia) & 0,38 & 0,45 & 0,30 & 0,54 & 0,89 \\
\hline $\mathrm{ra}(\mathrm{s} / \mathrm{m})$ & 138 & 200 & 162 & 156 & 138 \\
\hline $\mathrm{ra}$ & 202 & 179 & 88 & 143 & 204 \\
\hline
\end{tabular}

As figuras $26,27,28,29$ e 30 , mostram o comportamento do fluxo diário de calor latente ao longo dos dias 31/08, 01, 02, 03 e 04/09. Observou-se o mesmo comportamento para todos os dias observados, ou seja a evapotranspiraçao foi nula durante todo o periodo noturno; começou a aumentar aproximadamente entre 6:00 e 8:00 horas, atingiu um máximo em torno de 12:00/14:00 horas voltando a se aproximar de zero por volta das 17:00/18:00 h. No dia 02/09, houve fluxo ascendente de calor latente durante a noite e durante o dia o fluxo se manteve mais constante (ver Figura 28). 
66.

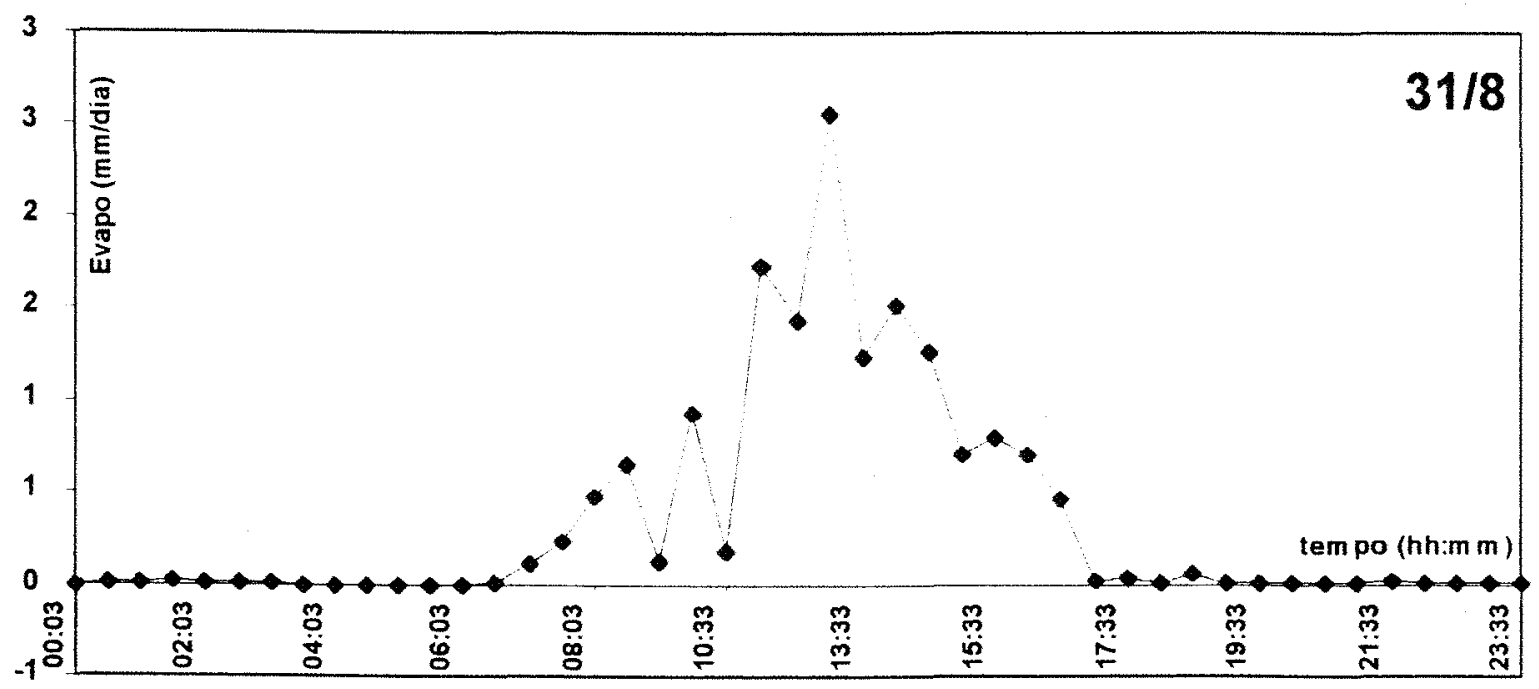

Figura 26 - Fluxo de calor latente em função do tempo, para o dia $31 / 08 / 94$.

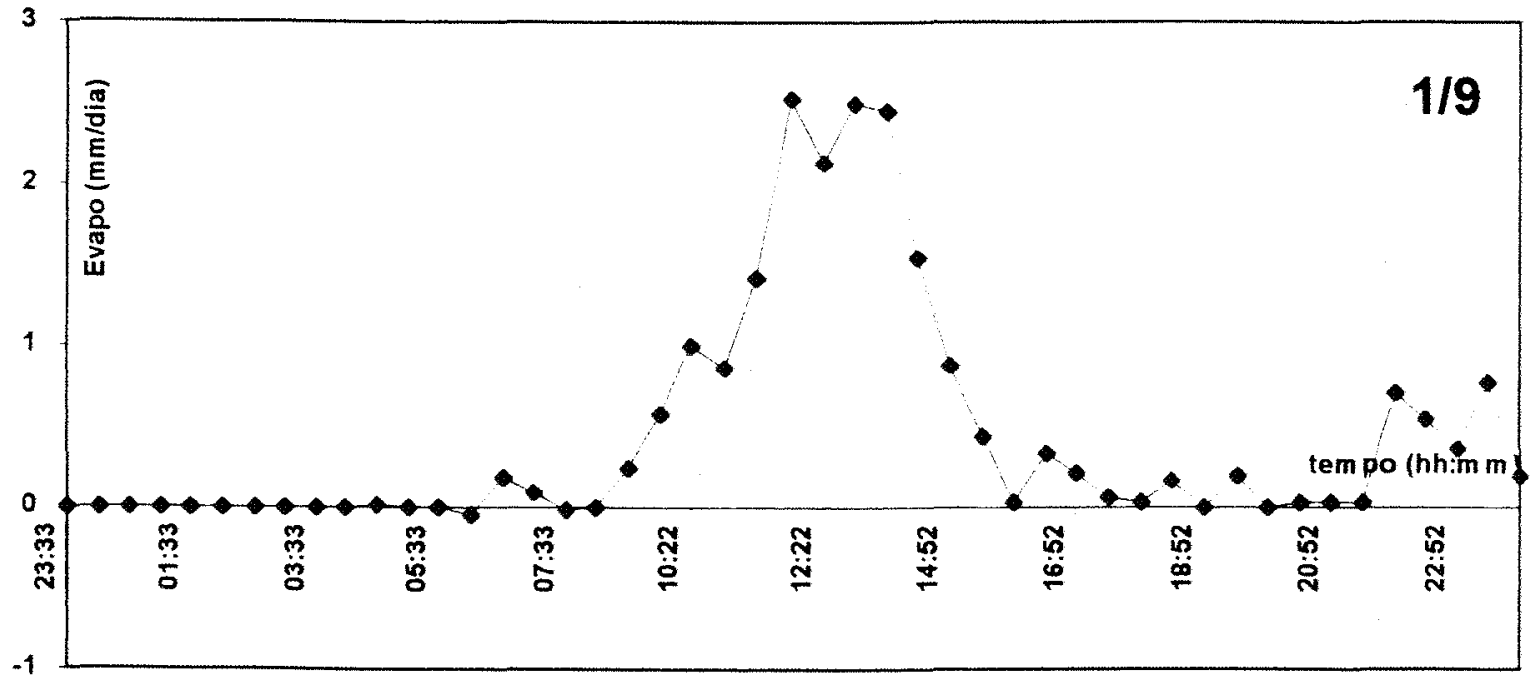

Figura 27 - Fluxo de calor latente em função do tempo, para o dia $01 / 09 / 94$ 


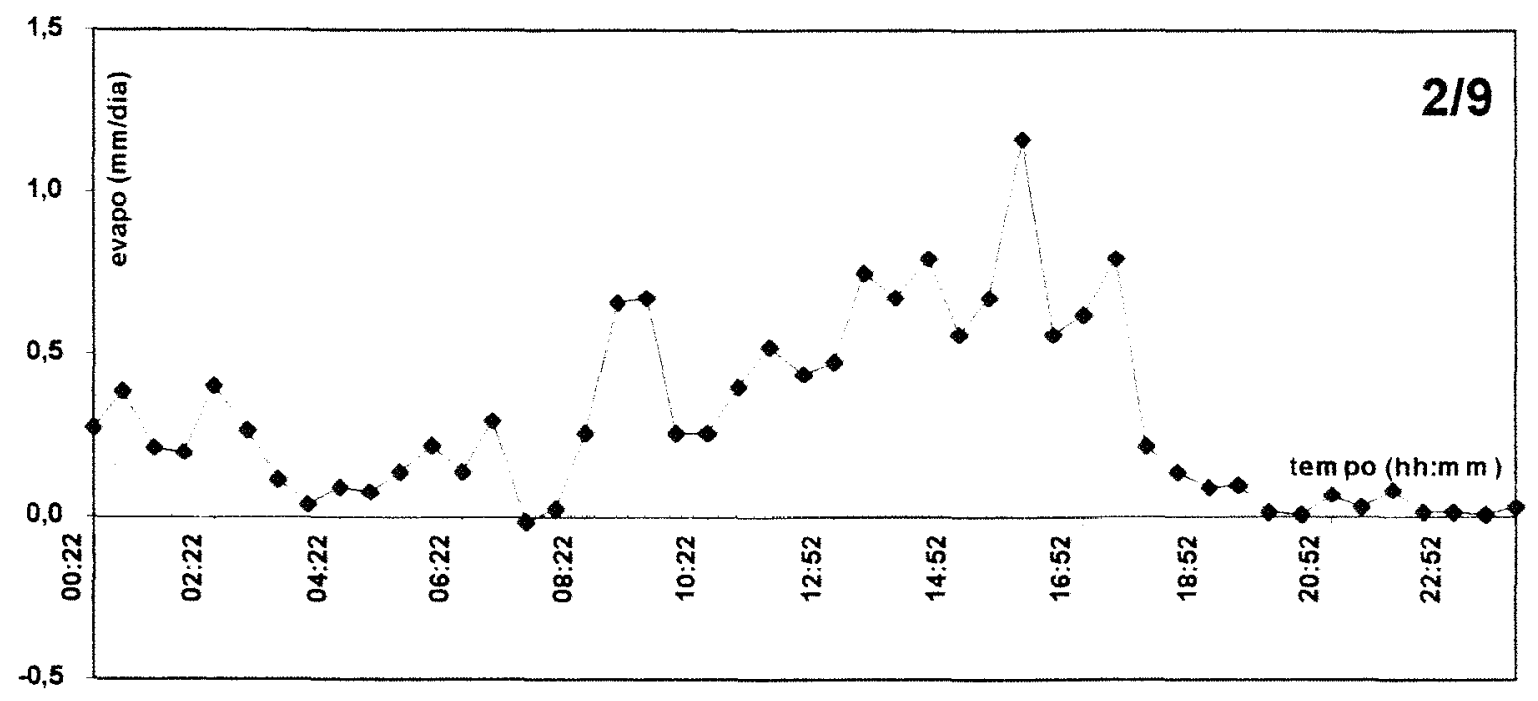

Figura 28 - Fluxo do calor latente em funçao do tempo, para o dia $02 / 09 / 94$

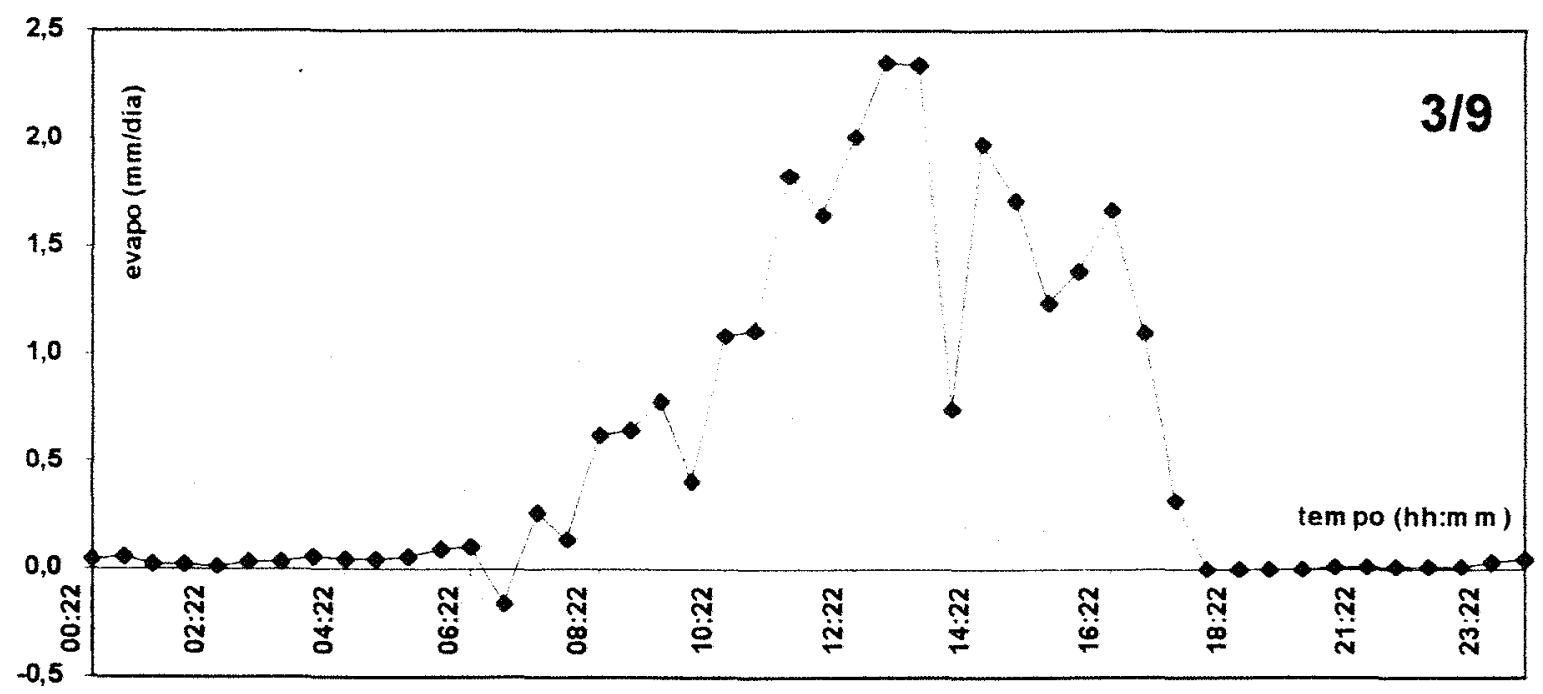

Figura 29 - Fluxo do calor latente em função do tempo, para o dia $03 / 09 / 94$. 


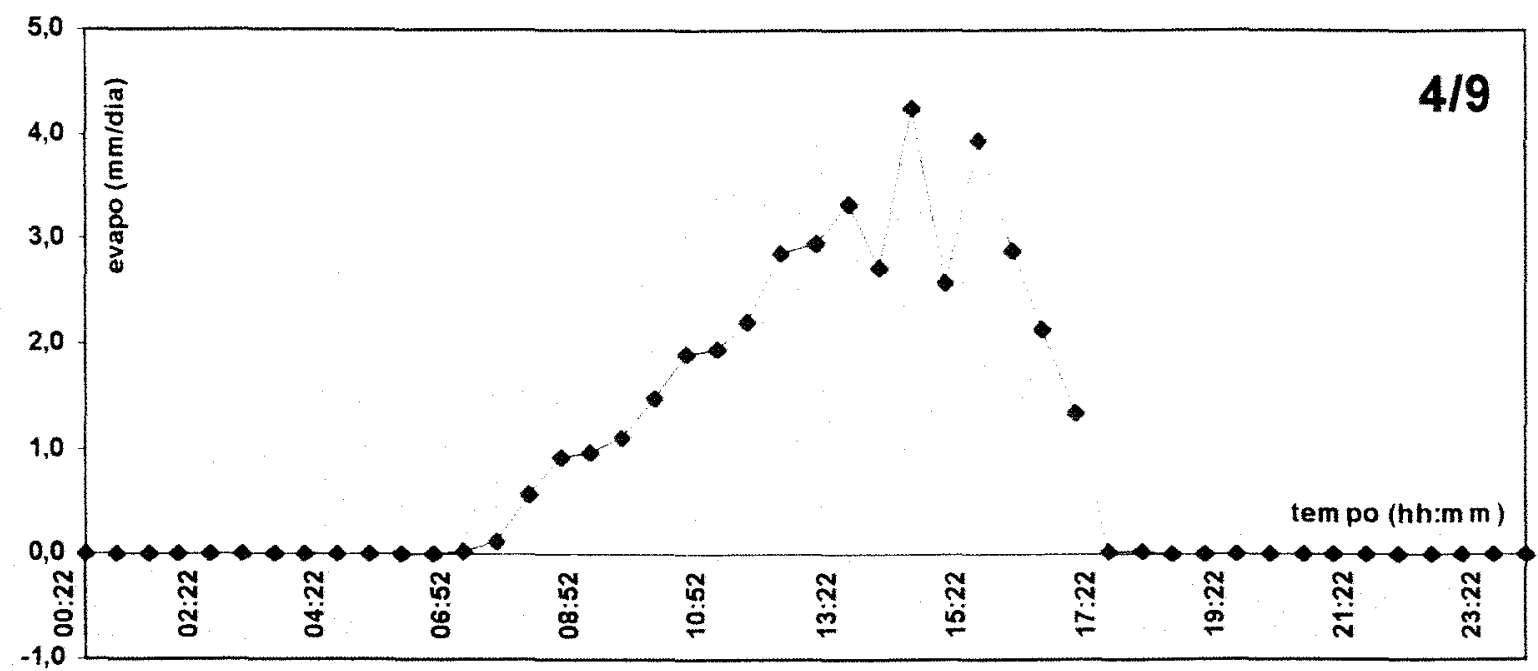

Figura 30 - Fluxo do calor latente em função do tempo, para o dia $04 / 09 / 94$.

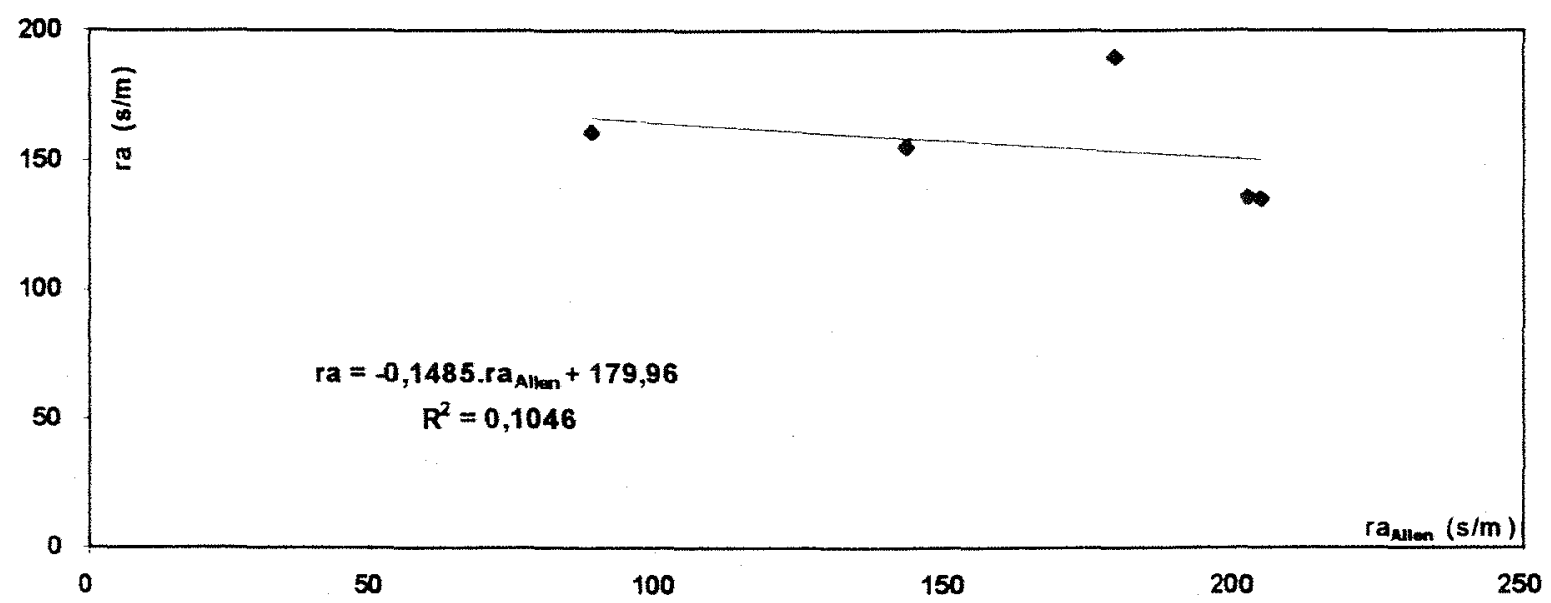

Figura 31 - Resistência aerodinâmica efetiva diária em função da resistência aerodinâmica média diária conforme proposto por ALLEN (1986).

Não foi possivel verificar nenhum padrão no comportamento dos valores das resistências aerodinâmicas efetivas diárias quando comparados aos da resistência aerodinâmica média diária conforme proposto por ALLEN (1986). O coeficiente de determinação entre a 
69.

resistência aerodinâmica efetiva diária e a proposta por ALLEN (1986) foi extremamente baixo e os coeficientes obtidos (Figura 31) indicam que elas são diferentes.

A discrepância apresentada entre as duas estimativas da resistência aerodinâmica efetiva média diária pode ter ocorrido devido à diferença entre os métodos de estimativa utilizados. Diferentemente do método aerodinâmico, o método de estimativa proposto por ALLEN (1986) não leva em consideração as correções devido à estabilidade, e considera os parâmetros de e zOm como funções somente a altura do dossel.

As simplificações propostas por ALLEN (1986) resultaram em uma dependência direta da resistência em relação à velocidade do vento e sua aplicação no presente estudo indicou uma variação em raAllen de 88 a $204 \mathrm{~s} / \mathrm{m}$, enquanto os valores da resistência efetiva diária foram relativamente constantes, variando de 138 a $200 \mathrm{~s} / \mathrm{m}$, indicando que o regime de turbulência alterou significativamente os parâmetros envolvidos no cálculo da resistência. 


\section{CONCLUSÃO}

Neste trabalho foi observado que para a maioria dos dias analisados, a atmosfera foi neutra somente em períodos muito curtos, próximos do amanhecer e do entardecer.

O deslocamento do plano zero e o comprimento rugoso para o momentum influenciaram significativamente a estimativa da resistência aerodinâmica e não são funções simplesmente da altura do dossel, conforme proposto por ALLEN (1986), mas também do próprio escoamento.

Os valores da resistência aerodinâmica calculada a partir dos parâmetros estimados, levando em consideração as funções correções, foram diferentes e maiores do que aqueles calculados conforme a metodologia proposta por ALLEN (1986).

Quanto maior a estabilidade, maior a diferença entre as estimativas analisadas de resistências aerodinâmicas à transferência do vapor de água e menor a correlação entre elas. Não é recomendável utilizar a metodologia proposta por ALLEN (1986), visto que mesmo para condição próxima da neutralidade, apesar de ser boa a correlação, a metodologia subestima os valores da resistência aerodinâmica à transferência do vapor de água.

O valor da resistência aerodinâmica efetiva diária, estimada a partir da integração do fluxo de calor latente para 24 horas, se manteve 
praticamente constante comparado com a variação do valor de raAllen, obtido a partir da velocidade de vento média de 24 horas. 


\section{REFERÊNCIAS BIBLIOGRÁFICAS}

ALLEN, R.G. A Penman for all seasons. Journal of Irrigation and Drainage Engineering, 112(4): 348-69, 1986.

ALLEN, R.G.; JENSEN, M.E.; WRIGHT, J.L.;BURMAN, R.D. Estimates of reference evapotranspiration. Agronomy Journal, 81(4): 650-62, 1989.

BARKER, E.H. \& BAXTER, T.L. A note on the computation of atmospheric surface layer fluxes for use in numerical modeling. Journal of Applied Meteorology, 14: 620-22, 1975.

BERKOWICZ, R. \& PRAHM, L.P. Sensible heat flux estimated from routine meteorological data by resistance method. American Meteorological Society, 21: 1845-64, 1982.

BRUTSAERT, $W$. Comments on surface roughness parameters and the height of dense vegetation. Journal of the Meteorological Society of Japan, 53(1): 96-7, 1975.

BRUTSAERT, $W$. The roughness length for water vapor, sensible heat, and other scalars. Journal of the Atmospheric Sciences, 32(10): 2082-2031, 1975.

BUSINGER, J.A.; WYNGAARD, J.C.; YZUME, Y.; BRADLEY, E.F. FluXprofile relationships in the atmospheric surface layer. Journal of the Atmospheric Sciences, 28: 181-9, 1971.

BUSINGER, J.A. A note on the Businger-Dyer profiles. Boundary-Layer Meteorology, 42: 145-51, 1988. 
73.

CUENCA, R.H.; ASCE, M.; NICHOLSON, M.T. Application of Penman Equation Wind Function. Journal of the Irrigation and Drainage Division, 108: 13-23, 1982.

COWAN, I.R. Mass, heat and momentum exchange between stands of plants and their atmospheric environment. Quarterly Journal of the Royal Meteorological Society, 94: 523-44, 1968.

DEHEER-AMISSAH，A.; HOGSTROM, U.; SMEDMAN-HOGSTROM, ANR-SOFI. Calculation of sensible and latent heat fluxes, and surface resistance from profile data. Boundary-Layer Meteorology, 20: $35-49,1981$.

DYER, A.J. \& HICKS, B.B. Flux-gradient relationships in the constant flux layer. Quarterly Journal of the Royal Meteorological Society, 96: $715-21,1970$.

DYER, A.J. A review of flux-profile relationships. Boundary-Layer Meteorology, 12: 141-51, 1974.

DUYNKERKE, P.G. The roughness length for heat and other vegetation parametrs for a surface of short grass. American Meterological Society, 31(6): 579-86, 1992.

FICHTL, G. H. Characteristics of turbulence observed at the NASA 150-n meteorological tower, Journal Appl. Meteor., 7(5): 838-44, 1968.

FOOD AND AGRICULTURE ORGANIZATION OF THE UNITED NATIONS. Guidelines for predicting crop water requeriments. Roma, 1975. 179p.

FOOD AND AGRICULTURE ORGANIZATION OF THE UNITED NATIONS. Report on the expert consuitation on procedures for revi- 
74.

sion of FAO guidelines for prediction of crop water requeriments. Roma, 1991. 45p.

HOGSTROM, U. Analysis of turbulence structure in the surface layer with a modified similarity formulation for near neutral conditions. Journal of the Atmospheric Sciences, 47(16): 1949-72, 1990.

KIZER, M.A. \& ELLIOTT, R.L. Eddy correlation systems for measuring evapotranspiration. American Society of Agricultural Engineers, 34(2): 387-92, 1991.

LO, A.K. An analytical-empirical method for determining the roughness length and zero-plane displacement. Boundary-layer Meteorology, 12: 141-151, 1977.

MONIN, A.S. \& YAGLOM, A.M. Turbulence in a thermally stratified medium. In: LUMLEY, J.L., ed. Statistical Fluid Mechanics. Massachusetts, The MIT Press, 1977. cap. 4, p.417-526.

MONTEITH, J.L. Evaporation and environment. Symp. Soc. Exp. Biol. XIX, p.205-234, 1965.

MONTEITH, J.L. Basic Physics, momentum transfer, the micro-meteorology of crops. In: EDWARD ARNOLD. Principles of Environmental Physics. London, 1973. caps. 2, 6, 12.

MONTEITH, J.L. Evaporation and surface temperature. Quarterly Journal Meteorological Society, 107: 1-27, 1981.

PANOFSKY, H.A.; BLACKADAR, A.K.; MCVEHIL, G.E. The diabatic wind profile. Quarterly Journal of the Royal Meteorological Society, 86: $390-98,1960$.

PARLANGE, M.B. \& KATUL, G.G. An advection-aridity evaporation model. Water Resouces Research, 28(1): 127-32, 1992. 
PARLANGE, M.B. \& KATUL, G.G. Estimation of bare soil evaporation using skin temperature measurements. Journal of Hidrology, 132: 91-106, 1992.

PAULSON, C.A. The mathematical representation of wind speed and temperature profiles in the unstable atmospheric. Journal of Applied Meteorology, 9: 857-61, 1970.

PENMAN, H.L. Natural evaporation from open water, bare soil and grass. Proceedings of the Royal Society of London, 193: 120-45, 1948.

PEREIRA, A.R. Introdução à micrometeorologia. In: DEPARTAMENTO DE FÍSICA E METEOROLOGIA. Piracicaba, ESALQ, 1992. 1-97.

SANTOS, R. Z. \& ANDRÉ, R. G.B. Relações energéticas e aerodinámicas em uma cultura de feijão. Revista Brasileira de Agrometeorologia, 1: 11-18, 1993.

SAUGIER, B. \& RIPLEY, E. Evaluation of the aerodynamic method of determining fluxes over natural grassland. Quarterly Journal of the Royal Meteorological Society, 104(440): 257-70, 1978.

SAXTON, K.E. Sensitivity analises of the combination evapotranspiration equation. Agricultural Meteorology, 15: 343-353, 1975.

SENTELHAS, P. C.; PEDRO Jr, M. J.; MARTINS, F. P. Caracteristicas aerodinâmicas da videira conduzida em espaldeira. Revista Brasileira de Agrometeorologia, 1:25-30, 1993.

STEARNS, C.R. Determining surface roughness and displacement height. Boundary-Layer Meteorology, 1: 102-11, 1970.

TANNER, C.B. Measurement of evapotranspiration. In: Irrigation of agricultural lands. Agronomy Mono., 1967. p.534-74. 
THOM. A.S. \& OLIVER, H.R. On Penman's equation for estimating regional evaporation. Quarterly Journal of the Royal Meteo-rological Society, 103: 345-57, 1977.

VISWANADHAM, Y. Micrometeorological measurements in amazon forest during GTEIABLE 2A mission. Journal of Geophysical Research, 95(D9): 13669-82, 1990. 
77.

APÊNDICE 1 
78.

Tabela 10 - Medidas de: (a) temperatura de bulbo seco e úmido nos níveis situados respectivamente a $0,40 \mathrm{~m}$ e $1,50 \mathrm{~m}$ de altura do solo; (b) velocidade do vento nos níveis situados respectivamente a $0,40 \mathrm{~m}, 0,80 \mathrm{~m}$ e $1,50 \mathrm{~m}$ de altura do solo.

\begin{tabular}{|c|c|c|c|c|c|c|c|c|c|}
\hline DATA & HORA & $\begin{array}{l}\mathrm{TS}_{1} \\
\left({ }^{\circ} \mathrm{C}\right)\end{array}$ & $\begin{array}{l}\mathrm{TU}_{1} \\
\left({ }^{\circ} \mathrm{C}\right)\end{array}$ & $\begin{array}{l}\mathrm{TS}_{2} \\
\left({ }^{\circ} \mathrm{C}\right)\end{array}$ & $\begin{array}{l}\mathrm{TU}_{2} \\
\left({ }^{\circ} \mathrm{C}\right)\end{array}$ & $\begin{array}{c}u_{1} \\
(\mathbf{m} / \mathbf{s})\end{array}$ & $\begin{array}{c}\mathrm{u}_{2} \\
(\mathrm{~m} / \mathrm{s})\end{array}$ & $\begin{array}{c}\mathrm{u}_{3} \\
(\mathrm{~m} / \mathrm{s})\end{array}$ & $\begin{array}{l}P_{\text {atm }} \\
\text { (kPa) }\end{array}$ \\
\hline $31 / 08$ & $00: 03$ & 21,275 & 20,391 & 21,694 & 20,524 & 0,226 & 0,3 & 0,317 & 99,32 \\
\hline $31 / 08$ & $00: 33$ & 21,033 & 20,160 & 21,488 & 20,237 & 0,144 & 0,226 & 0,304 & 99,32 \\
\hline $31 / 08$ & $01: 03$ & 21,396 & 20,100 & 22,173 & 20,225 & 0,282 & 0,417 & 0,504 & 99,32 \\
\hline $31 / 08$ & $01: 33$ & 21,686 & 19,979 & 22,250 & 20,039 & 0,59 & 0,772 & 0,962 & 99,32 \\
\hline $31 / 08$ & $02: 03$ & 22,399 & 20,439 & 23,203 & 20,536 & 0,408 & 0,556 & 0,677 & 99,55 \\
\hline $31 / 08$ & $02: 33$ & 21,505 & 20,233 & 22,487 & 20,367 & 0,326 & 0,469 & 0,59 & 99,55 \\
\hline $31 / 08$ & $03: 03$ & 21,008 & 19,821 & 21,895 & 20,055 & 0,352 & 0,538 & 0,741 & 99,55 \\
\hline $31 / 08$ & $03: 33$ & 20,912 & 19,651 & 21,891 & 19,886 & 0,395 & 0,499 & 0,569 & 99,55 \\
\hline $31 / 08$ & $04: 03$ & 20,051 & 19,287 & 20,669 & 19,501 & 0,282 & 0,452 & 0,655 & 99,55 \\
\hline $31 / 08$ & $04: 33$ & 19,433 & 19,019 & 20,120 & 19,335 & 0,123 & 0,208 & 0,304 & 99,55 \\
\hline $31 / 08$ & $05: 03$ & 19,275 & 18,752 & 19,857 & 18,979 & 0,174 & 0,282 & 0,374 & 99,55 \\
\hline $31 / 08$ & $05: 33$ & 18,995 & 18,496 & 19,647 & 18,772 & 0,243 & 0,365 & 0,46 & 99,55 \\
\hline $31 / 08$ & $06: 03$ & 18,338 & 18,070 & 18,914 & 18,354 & 0,109 & 0,182 & 0,208 & 99,55 \\
\hline $31 / 08$ & $06: 33$ & 18,752 & 18,436 & 18,959 & 18,460 & 0,291 & 0,421 & 0,543 & 99,55 \\
\hline $31 / 08$ & $07: 03$ & 21,190 & 20,064 & 21,150 & 19,857 & 0,759 & 0,932 & 1,122 & 99,55 \\
\hline $31 / 08$ & $07: 33$ & 23,797 & 21,359 & 23,480 & 20,916 & 0,603 & 0,75 & 0,875 & 99,55 \\
\hline $31 / 08$ & $08: 03$ & 25,827 & 22,483 & 25,103 & 21,746 & 0,711 & 0,867 & 1,005 & 99,55 \\
\hline $31 / 08$ & $08: 33$ & 30,122 & 24,554 & 29,940 & 23,492 & 0,517 & 0,629 & 0,707 & 99,55 \\
\hline $31 / 08$ & $09: 03$ & 31,308 & 24,470 & 30,822 & 24,210 & 0,551 & 0,638 & 0,672 & 99,55 \\
\hline $31 / 08$ & $10: 03$ & 35,086 & 25,707 & 34,332 & 24,827 & 0,849 & 1,001 & 1,117 & 99,55 \\
\hline $31 / 08$ & $10: 33$ & 35,790 & 25,059 & 35,062 & 24,811 & 1,165 & 1,355 & 1,514 & 99,55 \\
\hline $31 / 08$ & $11: 33$ & 38,133 & 26,904 & 37,045 & 25,779 & 1,617 & 1,905 & 2,107 & 99,16 \\
\hline $31 / 08$ & $12: 33$ & 38,833 & 26,665 & 38,518 & 25,707 & 1,557 & 1,733 & 1,918 & 99,16 \\
\hline $31 / 08$ & $13: 03$ & 39,649 & 27,621 & 38,499 & 26,198 & 1,626 & 1,785 & 2,017 & 99,16 \\
\hline $31 / 08$ & $13: 33$ & 39,183 & 27,143 & 38,448 & 26,286 & 1,501 & 1,695 & 1,837 & 99,16 \\
\hline $31 / 08$ & $14: 03$ & 39,183 & 26,784 & 38,961 & 25,715 & 1,368 & 1,553 & 1,716 & 99,16 \\
\hline $31 / 08$ & $14: 33$ & 39,300 & 27,023 & 39,004 & 26,050 & 1,083 & 1,243 & 1,372 & 99,16 \\
\hline $31 / 08$ & $15: 03$ & 39,300 & 27,143 & 39,172 & 26,469 & 0,858 & 0,992 & 1,1 & 99,16 \\
\hline $31 / 08$ & $15: 33$ & 38,600 & 26,306 & 38,429 & 25,531 & 0,914 & 1,087 & 1,204 & 99,16 \\
\hline $31 / 08$ & $16: 03$ & 37,431 & 26,425 & 37,209 & 25,890 & 1,117 & 1,364 & 1,574 & 99,16 \\
\hline $31 / 08$ & $16: 33$ & 36,142 & 25,946 & 36,174 & 25,527 & 0,936 & 1,143 & 1,342 & 99,16 \\
\hline $31 / 08$ & $17: 03$ & 34,026 & 25,587 & 34,474 & 25,335 & 0,174 & 0,322 & 0,439 & 99,33 \\
\hline
\end{tabular}




\begin{tabular}{|c|c|c|c|c|c|c|c|c|c|}
\hline \begin{tabular}{|l|} 
DATA \\
\end{tabular} & HORÁ & $\begin{array}{l}\mathrm{TS}_{1} \\
\left({ }^{\circ} \mathrm{C}\right)\end{array}$ & $\begin{array}{l}\mathrm{TU}_{1} \\
\left({ }^{\circ} \mathrm{C}\right)\end{array}$ & $\begin{array}{l}\mathrm{TS}_{2} \\
\left({ }^{\circ} \mathrm{C}\right)\end{array}$ & $\begin{array}{l}\mathrm{TU}_{2} \\
\left({ }^{\circ} \mathrm{C}\right)\end{array}$ & $\begin{array}{c}u_{1} \\
(\mathrm{~m} / \mathrm{s})\end{array}$ & $\begin{array}{c}u_{2} \\
(\mathrm{~m} / \mathrm{s})\end{array}$ & $\begin{array}{c}u_{3} \\
(\mathrm{~m} / \mathrm{s})\end{array}$ & $\begin{array}{l}\text { Patm } \\
(\mathrm{kPa})\end{array}$ \\
\hline $31 / 08$ & $17: 33$ & 31,190 & 24,362 & $\mid \frac{1}{32,070}$ & 23,985 & 0,23 & 0,352 & 0,482 & \\
\hline $31 / 08$ & $: 03$ & 28,694 & 23,761 & 29,297 & 23,572 & 0,313 & & 582 & \\
\hline $31 / 08$ & 33 & 28,575 & 23,339 & 28,829 & 23,251 & & 0,59 & & \\
\hline & 03 &, 694 & 23,785 & 29,512 & 23,825 & 551 & & & \\
\hline $31 / 08$ & 33 & 27,621 & 23,929 & 28,019 & 23,881 & 0,421 & 569 & 703 & \\
\hline $31 / 08$ & $5: 03$ & 27,979 & 23,520 & 28,512 & 23,596 & 491 & & & \\
\hline & 33 & 27,621 & 23,568 & 28,202 & 23,624 & 413 & 564 & & \\
\hline $31 / 08$ & $1: 03$ & 27,023 & 23,833 & 27,529 & 23,757 & 0,195 & 374 & 0,513 & 33 \\
\hline & & & & & & & & & \\
\hline $31 / 08$ & $2: 03$ & 26,665 & 23,700 & 27,079 & 23,616 & 0,221 & 339 & & \\
\hline $31 / 08$ & $2: 33$ & 26,784 & 23,652 & 27,127 & 23,692 & 0,348 &, 478 & 0,56 & \\
\hline $31 / 08$ & 23:03 & 5,946 & 23,231 & 26,473 & & & 564 & & \\
\hline $31 / 08$ & $3: 33$ & 25,131 & 22,797 & 25,723 & 22,845 & 282 & 421 & & \\
\hline $01 / 09$ & $00: 03$ & 26,665 & 22,604 & 27,131 & 22,696 & 0,577 & 724 & & \\
\hline $01 / 09$ & $00: 33$ &, 567 & 21 & 25,455 & & 65 & & & \\
\hline $01 / 09$ & $1: 03$ & 23,845 & 21,541 & 24,831 & 21 & 0,352 & 0,439 & 78 & \\
\hline $01 / 09$ & $1: 33$ & 23,098 & & & 39 & 52 & 0,252 & 361 & \\
\hline $01 / 09$ & $2: 03$ & 2,724 & & 23, & & & 313 & & \\
\hline $01 / 09$ & $2: 33$ & 21,505 & 306 & 22,012 & & 0,178 & 0,3 & 382 & \\
\hline $01 / 09$ & $3: 03$ & 1,843 & & 22,563 & & 0,226 & 348 & & \\
\hline $01 / 09$ & $3: 33$ & 057 & & & & 0,08 & 213 & & \\
\hline $01 / 09$ & $4: 03$ & 21,057 & 19,942 & 21,509 & 084 & 0,278 & 0,369 & 34 & \\
\hline & $1: 33$ & 1,505 & 20,124 & 22,056 & & 0,486 & 0,659 & & \\
\hline $01 / 09$ & $5: 03$ & 20,924 & 19 & 21,275 & & 0,06 & 0,182 & 56 & \\
\hline $01 / 09$ & $05: 33$ & 20,984 & 19,821 & 21,396 & 19,890 & 0,295 & 0,43 & 564 & \\
\hline $01 / 09$ & 03 & 20,512 & 19,724 & 20,524 & 357 & 0,348 & 0,478 & & \\
\hline & $6: 33$ & 21,456 & 20,427 & 21,400 & & 0,322 &, 443 & & \\
\hline $01 / 09$ & $07: 03$ & 23,110 & 21,384 & 23,050 & & 0,217 & 0,322 & 0,365 & \\
\hline $01 / 09$ & $07: 33$ & 25,467 & 23,086 & 25,415 & 18 & 0,322 & 434 & 402 & \\
\hline & $08: 03$ & 27,860 & 24,554 & 27,223 & 24 & 0,404 & 0,513 & 564 & \\
\hline & $09: 03$ & 32,137 & 25,827 & 31,956 & 25,527 & & & & \\
\hline $01 / 09$ & $9: 45$ & 34,615 & 27,263 & 33,830 & 581 & 0,716 & 828 & 01 & \\
\hline & $10: 22$ & 36,494 & 27,143 & 36,170 & 26,146 & 0,854 & 0,983 & & \\
\hline & $10: 52$ & 36,963 & 27,621 & 35,865 & 26,872 & 1,169 & 1,415 & 566 & \\
\hline $01 / 09$ & $11: 22$ & 37,665 & 28,337 & 36,623 & 27,135 & 0,914 & 1,074 & 161 & 24 \\
\hline & $11: 52$ & 38,133 & & & & 1,351 & & & \\
\hline $01 / 09$ & $12: 22$ & 38,833 & 7,621 & 37,782 & 26,278 & 1,333 & 1,523 & 1,699 & \\
\hline
\end{tabular}


80.

\begin{tabular}{|c|c|c|c|c|c|c|c|c|c|}
\hline DATA & HORÁ & $\begin{array}{l}\mathrm{TS}_{1} \\
\left({ }^{\circ} \mathrm{C}\right)\end{array}$ & $\begin{array}{l}\mathrm{TU}_{1} \\
\left({ }^{\circ} \mathrm{C}\right)\end{array}$ & $\begin{array}{l}\mathrm{TS}_{2} \\
\left({ }^{\circ} \mathrm{C}\right)\end{array}$ & $\begin{array}{l}\mathrm{TU}_{2} \\
\left({ }^{\circ} \mathrm{C}\right)\end{array}$ & $\begin{array}{c}u_{1} \\
(\mathrm{~m} / \mathrm{s})\end{array}$ & $\begin{array}{c}\mathrm{u}_{2} \\
(\mathrm{~m} / \mathrm{s})\end{array}$ & $\begin{array}{c}u_{3} \\
(\mathrm{~m} / \mathrm{s})\end{array}$ & $\begin{array}{l}\text { Patm } \\
(\mathrm{kPa})\end{array}$ \\
\hline $01 / 09$ & $2: 52$ & 39,416 & 28,098 & 38,615 & 26,601 & 1,389 & 1,579 & 1,776 & 99,24 \\
\hline $01 / 09$ & 22 & 3,717 & 27,860 & 37,942 & 26,361 & 437 & 643 & & D, $<4$ \\
\hline $01 / 09$ & 22 & 3,483 & 27,740 & & 26,561 & 178 & 351 & & 3,24 \\
\hline $01 / 09$ & 52 & 483 & 27,143 & 38,483 & 130 & 083 & 247 & & \\
\hline $01 / 09$ & $5: 22$ & 7,899 & 27,023 & 38,043 & 26,134 & 091 & ,243 & 364 & $\overline{9,24}$ \\
\hline $01 / 09$ & 52 & 6,494 & 26,545 & 36,744 & 25,435 & 655 & 785 & & 24 \\
\hline 109 & 22 & 6,260 & & & 950 & 408 & 513 & & \\
\hline $01 / 09$ & $5: 52$ & 3,555 & 25,827 & 33,743 & 25,195 & 0,317 & 0,473 & 0,573 & 99,24 \\
\hline $01 / 09$ & 22 & & 25,227 & 32 & 24,274 & 0,395 & 547 &, 72 & 9,5 \\
\hline & $: 52$ & 30,003 & 24 & 31,047 & 24,314 & 0,46 & 646 & & 3,5 \\
\hline $01 / 09$ & $8: 22$ & 29,884 & 24,338 & 30,589 & 23,921 & 0,621 & 0,824 & & $\overline{99,5}$ \\
\hline $01 / 09$ & 52 & 28,814 & & 254 & 386 & 0,447 & 0,586 & 100 & 9,5 \\
\hline $01 / 09$ & 22 & 28,218 & & & 660 & 0,513 & 0,69 & & 3,5 \\
\hline $01 / 09$ & $9: 52$ & 27,263 & 23,917 & 27,649 & 23,745 & 0,278 & 0,395 & 0,478 & 9,5 \\
\hline $01 / 09$ & $: 22$ & 26,665 & 23,965 & 27,593 & 716 & 0,434 & 0,603 &, 785 & 9,5 \\
\hline $01 / 09$ & 52 & 29,290 & 24,218 & 928 & 23,717 & 0,754 & 0,919 & 78 &, 5 \\
\hline $01 / 09$ & $21: 22$ & 28,218 & 23 & 29 & 22,978 & 0,668 & 0,841 & & , \\
\hline $01 / 09$ & $21: 52$ & 27,740 & 23,026 & 28,277 & 515 & 1,557 & 1,909 & 287 & 99,5 \\
\hline $01 / 09$ & & 27,263 & 22,893 & 27,621 & 540 & 764 & 2,12 & 13 & 3,5 \\
\hline $01 / 09$ & $2: 52$ & 27,740 & 22,737 & 562 & 451 & 1,407 & 1,708 & & 9,5 \\
\hline $01 / 09$ & $3: 22$ & 26,904 & 22,905 & 27,103 & 22,222 & 1,475 & 1,776 & 081 & 9,5 \\
\hline $01 / 09$ & $3: 52$ & 26,665 & 22,712 & 928 & 22,081 & 0,685 &, 854 & 988 & 9,5 \\
\hline $02 / 09$ & & 545 & 22 & & & 0,707 & 0,884 & & 1,5 \\
\hline $02 / 09$ & $: 52$ & 24,338 & 22,157 & 510 & 387 & 2,445 & 2,799 & 3,143 & 9,5 \\
\hline $02 / 09$ & $1: 22$ & 21,734 & 21,408 & 21,799 & 239 & 2,624 & 3,003 & 3,33 & 9,5 \\
\hline $02 / 09$ & & 21,408 & 20,766 & 936 & 394 & & 2,964 & 3,288 & 9,5 \\
\hline $02 / 09$ & $2: 22$ & 21,311 & 20,500 & & & 3,215 & 3,702 & 4,163 & 00,37 \\
\hline 02109 & $02: 52$ & 21,190 & 20,282 & 21,319 & 051 & 2,3 & 2,603 & 2,892 & 00,37 \\
\hline $02 / 09$ & $03: 22$ & 20,573 & 19,881 & 20,653 & 699 & 1,173 & 1,381 & 1,561 & $\overline{37}$ \\
\hline $02 / 09$ & $3: 52$ & 19,881 & 19,578 & 445 & 104 & 1,798 & 2,193 & 2,573 & \\
\hline 02109 & $04: 22$ & 19,966 & 19,712 & 691 & 19,514 & 1,238 & 1,488 & 1,712 & 100,37 \\
\hline $02 / 09$ & $04: 52$ & 19,821 & 19,469 & 643 & 19,303 & 1,143 & 1,307 & 1,467 & 100,37 \\
\hline $02 / 09$ & $05: 22$ & 19,433 & 18 & & 306 & 1,514 & 1,755 & 1,952 & 100,37 \\
\hline $02 / 09$ & $05: 52$ & 19,031 & 18,290 & 056 & 062 & 1,776 & 2,128 & 2,432 & 100,31 \\
\hline $02 / 09$ & $06: 22$ & 18,411 & \begin{tabular}{|l|}
17,717 \\
\end{tabular} & 423 & 17,522 & 1,445 & 1,682 & 1,888 & 100,37 \\
\hline & & 18,010 & & & & 1,592 & 1,837 & 2,072 & 100,37 \\
\hline $02 / 09$ & $07: 22$ & 17,181 & 668 & $1,0<0$ & 388 & 1,467 & 1,000 & 1,010 & 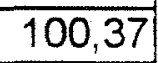 \\
\hline
\end{tabular}




\begin{tabular}{|c|c|c|c|c|c|c|c|c|c|}
\hline DATA & HORÁ & $\begin{array}{l}\mathrm{TS}_{1} \\
\left({ }^{\circ} \mathrm{C}\right)\end{array}$ & $\begin{array}{l}\mathrm{TU}_{1} \\
\left({ }^{\circ} \mathrm{C}\right)\end{array}$ & $\begin{array}{l}\mathrm{TS}_{2} \\
\left({ }^{\circ} \mathrm{C}\right)\end{array}$ & $\begin{array}{l}\mathrm{TU}_{2} \\
\left({ }^{\circ} \mathrm{C}\right)\end{array}$ & $\begin{array}{c}u_{1} \\
(\mathrm{~m} / \mathrm{s})\end{array}$ & $\begin{array}{c}u_{2} \\
(\mathrm{~m} / \mathrm{s})\end{array}$ & $\begin{array}{c}\mathrm{u}_{3} \\
(\mathrm{~m} / \mathrm{s}) \\
\end{array}$ & $\begin{array}{l}P_{\text {atm }} \\
(\mathrm{KPa})\end{array}$ \\
\hline $02 / 09$ & $07: 52$ & 17,595 & 16,668 & 17,685 & 16,660 & 1,553 & 1,785 & 1,995 & 100,37 \\
\hline 02109 & $8: 22$ &, 181 & 3,240 & 16,701 & 15,747 & ,407 & 609 & 1,798 & 0,37 \\
\hline $02 / 09$ & $8: 52$ & 9,505 & 705 & 19,267 & 16,941 & 025 & 291 & 2,53 &, 37 \\
\hline $02 / 09$ & 22 &, 068 & 17,144 & 18,651 & 16,306 & 785 & 051 & 2,295 & \\
\hline $02 / 09$ & $9: 52$ & 18,983 & 17,132 & 18,501 & 16,680 & 1,592 & 1,815 & 2 & $\overline{0,37}$ \\
\hline 02109 & 22 & 35 & 17,437 & 18,488 & 16,888 & 1,69 & ,931 &, 111 &, 37 \\
\hline 02109 & 52 & 20 & 18,046 & 19,590 & 17,457 & 1,669 & 901 & 098 & \\
\hline $02 / 09$ & 11:22 & 21, & 18,423 & 21,287 & 17,782 & 1,764 & 2,025 & 2,265 &, 05 \\
\hline $02 / 09$ & 22 & 23,146 & 19,080 & 22,572 & 18,529 & 721 & & 2,24 & 05 \\
\hline 02109 & 52 & 23,363 & 19,554 & 22,704 & 18,930 & 574 & 1,819 & 2,025 & \\
\hline $02 / 09$ & $13: 22$ & 24,122 & 19,991 & 22,853 & 19,064 & 1,798 & 2,09 & 2,347 & 100,05 \\
\hline $02 / 09$ & $3: 52$ & 24,326 & 20,355 & 23,801 & 19,623 & 1,66 &, 931 & 2171 & 05 \\
\hline $02 / 09$ & 22 & 24,518 & 20,742 & 24,354 & 19,970 & 712 & 2 & 2,257 & \\
\hline $02 / 09$ & $14: 52$ & 24,711 & 20,900 & 24,358 & 20,346 & 1,776 & 2,103 & 2,406 & 100,05 \\
\hline $02 / 09$ & 22 & 24,554 & 20,597 & 24,186 & 19,983 & 098 & & 2,816 & \\
\hline 02109 & 52 & 24,218 & 20,451 & 23,504 & 19,323 & 1,832 & 171 & 2,445 & $\overline{05}$ \\
\hline $02 / 09$ & 16:22 & 23,965 & 20,355 & 23,548 & 19,740 & 1,647 & & 2,197 & 100,05 \\
\hline $02 / 09$ & 52 & 23,279 & 20,039 & 23,106 & 19,380 & 1,57 & 349 & 2,107 & 05 \\
\hline $02 / 09$ & $17: 22$ & 22,097 & 19,104 & 21,763 & 18,087 & 1,316 & 1,51 & 1,69 & 13 \\
\hline $02 / 09$ & $17: 52$ & 20,888 & 18,241 & 20,920 & 17,973 & 1,699 &, 935 & 2,154 & 100,13 \\
\hline $02 / 09$ & 22 & 20,039 & 17,242 & 20,245 & 16,929 & 1,29 & 475 & 1,639 & 13 \\
\hline $02 / 09$ & $3: 52$ & 19,299 & 16,961 & 19,562 & 16,680 & 152 & 32 & 1,48 & 13 \\
\hline $02 / 09$ & 9:22 & 18,922 & 16,717 & 19,165 & 16,456 & 1,022 & 191 & 1,355 & 13 \\
\hline $02 / 09$ & 19:52 & 18,582 & 16,472 & 18,772 & 16,232 & 0,625 & 0,75 & 0,836 & 13 \\
\hline $02 / 09$ & $0: 22$ & 17 & 16,314 & 18,253 & 16,118 & 741 & 388 & 1,001 & 13 \\
\hline $02 / 09$ & 52 & 17,669 & 16,033 & 17,953 & 15,870 & 1,148 & 325 & 1,497 & 100,13 \\
\hline $02 / 09$ & $21: 22$ & 17,315 & 15,922 & 17,563 & 15,743 & 0,992 & 143 & 1,273 & 100,13 \\
\hline $02 / 09$ & $1: 52$ & 17,010 & 15,666 & 17,274 & 15,478 & 1,091 & 273 & 1,445 & $\longdiv { 1 3 }$ \\
\hline $02 / 09$ & $22: 22$ & 16,692 & 15,433 & 16,932 & 15,282 & 0,69 & 0,824 & 0,94 & 100,13 \\
\hline $02 / 09$ & $22: 52$ & 16,106 & 15,274 & 16,375 & 15,107 & 0,616 & 0,75 & 0,871 & 100,13 \\
\hline $02 / 09$ & $23: 22$ & 15,861 & 14,919 & 16,179 & 14,776 & 0,56 & 0,694 & 0,815 & 100,13 \\
\hline $02 / 09$ & $3: 52$ & 15,666 & 15,017 & 15,923 & 14,866 & 0,685 & 0,836 & 0,966 & 100,13 \\
\hline $03 / 09$ & & 15,408 & 14,943 & 15,682 & 14,714 & 0,387 & 0,56 & 0,672 & 00,13 \\
\hline $03 / 09$ & $00: 52$ & 15,151 & 14,674 & 15,339 & 14,514 & 0,534 & 0,685 & 0,824 & 100,13 \\
\hline $03 / 09$ & $01: 22$ & 14,857 & 14,489 & 15,062 & 14,338 & 0,391 & 0,525 & 0,621 & $\longdiv { 1 3 }$ \\
\hline & & 14,771 & 14,539 & 14,914 & 14,326 & 0,265 & & 0,465 & 100,13 \\
\hline $03 / 09$ & $02: 22$ & 14,784 & 14,465 & 14,951 & 14,326 & 0,269 & 0,395 & 0,473 & 100,27 \\
\hline
\end{tabular}




\begin{tabular}{|c|c|c|c|c|c|c|c|c|c|}
\hline DATA & ORÁ & $\begin{array}{l}\mathrm{TS}_{1} \\
\left({ }^{\circ} \mathrm{C}\right)\end{array}$ & $\begin{array}{l}\mathrm{TU}_{1} \\
\left({ }^{\circ} \mathrm{C}\right)\end{array}$ & $\begin{array}{l}\mathrm{TS}_{2} \\
\left({ }^{\circ} \mathrm{C}\right)\end{array}$ & $\begin{array}{l}\mathrm{TU}_{2} \\
\left({ }^{\circ} \mathrm{C}\right)\end{array}$ & $\begin{array}{c}u_{1} \\
(\mathrm{~m} / \mathrm{s})\end{array}$ & $\begin{array}{c}u_{2} \\
(\mathrm{~m} / \mathrm{s})\end{array}$ & $\begin{array}{c}u_{3} \\
(\mathrm{~m} / \mathrm{s})\end{array}$ & $\begin{array}{l}P_{\text {atm }} \\
\text { (kPa) }\end{array}$ \\
\hline $03 / 09$ & $2: 52$ & 14,919 & 14,551 & 15,041 & 14,375 & 0,395 & 0,517 & 0,612 & \\
\hline $03 / 09$ & $3: 22$ & 4,992 & 4,539 & 15,159 & 4,363 & 556 & 685 & & 27 \\
\hline $03 / 09$ & 52 & ,735 & 14,318 & $\mid 14,898$ & & & & & \\
\hline & 22 & 4,624 & 14,195 & 14,837 & 14,035 & 668 & & & \\
\hline $03 / 09$ & $4: 52$ & 4,416 & 14,036 & 14,604 & 13,888 & 0,772 & 923 & 061 & 0,27 \\
\hline $03 / 09$ & $5: 22$ & & 13,728 & 14,236 & 13,597 & 836 & 983 & & \\
\hline & 52 & & 13,618 & 14,310 & 13,478 & 377 & 1,6 & & \\
\hline $03 / 09$ & $6: 22$ & 4,575 & 13,815 & 14,612 & 13,659 & 1,329 &, 531 & & \\
\hline & & & & 14,6 & 14,207 & 307 & 506 & & \\
\hline & $: 22$ & & 14,526 & 15,462 & 14,031 & 432 & & & \\
\hline $03 / 09$ & $7: 52$ & 17,607 & 15,482 & 17,684 & 15,270 & 1,488 & 1,703 & & \\
\hline 09 & 3:22 & & 15,996 & 17,551 & 15,008 & 243 & 428 & & \\
\hline & 52 & 19,420 & 16,692 & 18,711 & 731 & 338 & 527 & & \\
\hline 109 & $9: 22$ & 20,233 & 17,486 & 19,732 & 342 & 122 & 294 & & \\
\hline 09 & 52 & 21 & 17,680 & 19,728 & 786 & 437 & 647 & & \\
\hline & 22 & 22,387 & 18,411 & 21,311 & 17,030 & 544 & 89 & & \\
\hline 09 & $: 52$ & 23,171 & & 22,387 & & 411 & 617 & & \\
\hline & 22 & 24 & 19 & 23,749 & & 596 & 828 & & \\
\hline & $: 52$ & 25,827 & 20,694 & 24,563 & 19,064 & 531 & 759 & 1,939 & \\
\hline 09 & $2: 22$ & & 21,0 & 25,435 & & & & 2,18 & \\
\hline 109 & .52 & 27, & 21,492 & 26,868 & 59 & 604 & 1,832 & 03 & \\
\hline & $3: 22$ & 26,784 & 21,783 & 25,803 & 19,590 & 1,385 & 1,57 & 755 & \\
\hline 09 & 52 & 27,621 & 22,387 & 27,840 & 44 & & 1,6 & & \\
\hline 109 & $4: 22$ & 26,545 & 22,242 & 24,967 & 20 & 1,463 & .673 & 854 & \\
\hline & $14: 52$ & 27,143 & 22,121 & 26,258 & 20,488 & 1,437 & 635 & 807 & \\
\hline & 22 & 27 & 22,350 & 27,346 & 311 & 191 & & 544 & \\
\hline & $5: 52$ & 26 & 22,278 & 25,615 & 20 & 1,402 & 652 & 875 & \\
\hline $03 / 09$ & $6: 22$ & 26,186 & 21,831 & 25,898 & 20,322 & 1,63 & 914 & 163 & \\
\hline $03 / 09$ & $8: 52$ & 25,107 & 21,311 & 24,651 & 035 & 195 & 1,407 & 1,574 & \\
\hline & $7: 22$ & 23,725 & 20,464 & 23,721 & 341 & 0,651 & 0,806 & 0,936 & \\
\hline & $7: 52$ & 22,893 & 19,517 & 23,705 & 19,716 & 0,195 & 0,348 & 0,473 & \\
\hline $03 / 09$ & $8: 22$ & 20,742 & 19,311 & 21,456 & 432 & 0 & 0,1 & 0,187 & \\
\hline & & 20,2 & & 20,589 & & 0,06 & 0,161 & 0,208 & \\
\hline $03 / 09$ & $20: 22$ & 18,411 & 18,241 & 18,890 & 18,399 & 0 & 0,06 & 0,08 & \\
\hline & $0: 52$ & 18,630 & 18,192 & 19,226 & 18,229 & 0,02 & 0,178 & 0,304 & \\
\hline & & & & & & & & & \\
\hline $03 / 09$ & $21: 52$ & 18,509 & 7,400 & $t_{1}$ & 17,303 & 0,239 & 0,400 & 0,021 & \\
\hline
\end{tabular}


83.

\begin{tabular}{|c|c|c|c|c|c|c|c|c|c|}
\hline DATA & IORÁ & $\begin{array}{l}\mathrm{TS}_{1} \\
\left({ }^{\circ} \mathrm{C}\right)\end{array}$ & $\begin{array}{l}\mathrm{TU}_{1} \\
\left({ }^{\circ} \mathrm{C}\right)\end{array}$ & $\begin{array}{l}\mathrm{TS}_{2} \\
\left({ }^{\circ} \mathrm{C}\right)\end{array}$ & $\begin{array}{l}\mathrm{TU}_{2} \\
\left({ }^{\circ} \mathrm{C}\right)\end{array}$ & $\begin{array}{c}u_{1} \\
(\mathrm{~m} / \mathrm{s})\end{array}$ & $\begin{array}{c}\mathrm{u}_{2} \\
(\mathrm{~m} / \mathrm{s})\end{array}$ & $\begin{array}{c}u_{3} \\
(\mathrm{~m} / \mathrm{s})\end{array}$ & $\begin{array}{l}\text { Patm } \\
\text { (kPa) }\end{array}$ \\
\hline $3 / 09$ & $2: 22$ & 18,338 & 17,132 & 19,056 & 17,030 & 0,3 & 0,486 & 0,646 & \\
\hline $1 / 09$ & .52 & & & 18,853 & & & & & \\
\hline $03 / 09$ & $3: 22$ & 18,180 & 16,912 & 18,663 & 16,676 &, 482 & & & \\
\hline & $3: 52$ & 17,924 & & & & & & & \\
\hline $04 / 09$ & $: 22$ & 17,193 & 16,399 & 17,680 & 16,363 & 0,439 & & & \\
\hline $04 / 09$ & $00: 52$ & 17,425 & 16,265 & 17,786 & 16,155 & 0,452 & 0,603 & & \\
\hline $1 / 09$ & $1: 22$ & 935 & & 416 & & 0,08 & & & \\
\hline $04 / 09$ & $1: 52$ & 6,057 & 15,727 & 16,367 & 15,780 & 0,105 & 208 & 278 & \\
\hline $04 / 09$ & $2: 22$ & 15,360 & & 15,788 & 14,980 & 0,04 & 234 & 274 & \\
\hline & .52 & & & & & 0 & 0,02 & 3,04 & \\
\hline 109 & $3: 22$ & 15,188 & 15,029 & 15,457 & 15,143 & 0,06 & 0,148 & 157 & \\
\hline 109 & $03: 52$ & 14,575 & 14,465 & 14,825 & 14,612 & 0,14 & 261 & 313 & \\
\hline & 122 & 1,563 & 14,379 & 14,870 & 14,649 & 0,02 & 04 & 06 & \\
\hline & $4: 52$ & 15,213 & 14,955 & 15,649 & 15,107 & 0,182 & &, 46 & \\
\hline $04 / 09$ & $05: 22$ & 15,164 & 14,955 & 584 & 94 & 0,234 & 348 & 499 & \\
\hline & $: 52$ & 14,747 & 14,563 & 15,254 & 14,804 & 0,04 & & & \\
\hline & $06: 52$ & 16,839 & 16,595 & 16,851 & 16,513 & 0,452 & 573 & & \\
\hline & $7: 22$ & 20,730 & 18 & 21,1 & 17,851 & 776 & 97 & & \\
\hline & $7: 52$ & 20,136 & 18,144 & 20,027 & 17,356 & 325 & 57 & & \\
\hline & $8: 22$ & 21,638 & 19,068 & 20,936 & & 359 & & & \\
\hline 109 & $08: 52$ & 23,652 & 19,821 & 23,620 & 18 & 338 & 23 & 678 & \\
\hline & $9: 22$ & 23,953 & 20,088 & 23,432 & 18,513 & 234 & & & \\
\hline & $09: 52$ & 24,662 & 21,093 & 24,258 & & & & & \\
\hline & $0: 22$ & 25,347 & 21,831 & 24,666 & 19 & 1,299 & & 665 & \\
\hline & $10: 52$ & 27,502 & 22,809 & 26,437 & 20,754 & 1,273 & 475 & 16 & 76 \\
\hline & $1: 22$ & 28,694 & 23,484 & 27,760 & 21, & 1,217 & & 527 & 76 \\
\hline & $1: 52$ & 30,478 & 24,025 & 29,377 & 21 &, 424 & & 751 & 76 \\
\hline & $12: 52$ & 31,308 & 26,066 & 30,059 & 23,452 & 1,264 & 445 & 557 & 76 \\
\hline & $3: 22$ & 31,900 & 25,587 & 31,435 & 23,114 & 1,536 & 764 & 012 & $\overline{76}$ \\
\hline & $13: 52$ & 32,374 & 25,707 & 30,795 & 23,692 & 1,471 & & & $\overline{76}$ \\
\hline & $14: 22$ & 32,492 & 26,545 & 31,573 & 23,628 & 1,561 & 841 & 064 & 76 \\
\hline $04 / 09$ & $4: 52$ & 32,728 & 25,946 & 32,417 & 23,472 & 359 & 1,561 & 703 & 9,76 \\
\hline & & 31,900 & & & 24,999 & 1,281 & 1,51 & & 9,76 \\
\hline & $5: 52$ & 31,190 & 27,860 & 30,553 & 25,251 & 1,053 &, 225 & & 76 \\
\hline & $6: 22$ & 31,190 & 26,545 & 31,095 & 24,226 & 1,07 & 1,238 & 1,385 & 76 \\
\hline & & 29,528 & 26,306 & & 24,623 & & & & 9,76 \\
\hline $04 / 09$ & 1.22 & 20 & & & 32 & 0,382 & 0,499 & 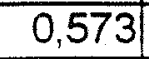 & $\forall \theta, \pi$ \\
\hline
\end{tabular}


84.

\begin{tabular}{|c|c|c|c|c|c|c|c|c|c|}
\hline DATA & HORÁ & $\begin{array}{l}\mathrm{TS}_{1} \\
\left(^{\circ} \mathrm{C}\right)\end{array}$ & $\begin{array}{l}\mathrm{TU}_{1} \\
\left({ }^{\circ} \mathrm{C}\right)\end{array}$ & $\begin{array}{l}\mathrm{TS}_{2} \\
\left({ }^{\circ} \mathrm{C}\right)\end{array}$ & $\begin{array}{l}\mathrm{TU}_{2} \\
\left(^{\circ} \mathrm{C}\right)\end{array}$ & $\begin{array}{c}u_{1} \\
(\mathrm{~m} / \mathrm{s})\end{array}$ & $\begin{array}{c}u_{2} \\
(\mathrm{~m} / \mathrm{s})\end{array}$ & $\begin{array}{c}u_{3} \\
(\mathrm{~m} / \mathrm{s})\end{array}$ & $\begin{array}{l}P_{\text {atm }} \\
(\mathrm{kPa})\end{array}$ \\
\hline $04 / 09$ & $7: 52$ & 26,066 & 22,302 & 26,397 & 21,021 & 0,114 & 0,191 & 0,261 & \\
\hline $04 / 09$ & 22 & 4,458 & 21,287 & 24,791 & 21,122 & 0,02 & & & \\
\hline $04 / 09$ & 52 & 22,857 & & 23,588 & 21,045 & 0,326 & 0,452 &, 681 & $\overline{99,76}$ \\
\hline $04 / 09$ & & & & 22,427 & 20,597 & 0,06 & 169 & & \\
\hline $04 / 09$ & 52 & 20,815 & & 21,420 & 20,274 & 0 & 0 & 0,04 & 76 \\
\hline $04 / 09$ & $20: 22$ & 21 & & 21,4 & 20,116 & 0,02 & 118 & 0,157 & 99,76 \\
\hline $04 / 09$ & $20: 52$ & 20,621 & 639 & 21,069 & 19,663 & 0,02 & 0,123 & 182 & 99,76 \\
\hline $04 / 09$ & $21: 22$ & 19,881 & 372 & 20,261 & 19,420 & 0,114 & 0,208 & & $\overline{76}$ \\
\hline $04 / 09$ & $21: 52$ & 19,420 & & 19,849 & 19,234 & 0,02 & 0,114 & & $\overline{99,7 €}$ \\
\hline $04 / 09$ & $22: 22$ & 18,971 & & 19,538 & 18,663 & 0,127 & 0,191 & 0,243 & $\overline{99,76}$ \\
\hline $04 / 09$ & $22: 52$ & 18,655 & 217 & 18,975 & 18,310 & 0,213 & 0,33 & 404 & 99,76 \\
\hline & $23: 22$ & & & & & & 0,2 & & 99,76 \\
\hline $04 / 09$ & $23: 52$ & & & & & 0,248 & 0,304 & 0,382 & $\overline{99,76}$ \\
\hline
\end{tabular}

